Atmos. Chem. Phys., 17, 10535-10563, 2017

https://doi.org/10.5194/acp-17-10535-2017

(c) Author(s) 2017. This work is distributed under

the Creative Commons Attribution 3.0 License.

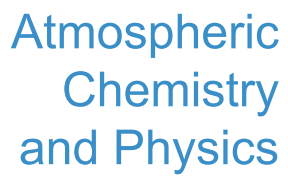

(c) (P)

\title{
A quantitative analysis of the reactions involved in stratospheric ozone depletion in the polar vortex core
}

\author{
Ingo Wohltmann, Ralph Lehmann, and Markus Rex \\ Alfred Wegener Institute for Polar and Marine Research, Potsdam, Germany \\ Correspondence to: Ingo Wohltmann (ingo.wohltmann@awi.de)
}

Received: 25 January 2017 - Discussion started: 6 March 2017

Revised: 20 July 2017 - Accepted: 21 July 2017 - Published: 8 September 2017

\begin{abstract}
We present a quantitative analysis of the chemical reactions involved in polar ozone depletion in the stratosphere and of the relevant reaction pathways and cycles. While the reactions involved in polar ozone depletion are well known, quantitative estimates of the importance of individual reactions or reaction cycles are rare. In particular, there is no comprehensive and quantitative study of the reaction rates and cycles averaged over the polar vortex under conditions of heterogeneous chemistry so far. We show time series of reaction rates averaged over the core of the polar vortex in winter and spring for all relevant reactions and indicate which reaction pathways and cycles are responsible for the vortex-averaged net change of the key species involved in ozone depletion, i.e., ozone, chlorine species $\left(\mathrm{ClO}_{\mathrm{x}}, \mathrm{HCl}, \mathrm{ClONO}_{2}\right)$, bromine species, nitrogen species $\left(\mathrm{HNO}_{3}, \mathrm{NO}_{\mathrm{x}}\right)$ and hydrogen species $\left(\mathrm{HO}_{\mathrm{x}}\right)$. For clarity, we focus on one Arctic winter (2004-2005) and one Antarctic winter (2006) in a layer in the lower stratosphere around $54 \mathrm{hPa}$ and show results for additional pressure levels and winters in the Supplement. Mixing ratios and reaction rates are obtained from runs of the ATLAS Lagrangian chemistry and transport model (CTM) driven by the European Centre for Medium-Range Weather Forecasts (ECMWF) ERAInterim reanalysis data. An emphasis is put on the partitioning of the relevant chemical families (nitrogen, hydrogen, chlorine, bromine and odd oxygen) and activation and deactivation of chlorine.
\end{abstract}

\section{Introduction}

After the discovery of the ozone hole (Farman et al., 1985), the chemistry of polar ozone depletion in the stratosphere has been the subject of ongoing research for the last 30 years (see, e.g., articles, review papers and text books by Solomon et al., 1986; Wayne et al., 1995; Portmann et al., 1996; Brasseur et al., 1999; Solomon, 1999; Brasseur and Solomon, 2005; WMO, 2011; Müller, 2012; Solomon et al., 2015). In general, the chemistry of polar ozone depletion is understood very well (see, e.g., the recent overview in Müller, 2012, or von Hobe et al., 2013). Remaining issues, such as uncertainties in the formation pathways of polar stratospheric clouds (PSCs) or uncertainties in the contribution of the different cloud types to chlorine activation (e.g., Lowe and MacKenzie, 2008; Peter and Grooß, 2012; Wohltmann et al., 2013), do not pose a serious challenge to the generally accepted basic theory.

While the reaction pathways and reaction cycles that are involved in ozone depletion are well known (e.g., Portmann et al., 1996; Solomon, 1999; Müller, 2012), quantitative estimates of the importance of single reactions or reaction cycles are rare and are limited to case studies or certain aspects of the chemical system (e.g., Portmann et al., 1996; Grenfell et al., 2006; Frieler et al., 2006) or apply mainly to conditions undisturbed by heterogeneous chemistry (e.g., Brasseur and Solomon, 2005).

Here, we give a comprehensive overview of the temporal evolution of the vortex-averaged reaction rates and mixing ratios and associated reaction pathways and cycles for one Arctic winter (2004-2005) and one Antarctic winter (2006) in a layer in the lower stratosphere around $54 \mathrm{hPa}$. Results for additional winters and pressure levels can be found in the Supplement and are summarized in the paper. Vortex- 
averaged mixing ratios and reaction rates are obtained from runs of the Lagrangian (trajectory-based) ATLAS chemistry and transport model (Wohltmann and Rex, 2009; Wohltmann et al., 2010). Since results cannot be based on direct observations due to a lack of measurements of the mixing ratios of minor species and reaction rates, only a model-based approach is feasible. The most important model parameters that influence the vortex-averaged rates are the initial mixing ratios, the laboratory measurements of the rate coefficients of the reactions (taken from Sander et al., 2011) and the meteorological data that drive the model, which are taken from the European Centre for Medium-Range Weather Forecasts (ECMWF) ERA-Interim reanalysis (Dee et al., 2011). A detailed study of the uncertainties is outside the scope of this paper, but some of the major uncertainties will be noted. For a study of the uncertainties, see, e.g., Kawa et al. (2009).

Reasonable agreement of the modeled and observed mixing ratios for many species gives us confidence that our results represent the real atmosphere well in most cases (see the basic validation against observations in Sect. 6 and extensive additional comparisons of the model to measurements in the Supplement). There was, however, a significant overestimation of $\mathrm{HCl}$ compared to measurements in our original model runs, which has also been observed in other models like SDWACCM (Brakebusch et al., 2013; Wegner, 2013; Solomon et al., 2015) or MIMOSA-CHIM (Kuttippurath et al., 2015). Interestingly, the SLIMCAT CTM shows a discrepancy of the same order of magnitude, but with the opposite sign, in a recent publication (Santee et al., 2008).

Hence, we consider the differences in $\mathrm{HCl}$ between models and observations as "state-of-the-art" in current CTMs and apply an empirical correction to bring the $\mathrm{HCl}$ mixing ratios in closer agreement to observations. The correction is based on changing the $\mathrm{HCl}$ solubility, which is a possible cause for this discrepancy. This introduces some uncertainty in our results, which is explored in Sect. 6 and by comparisons to the uncorrected runs shown in the Supplement. However, a detailed discussion of this important issue would deserve its own study.

While it is easy to identify the gross production or loss of a species by single reactions, it is difficult to identify what causes the net loss or production of a species (e.g., Lehmann, 2002). Often, the reactions that directly produce or remove a species of interest are part of a complicated chain of reactions, frequently involving reaction cycles. Many of these cycles will consume as much of a species as they produce (null cycles, equilibria); others will lead to a net loss of the species (loss cycles). Numerous loss cycles in the stratosphere are catalytic cycles; i.e., they destroy the species of interest with the help of another species that is constantly recycled in the loss cycle. To complicate things further, cycles may share species and reactions. Hence, it is of crucial importance to know the reaction cycles and pathways in the chemical system to actually understand the underlying reasons for the loss or production of a species, and these relationship are discussed in the following.

In Sect. 2, the methods and the model are introduced. The section contains a description of the ATLAS model and the setup of the runs and explains the method to obtain vortexaveraged reaction rates. In Sect. 3, we give an overview of the typical evolution of polar ozone chemistry in winter to provide a foundation for the following discussion. Section 4 discusses reactions and partitioning sorted by chemical families, i.e., nitrogen, hydrogen, chlorine, bromine and oxygen compounds. Section 5 explores how far the results can be generalized to other years. Section 6 discusses the $\mathrm{HCl}$ discrepancy and gives a short discussion of validation of other species with observations. Section 7 contains the conclusions.

Results of this study are extensively used in a companion paper (Wohltmann et al., 2017) to develop a fast model for polar ozone chemistry.

\section{Model and methods}

\subsection{Model overview}

ATLAS is a global chemistry and transport model (CTM) based on a Lagrangian (trajectory-based) approach. A detailed description of the model can be found in Wohltmann and Rex (2009) and Wohltmann et al. (2010). Updates to the chemistry module and polar stratospheric cloud module are described in Wohltmann et al. (2013). The model includes a gas-phase stratospheric chemistry module, heterogeneous chemistry on polar stratospheric clouds, a particle-based Lagrangian denitrification module and a dehydration parameterization. The chemistry module comprises 47 active species and more than 180 reactions. Absorption cross sections and rate coefficients are taken from recent Jet Propulsion Laboratory (JPL) recommendations (Sander et al., 2011). In addition to the binary background aerosol, the model simulates three types of polar stratospheric clouds, i.e., supercooled ternary $\mathrm{HNO}_{3} / \mathrm{H}_{2} \mathrm{SO}_{4} / \mathrm{H}_{2} \mathrm{O}$ solutions (STS), solid clouds composed of nitric acid trihydrate (NAT) and solid ice clouds.

\subsection{Model setup}

Model runs are driven by meteorological data from the ECMWF ERA-Interim reanalysis (Dee et al., 2011). The initial horizontal model resolution is $150 \mathrm{~km}$. The runs use the hybrid pressure-potential temperature coordinate of the model, which is a pure potential temperature coordinate above $100 \mathrm{hPa}$. The vertical range of the model domain is 350 to $1900 \mathrm{~K}$. Vertical motion is driven by diabatic heating rates from ERA-Interim. Two model runs are started: one for the northern hemispheric winter and one for the southern hemispheric winter. The run for the Northern Hemisphere starts on 1 October 2004 and ends on 31 March 2005. The run for the Southern Hemisphere starts on 1 April 2006 and ends on 
30 November 2006. Model data before 15 November 2004 or 1 May 2006 are not used for analysis to allow for a spin-up of the mixing in the model and for a sufficiently stable vortex in the Northern Hemisphere. Results for two additional winters (2009-2010 in the Northern Hemisphere and 2011 in the Southern Hemisphere) are only shown in the Supplement.

The number density of NAT particles in the runs is set to $0.1 \mathrm{~cm}^{-3}$, the number density of ice particles is set to $0.01 \mathrm{~cm}^{-3}$ and the number density of the ternary solution droplets is set to $10 \mathrm{~cm}^{-3}$. A supersaturation of $\mathrm{HNO}_{3}$ over NAT of 10 (corresponding to about $3 \mathrm{~K}$ supercooling) is assumed to be necessary for the formation of the NAT particles. A detailed discussion of the rationale behind these choices can be found in Wohltmann et al. (2013). For ice particles, a supersaturation of 0.35 is assumed based on Microwave Limb Sounder (MLS) satellite measurements of $\mathrm{H}_{2} \mathrm{O}$ (Waters et al., 2006) and ECMWF temperatures.

The treatment of conditions where both NAT and STS clouds are allowed to form has changed compared to Wohltmann et al. (2013). Since mixed NAT/STS clouds are commonly observed (e.g., Pitts et al., 2011), they can now form in the model to allow for a more realistic behavior; see Nakajima et al. (2016) for details.

The settings for the polar stratospheric cloud parameterizations largely favor the formation of liquid clouds (binary liquids and STS clouds) over the formation of NAT clouds, and activation of chlorine predominantly occurs on liquid clouds in the model runs.

The Lagrangian particle model is used to simulate the nucleation, growth, sedimentation and evaporation of large NAT particles. These particles are formed with a nucleation rate of $7.8 \times 10^{-6}$ particles per hour and $\mathrm{cm}^{3}$, and an initial radius of $0.1 \mu \mathrm{m}$, wherever a supersaturation of 10 for $\mathrm{HNO}_{3}$ is exceeded. Dehydration by falling ice particles is simulated by a simple algorithm that irreversibly removes all ice above a given supersaturation, which is set to 0.7 here (note that the value 0.35 given above is only used in the chemistry module; the value in the dehydration module is set separately).

$\mathrm{H}_{2} \mathrm{O}, \mathrm{N}_{2} \mathrm{O}, \mathrm{HCl}, \mathrm{O}_{3}, \mathrm{CO}$ and $\mathrm{HNO}_{3}$ are initialized from all measurements of the MLS instrument performed during 1 November 2004 and 1 May 2006 for the Northern and Southern hemispheres, respectively. $\mathrm{CH}_{4}$ is initialized from a monthly mean HALOE (Halogen Occultation Experiment) climatology (mean of the years 1991-2002) as a function of equivalent latitude and pressure (Grooß and Russell III, 2005). $\mathrm{NO}_{\mathrm{x}}$ is initialized from the monthly mean HALOE data set by putting all $\mathrm{NO}_{\mathrm{x}}$ into $\mathrm{NO}_{2} \cdot \mathrm{ClONO}_{2}$ is calculated as the difference between $\mathrm{Cl}_{\mathrm{y}}$ and $\mathrm{HCl}$. $\mathrm{Cl}_{\mathrm{y}}$ is taken from a $\mathrm{Cl}_{\mathrm{y}}-\mathrm{N}_{2} \mathrm{O}$ tracer-tracer correlation from ER-2 aircraft and Triple balloon data (Grooß et al., 2002). As in Wohltmann et al. (2013), we increase the amount of $\mathrm{ClONO}_{2}$ by $10 \%$ at the expense of $\mathrm{HCl}$; see the discussion there. $\mathrm{BrONO}_{2}$ is assumed to contain all $\mathrm{Br}_{\mathrm{y}}$, which is taken from a $\mathrm{Br}_{\mathrm{y}}-\mathrm{CH}_{4}$ relationship from ER-2 aircraft and Triple balloon data in
Grooß et al. (2002). All Br $\mathrm{Br}_{\mathrm{y}}$ values are scaled with a constant factor to give maximum values of $19.9 \mathrm{ppt}$.

\subsection{Production and loss rates}

Reaction rates are calculated for every reaction separately in the ATLAS model. For this purpose, one artificial species per reaction is introduced to the model, which is produced at the same rate as the other products of the reaction. For instance, a reaction of the type

$\mathrm{A}+\mathrm{B} \rightarrow \mathrm{C}+\mathrm{D}$

is modified to

$\mathrm{A}+\mathrm{B} \rightarrow \mathrm{C}+\mathrm{D}+\mathrm{P}$

where $\mathrm{P}$ is an artificial product species. The mixing ratio of the artificial product species is reset to zero every $24 \mathrm{~h}$. This way, $\mathrm{P}$ directly gives the $24 \mathrm{~h}$ averaged rates of production of the species C and D by this reaction and the $24 \mathrm{~h}$ averaged loss rates of the species $\mathrm{A}$ and $\mathrm{B}$. The $24 \mathrm{~h}$ time period is used to capture the diurnal cycle of the photochemically active species. For technical reasons, heterogeneous reaction rates with the same chemical equation but on different surface types are added together in a single reaction rate.

\subsection{Vortex averages}

Production and loss rates are averaged over all air parcels of the model inside the polar vortex that are situated in a layer between 61.3 and $47.4 \mathrm{hPa}$. The logarithmic mean level of this layer is at $54 \mathrm{hPa}$. The vortex edge is assumed to be situated at the $36 \mathrm{PVU}$ contour of modified potential vorticity (PV) in the Northern Hemisphere and at the -36 PVU contour in the Southern Hemisphere. Modified PV is calculated from the potential vorticity field of the ERA-Interim reanalysis according to Lait (1994), with $\theta_{0}=475 \mathrm{~K}$. The Supplement shows results for the additional pressure levels 32, 42 and $70 \mathrm{hPa}$.

In order to obtain a more consistent picture of the ozone chemistry in the vortex, we exclude air parcels that experience a too-high amount of mixing with extra-vortex air during the course of the model run. This basically limits our results to the core of the vortex. For that purpose, we initialize a "vortex tracer" as an artificial chemical species near the start of the model run (15 November in the Northern Hemisphere, 1 May in the Southern Hemisphere), which is set to 1 inside the vortex and to 0 outside the vortex. The vortex tracer is then transported and mixed like any other species in the model and can take any value between 0 and 1 . We only include in the vortex mean those parcels for which the vortex tracer has a value greater than 0.7 . This value was chosen as a compromise between obtaining a sufficient number of trajectories for averaging and a set of trajectories that is chemically sufficiently homogeneous. 
Without the vortex tracer, the analysis would get much more complicated. An example may illustrate this: in the southern vortex, air masses rich in $\mathrm{NO}_{\mathrm{y}}$ are mixed into the edge region of the vortex during the course of the winter, while in the core of the vortex, air masses are depleted of nitrogen species due to denitrification. This leads not only to differences in mixing ratios of the nitrogen species over the vortex but also to different reactions being important in different parts of the vortex. For example, while very low ozone values are reached in the core of the vortex since deactivation into $\mathrm{ClONO}_{2}$ is hindered, ozone values at the edge are higher and chlorine is also deactivated into $\mathrm{ClONO}_{2}\left(\mathrm{ClONO}_{2}\right.$ "collar"; see, e.g., Douglass et al., 1995).

\subsection{Different air masses}

The $54 \mathrm{hPa}$ level is not a material surface and we look at different air masses at different points of time due to mixing, the movement of the isentropes relative to the pressure level and the additional sinking of the air masses relative to isentropes due to diabatic cooling. A similar caveat applies to the definition of the vortex edge. As a consequence of these transport effects, the temporal derivative of the vortex-averaged mixing ratio of a chemical species may deviate from the vortexaveraged chemical net change of this species.

Unfortunately, it is difficult to look at the same air mass over the course of several months, since an air mass with a well-defined extent at the beginning of the winter will completely lose its identity due to mixing and transport during the course of the winter.

\subsection{Equilibria}

In many cases, two species (X and $\mathrm{Y}$ ) with short lifetimes are in a fast equilibrium with each other and will not change their mixing ratios if the external conditions do not change. For example, consider two fast reactions of the form

$\mathrm{X}+\mathrm{Z}_{1} \rightarrow \mathrm{Y}+\ldots$

$\mathrm{Y}+\mathrm{Z}_{2} \rightarrow \mathrm{X}+\ldots$

Then, assuming that the change of the mixing ratios is zero,

$\frac{\mathrm{d}[\mathrm{X}]}{\mathrm{d} t}=-k_{1}[\mathrm{X}]\left[\mathrm{Z}_{1}\right]+k_{2}[\mathrm{Y}]\left[\mathrm{Z}_{2}\right]=0$,

where $[\mathrm{X}]$ is the concentration of $\mathrm{X}$ and $k_{1}$ and $k_{2}$ are the reaction coefficients, we obtain equilibrium conditions like

$\frac{[\mathrm{X}]}{[\mathrm{Y}]}=\frac{k_{2}\left[Z_{2}\right]}{k_{1}\left[Z_{1}\right]}$.

Similar equations can be derived for more complex reaction systems. We use the equilibrium conditions in the following not only to show relationships between mixing ratios of different species but also to determine the reactions involved in an equilibrium. For a given set of species, we start with a small set of reactions involved in the equilibrium derived from the vortex-averaged reaction rates and calculate the mixing ratios of the species from the equilibrium conditions. Then, we compare these mixing ratios with the mixing ratios in the output of the model. If the mixing ratios determined by the two methods do not agree with each other, we add reactions until we reach good agreement with a set of reactions as small as possible.

\section{Short overview of the chemical evolution}

The evolution of the chemistry of polar ozone depletion can be divided into several phases (first defined by Portmann et al., 1996). For orientation, Fig. 1 shows the evolution of temperature and sunlight in both hemispheres.

After the polar vortex forms in late autumn and early winter in response to the cooling of the atmosphere in the beginning of polar night, air masses in the vortex are well isolated from midlatitudes (e.g., Solomon, 1999). In the first phase in early winter, chlorine, the main player in the chemistry of lower stratospheric ozone depletion, is present mainly in the form of species that do not directly contribute to ozone depletion. These passive reservoir gases are mainly $\mathrm{HCl}$ and $\mathrm{ClONO}_{2}$ (e.g., Solomon, 1999). Chemical activity is low due to the lack of sunlight in the polar night. This period lasts from the forming of the vortex until the first polar stratospheric clouds form.

In the second phase, $\mathrm{HCl}$ and $\mathrm{ClONO}_{2}$ are transformed from passive reservoir gases to $\mathrm{Cl}_{2}$ through heterogeneous reactions on the surface of polar stratospheric clouds (e.g., Solomon et al., 1986), which condense when temperatures in the polar night get cold enough. A second effect of the clouds can be the removal of large quantities of $\mathrm{HNO}_{3}$ and $\mathrm{H}_{2} \mathrm{O}$ by sedimentation (denitrification and dehydration, e.g., Toon et al., 1986; Fahey et al., 1990), which can prolong ozone loss later in spring (e.g., Portmann et al., 1996). In the model setup used here, activation predominantly occurs on liquid STS clouds and only to a lesser part on solid NAT clouds. Unfortunately, observations of PSCs are not detailed enough to sufficiently constrain the ratio of activation on STS versus NAT clouds, and there is also uncertainty in other parameters like size distribution, number densities and required supersaturation. However, chlorine activation and ozone loss are robust quantities with respect to most changes in PSC parameterizations (Wohltmann et al., 2013).

The third phase starts when sunlight comes back, enabling catalytic cycles to destroy ozone in large quantities. $\mathrm{Cl}_{2}$ is transformed to $\mathrm{Cl}$ and $\mathrm{ClO}$ by photolysis. Then, ozone is removed mainly by the catalytic $\mathrm{ClO}$ dimer cycle and the catalytic ClO-BrO cycle (e.g., Solomon, 1999). The second cycle makes ozone destruction sensitive to the amount of bromine and to bromine chemistry. At the same time, reactions that deactivate active chlorine and that are dependent on sunlight gain importance. Hence, there is a constant competi- 

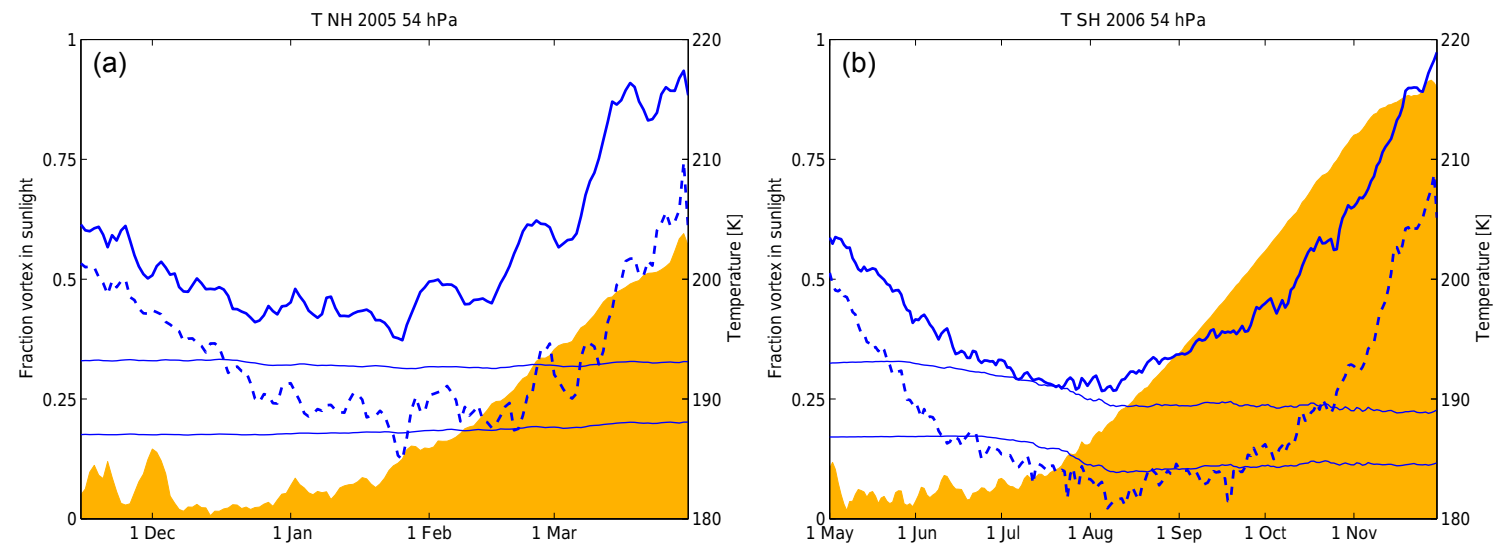

Figure 1. Vortex-averaged temperature (blue), vortex minimum temperature (dashed blue) and fraction of the vortex in sunlight (yellow) for the Arctic winter 2004-2005 (a) and the Antarctic winter 2006 (b) at $54 \mathrm{hPa}$. The upper thin blue line shows the threshold temperature for the formation of NAT clouds used in the model (based on vortex mean mixing ratios and considering supersaturation), and the lower thin blue line shows the same for ice clouds. The vortex tracer criterion described in the text was not applied (in contrast to all other figures).

tion between activation and deactivation in this phase, as long as it is cold enough (e.g., Portmann et al., 1996; Solomon et al., 2015).

In the fourth phase, when temperatures rise in spring and PSCs evaporate, chlorine is deactivated into the reservoir gases again and ozone loss significantly decreases.

\section{Budgets of the chemical families and chemical evolution arranged by families}

\subsection{Nitrogen species}

$\mathrm{NO}_{\mathrm{y}}$ is defined as the sum of all nitrogen-containing species except for the long-lived source gas $\mathrm{N}_{2} \mathrm{O}$, which is the source of all other nitrogen species in the stratosphere. $\mathrm{N}_{2} \mathrm{O}$ has both natural and anthropogenic sources in the troposphere (e.g., WMO, 2011; Montzka, 2012). Figure 2 shows the partitioning of $\mathrm{NO}_{\mathrm{y}}$ at $54 \mathrm{hPa}$. The majority of $\mathrm{NO}_{\mathrm{y}}$ is in the form of $\mathrm{HNO}_{3}$ in the considered altitude range. This is due to the fact that removal of $\mathrm{HNO}_{3}$ by photolysis and $\mathrm{OH}$ is not very efficient at these altitudes. The initial level of $\mathrm{HNO}_{3}$ is about 13 to $14 \mathrm{ppb}$ in both hemispheres and the initial $\mathrm{NO}_{\mathrm{y}}$ is about $1 \mathrm{ppb}$ higher. Figure 2 shows that the mixing ratio of $\mathrm{HNO}_{3}$ (and $\mathrm{NO}_{\mathrm{y}}$ ) declines to about $3 \mathrm{ppb}$ in February 2005 in the Northern Hemisphere and increases again in March due to transport (see Fig. 3, which shows that the rate of change by chemistry is small in this time period). In contrast, $\mathrm{HNO}_{3}$ decreases to about $0.5 \mathrm{ppb}$ (with $\mathrm{NO}_{\mathrm{y}}$ at $1 \mathrm{ppb}$ ) in the Southern Hemisphere after June 2006. The rate of change of $\mathrm{HNO}_{3}$ is not dominated by chemical changes but by denitrification, i.e., the irreversible removal of $\mathrm{HNO}_{3}$ by sedimenting cloud particles (e.g., Toon et al., 1986; Fahey et al., 1990), as shown in Fig. 3. Denitrification is much more severe in the Southern Hemisphere due to the lower temperatures (see Fig. 1, e.g., Solomon, 1999), leaving almost no $\mathrm{NO}_{\mathrm{y}}$. The amount of $\mathrm{NO}_{\mathrm{y}}$ present in the other important nitrogen reservoir $\mathrm{ClONO}_{2}$ is limited by the mixing ratio of $\mathrm{Cl}_{\mathrm{y}}$ (less than $3.5 \mathrm{ppb}$ ). Thus, $\mathrm{ClONO}_{2}$ never contributes more than about $25 \%$ to $\mathrm{NO}_{\mathrm{y}}$. The Supplement shows that $\mathrm{NO}_{\mathrm{y}}$ increases with height from $10 \mathrm{ppb}$ at $70 \mathrm{hPa}$ to $18 \mathrm{ppb}$ at $32 \mathrm{hPa}$, but that the majority is always in the form of $\mathrm{HNO}_{3}$ (Figs. S2, S26, S50 and S74 of the Supplement).

$\mathrm{NO}_{\mathrm{x}}$ is defined as the sum of the short-lived and reactive species $\mathrm{NO}, \mathrm{NO}_{2}, \mathrm{NO}_{3}$ and $2 \mathrm{~N}_{2} \mathrm{O}_{5}$, which only form under sunlit conditions from the longer-lived $\mathrm{HNO}_{3}$. Only a small part of $\mathrm{NO}_{\mathrm{y}}$ is in the form of $\mathrm{NO}_{\mathrm{x}}$ under sunlit conditions, typically less than $1.5 \mathrm{ppb}$ in the Northern Hemisphere and less than $0.5 \mathrm{ppb}$ in the Southern Hemisphere at $54 \mathrm{hPa}$. The Supplement shows that $\mathrm{NO}_{\mathrm{x}}$ increases from about $0.5 \mathrm{ppb}$ at $70 \mathrm{hPa}$ to about $2.5 \mathrm{ppb}$ at $32 \mathrm{hPa}$ in the Northern Hemisphere due to increasing radiation (Figs. S5 and S29 of the Supplement). For the following discussion, it is reasonable to define an "extended" $\mathrm{NO}_{\mathrm{x}}$, which also includes $\mathrm{ClONO}_{2}$ (and, much less importantly, $\mathrm{BrONO}_{2}$ and $\mathrm{HO}_{2} \mathrm{NO}_{2}$ ), since these species are in very fast equilibria with the "classical" $\mathrm{NO}_{\mathrm{x}}$ species under sunlit conditions.

The extended $\mathrm{NO}_{\mathrm{x}}$ mixing ratios can be changed by a number of reactions. Vortex-averaged reaction rates of these reactions for the Northern and Southern hemispheres are shown in Fig. 4. Extended $\mathrm{NO}_{\mathrm{x}}$ is almost exclusively produced from $\mathrm{HNO}_{3}$ under sunlit conditions by photolysis and reaction with $\mathrm{OH}$ :

$$
\begin{aligned}
& \mathrm{HNO}_{3}+h v \rightarrow \mathrm{NO}_{2}+\mathrm{OH} \\
& \mathrm{HNO}_{3}+\mathrm{OH} \rightarrow \mathrm{H}_{2} \mathrm{O}+\mathrm{NO}_{3} ;
\end{aligned}
$$

see, e.g., Portmann et al. (1996). The OH reaction contributes about $60-80 \%$ of the production (compare Fig. 7 in Portmann et al., 1996). Extended $\mathrm{NO}_{\mathrm{x}}$ is lost to $\mathrm{HNO}_{3}$ mainly by the heterogeneous reactions

$$
\mathrm{N}_{2} \mathrm{O}_{5}+\mathrm{H}_{2} \mathrm{O} \rightarrow \mathrm{HNO}_{3}+\mathrm{HNO}_{3}
$$



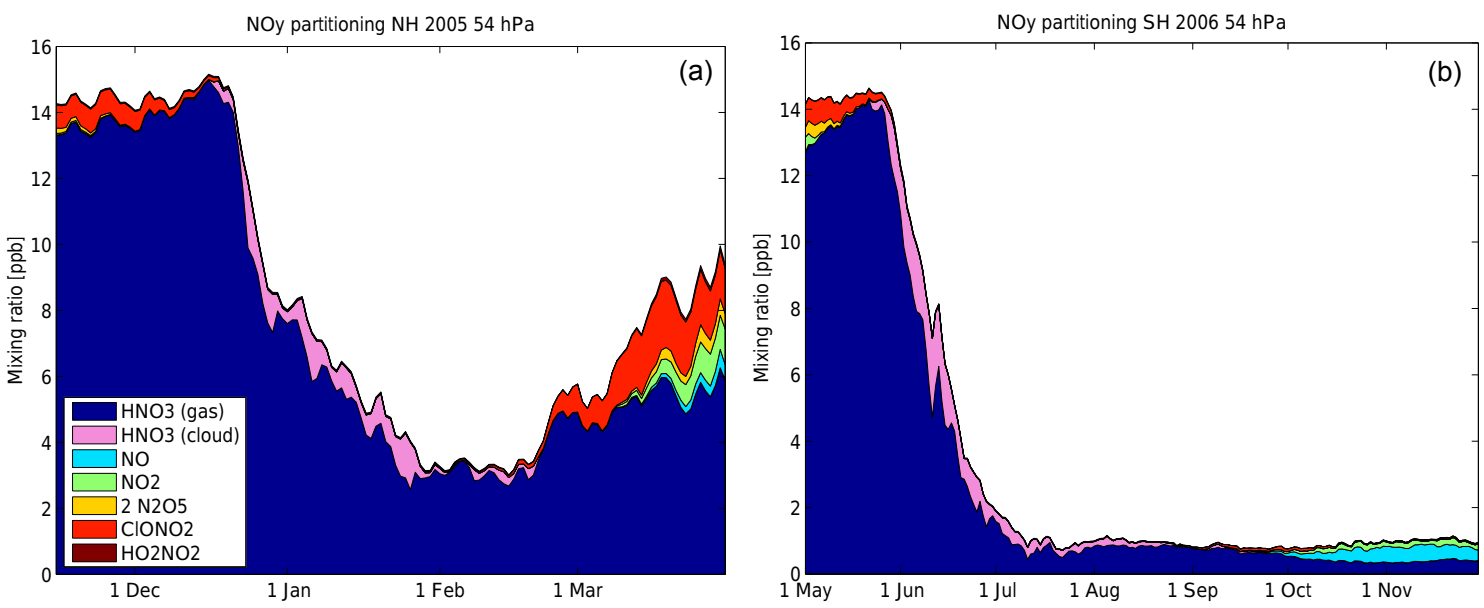

Figure 2. Vortex-averaged partitioning of $\mathrm{NO}_{\mathrm{y}}$ species for the Arctic winter 2004-2005 (a) and the Antarctic winter 2006 (b) at $54 \mathrm{hPa}$. Species $\mathrm{NO}_{3}, \mathrm{BrONO}_{2}, \mathrm{ClNO}_{2}$ and $\mathrm{N}$ are not shown due to their small mixing ratios.
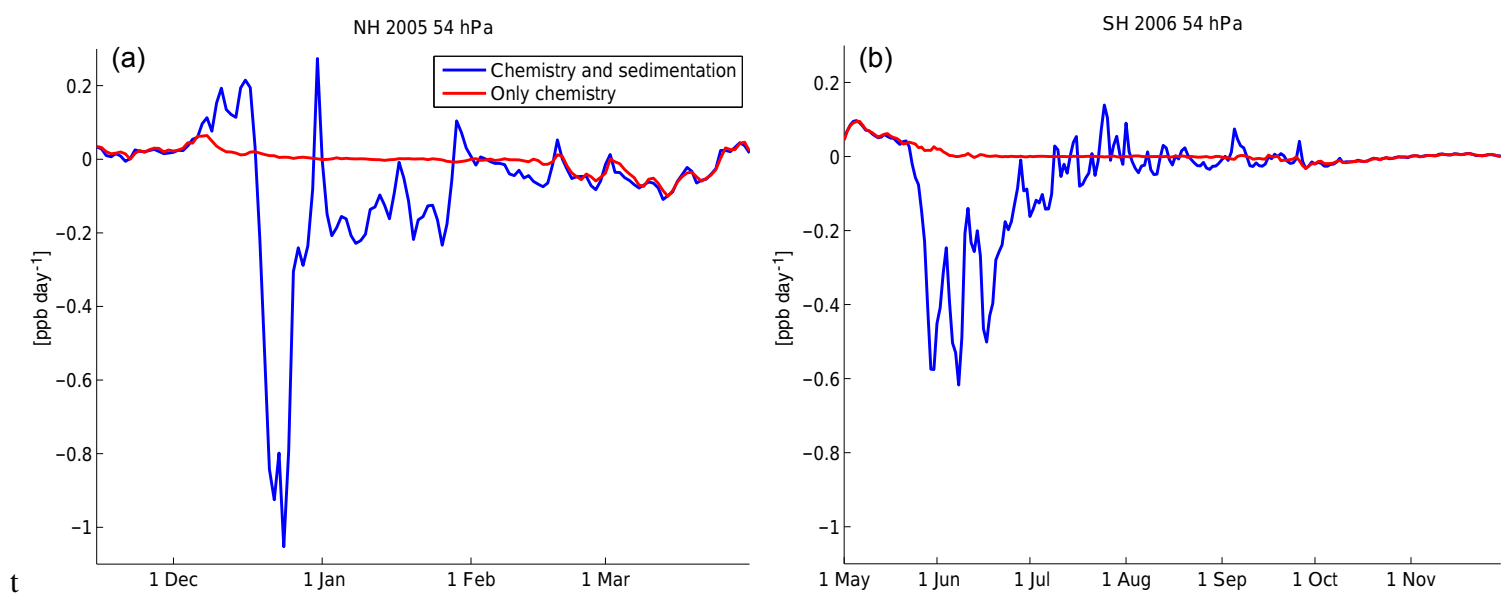

Figure 3. Vortex-averaged net chemical reaction rate of $\mathrm{HNO}_{3}$ (red) for the Arctic winter 2004-2005 (a) and the Antarctic winter 2006 (b) at $54 \mathrm{hPa}$ and sum of the vortex-averaged change by sedimentation and the net chemical reaction rate (blue).

$\mathrm{ClONO}_{2}+\mathrm{HCl} \rightarrow \mathrm{Cl}_{2}+\mathrm{HNO}_{3}$

and by the gas-phase reaction

$\mathrm{OH}+\mathrm{NO}_{2}+\mathrm{M} \rightarrow \mathrm{HNO}_{3}+\mathrm{M}$.

The reaction $\mathrm{N}_{2} \mathrm{O}_{5}+\mathrm{H}_{2} \mathrm{O}$ proceeds on the background aerosol, not only when polar stratospheric clouds are present. When sunlight comes back to the vortex in spring, Reactions (R1)-(R2) are not in equilibrium with Reactions (R3)(R5), and net production of extended $\mathrm{NO}_{\mathrm{x}}$ from $\mathrm{HNO}_{3}$ occurs (e.g., Portmann et al., 1996). Due to the denitrified conditions in the Southern Hemisphere, much less $\mathrm{NO}_{\mathrm{x}}$ is produced there (e.g., Douglass et al., 1995). While the rates of the reactions changing extended $\mathrm{NO}_{\mathrm{x}}$ increase by a factor of 4 from $70 \mathrm{hPa}$ to $32 \mathrm{hPa}$ in the Northern Hemisphere (Figs. S4 and S28 of the Supplement), the relative importance of the reactions does not change.
Note that the introduction of an extended $\mathrm{NO}_{\mathrm{x}}$ does not work very well under polar night conditions, since $\mathrm{ClONO}_{2}$ is not in equilibrium with the classical $\mathrm{NO}_{\mathrm{x}}$ then, which can be seen in the fact that extended $\mathrm{NO}_{\mathrm{x}}$ is lost in polar night due to heterogeneous reaction of $\mathrm{ClONO}_{2}$, although no $\mathrm{NO}$ or $\mathrm{NO}_{2}$ is present.

Figure 5 shows the partitioning of extended $\mathrm{NO}_{\mathrm{x}}$ during daytime and at night. Daytime averages are defined over the parts of the vortex where the solar zenith angle is smaller than $80^{\circ}$ and nighttime averages are defined over parts of the vortex where the solar zenith angle is larger than $100^{\circ}$ (note that this means that the areas for the daytime average and the nighttime average may not be coincident). Except for early winter, $\mathrm{NO}_{\mathrm{x}}$ is only present in appreciable quantities after the start of March 2005 or October 2006 in the Northern and Southern hemispheres, respectively. During daytime, the partitioning between $\mathrm{NO}$ and $\mathrm{NO}_{2}$ is so fast that steady state conditions can be assumed (e.g., Douglass et al., 1995). The 

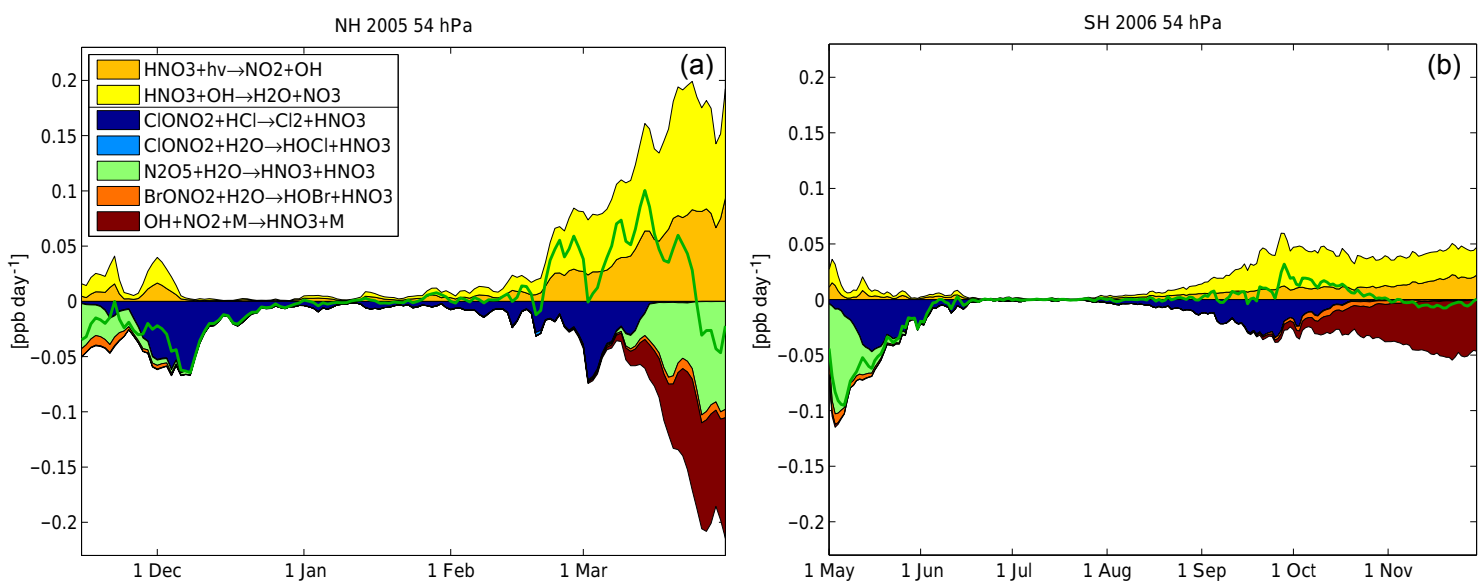

Figure 4. Vortex-averaged chemical reaction rates of reactions changing extended $\mathrm{NO}_{\mathrm{x}}\left(\mathrm{NO}+\mathrm{NO}_{2}+\mathrm{NO}_{3}+2 \mathrm{~N}_{2} \mathrm{O}_{5}+\mathrm{ClONO}_{2}+\right.$ $\mathrm{BrONO}_{2}+\mathrm{HO}_{2} \mathrm{NO}_{2}$ ) for the Arctic winter 2004-2005 (a) and the Antarctic winter 2006 (b) at $54 \mathrm{hPa}$. Production reactions are shown as positive and are separated by a line in the legend from the loss reactions, which are shown as negative. The net change of extended $\mathrm{NO}_{\mathrm{x}}$ is shown as a green line. Reactions with rates which cannot be distinguished from the zero line at plot resolution are not shown.
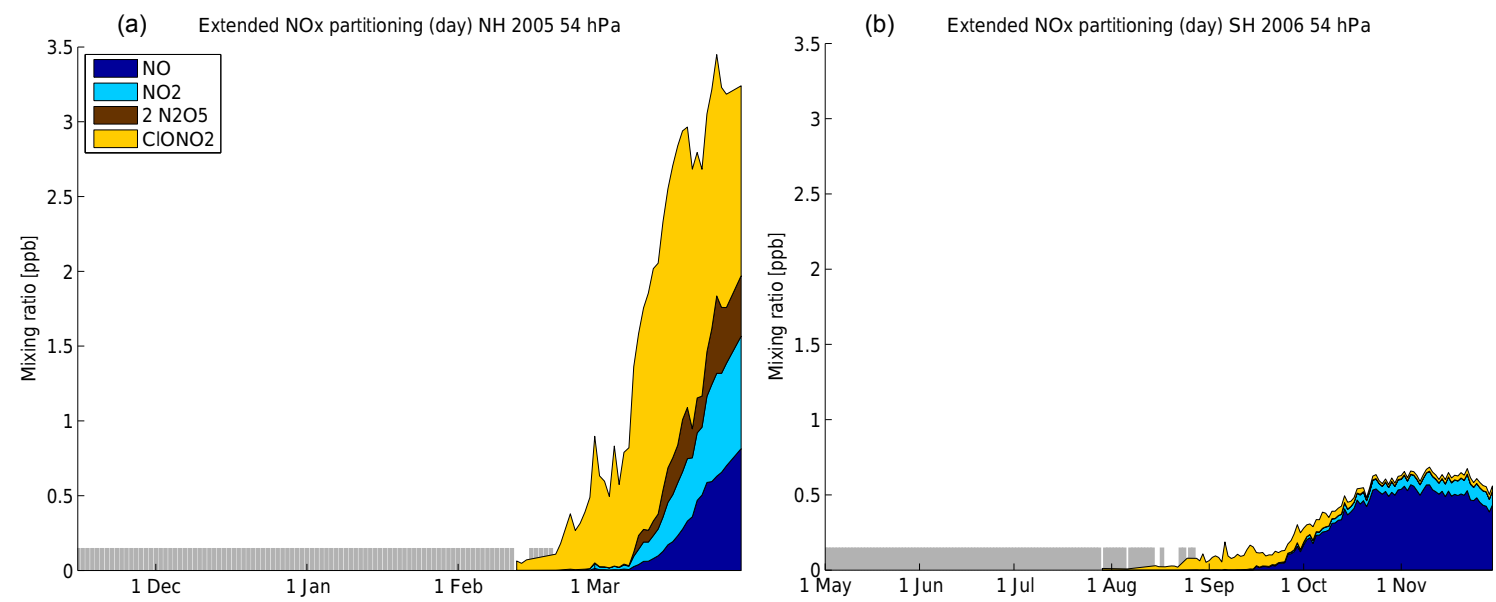

(c) Extended NOx partitioning (night) NH $200554 \mathrm{hPa}$

(d) Extended NOx partitioning (night) SH $200654 \mathrm{hPa}$
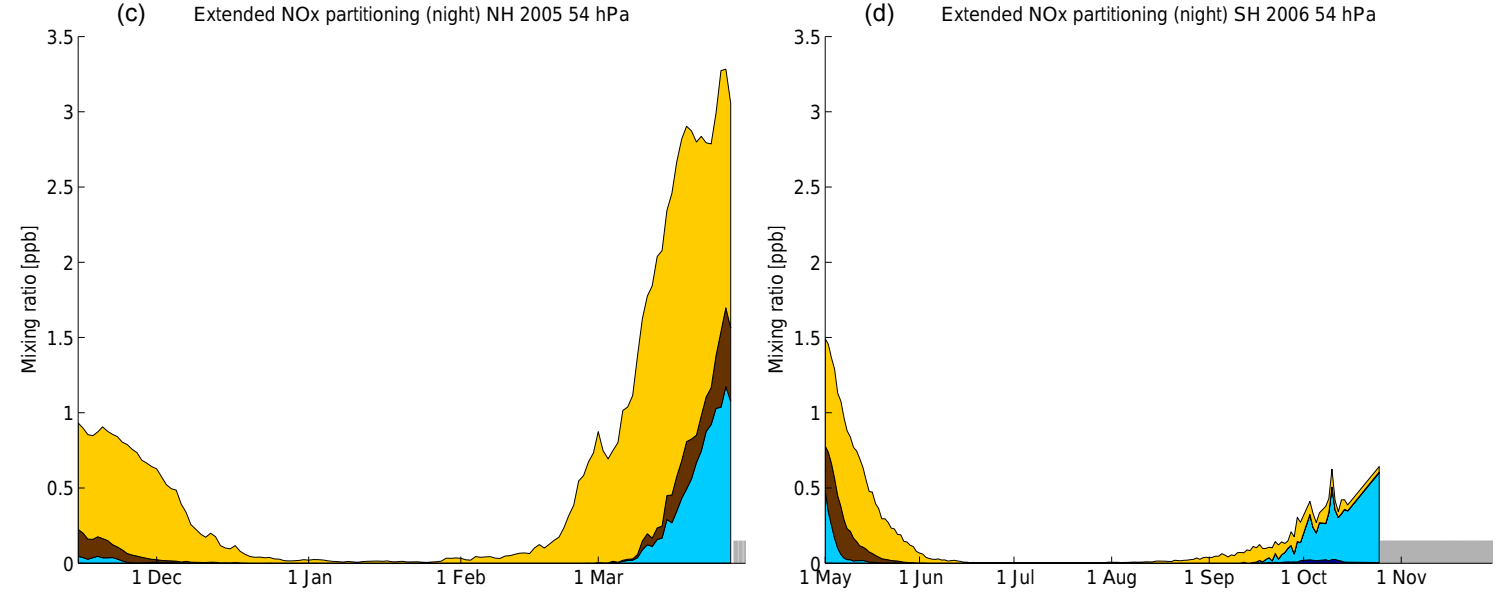

Figure 5. Vortex-averaged partitioning of extended $\mathrm{NO}_{\mathrm{x}}$ species for the Arctic winter 2004-2005 (a, c) and the Antarctic winter 2006 (b, d) at $54 \mathrm{hPa}$. Panels $(\mathbf{a}, \mathbf{b})$ show daytime averages (parts of the vortex where the solar zenith angle is smaller than $80^{\circ}$ ). Panels $(\mathbf{c}, \mathbf{d})$ show nighttime averages (parts of the vortex where the solar zenith angle is larger than $100^{\circ}$ ). Days without sufficient data for averaging are not shown (grey bars). 
three reactions that determine the equilibrium are

$$
\begin{aligned}
& \mathrm{O}_{3}+\mathrm{NO} \rightarrow \mathrm{NO}_{2}+\mathrm{O}_{2} \\
& \mathrm{ClO}+\mathrm{NO} \rightarrow \mathrm{Cl}+\mathrm{NO}_{2} \\
& \mathrm{NO}_{2}+h v \rightarrow \mathrm{NO}+\mathrm{O} .
\end{aligned}
$$

Figure 6 shows the formation and loss rates of NO to illustrate that these are the relevant reactions (the corresponding plots for $\mathrm{NO}_{2}$ look identical but mirrored). The equilibrium condition derived from these reactions is

$$
\frac{[\mathrm{NO}]}{\left[\mathrm{NO}_{2}\right]}=\frac{k_{\mathrm{R} 8}}{k_{\mathrm{R} 6}\left[\mathrm{O}_{3}\right]+k_{\mathrm{R} 7}[\mathrm{ClO}]} \text {. }
$$

In the Southern Hemisphere during daytime, the fraction of NO compared to $\mathrm{NO}_{2}$ is much higher than in the Northern Hemisphere (80-90\% NO and $10-20 \% \mathrm{NO}_{2}$ in the Southern Hemisphere, and 20-40\% NO and $60-80 \% \mathrm{NO}_{2}$ in the Northern Hemisphere; see Fig. 5 and Figs. S7, S31, S55 and S79 in the Supplement). The relative partitioning is approximately constant between 70 and $32 \mathrm{hPa}$ (Figs. S7, S31, S55 and S79 of the Supplement). The higher NO levels are caused by the much lower ozone levels in the Southern Hemisphere (see Fig. 19), which shift the equilibrium by hindering the $\mathrm{O}_{3}+\mathrm{NO}$ reaction (e.g., Douglass et al., 1995). At night, no $\mathrm{NO}$ is present, since the reaction $\mathrm{NO}_{2}+h v$ does not take place. $\mathrm{NO}_{3}$ does not significantly contribute to the budget of $\mathrm{NO}_{\mathrm{x}}$ due to the fast reaction into $\mathrm{NO}_{2}$ by

$\mathrm{NO}_{3}+h v \rightarrow \mathrm{NO}_{2}+\mathrm{O}$

during daytime and into $\mathrm{N}_{2} \mathrm{O}_{5}$ at night (see discussion of Reaction R13).

Despite the relatively low mixing ratios, $\mathrm{NO}_{\mathrm{x}}$ plays an important role in the chemistry of polar ozone depletion (the gas-phase catalytic $\mathrm{NO}_{\mathrm{x}}$ cycle is in general an important contributor to stratospheric ozone chemistry, e.g., outside of the vortex and in higher altitudes than discussed here). In addition to the equilibrium between $\mathrm{NO}$ and $\mathrm{NO}_{2}$, there is a fast equilibrium between $\mathrm{NO}_{2}$ and $\mathrm{ClONO}_{2}$ under sunlit conditions, so that all three species are coupled. $\mathrm{ClONO}_{2}$ is to a good approximation in an equilibrium between

$$
\begin{aligned}
\mathrm{ClONO}_{2}+h v & \rightarrow \mathrm{Cl}+\mathrm{NO}_{3} \\
& \rightarrow \mathrm{ClO}+\mathrm{NO}_{2}
\end{aligned}
$$

and

$$
\mathrm{ClO}+\mathrm{NO}_{2}+\mathrm{M} \rightarrow \mathrm{ClONO}_{2}+\mathrm{M}
$$

see, e.g., Portmann et al. (1996). Reaction (R10) is the dominant branch of the $\mathrm{ClONO}_{2}$ photolysis. The equilibrium condition for $\mathrm{ClONO}_{2}$ can be written as

$[\mathrm{ClO}]\left[\mathrm{NO}_{2}\right]=\frac{k_{\mathrm{R} 10}+k_{\mathrm{R} 11}}{k_{\mathrm{R} 12}}\left[\mathrm{ClONO}_{2}\right]$.
Alternatively, since $\mathrm{NO}$ and $\mathrm{NO}_{2}$ are in equilibrium, this can also be expressed in terms of $\mathrm{NO}$ :

$$
[\mathrm{ClO}][\mathrm{NO}]=\frac{\left(k_{\mathrm{R} 10}+k_{\mathrm{R} 11}\right) k_{\mathrm{R} 8}\left[\mathrm{ClONO}_{2}\right]}{k_{\mathrm{R} 12}\left(k_{\mathrm{R} 6}\left[\mathrm{O}_{3}\right]+k_{\mathrm{R} 7}[\mathrm{ClO}]\right)} .
$$

Production of $\mathrm{NO}_{\mathrm{x}}$ from $\mathrm{HNO}_{3}$ in spring will increase $\mathrm{NO}_{2}$. In turn, $\mathrm{ClONO}_{2}$ will increase almost instantly at the expense of $\mathrm{NO}_{2}$ to match the equilibrium condition again. In this sense, $\mathrm{ClONO}_{2}$ is produced from $\mathrm{HNO}_{3}$ via $\mathrm{NO}_{\mathrm{x}}$ in spring (e.g., Portmann et al., 1996). This is an important deactivation pathway for active chlorine in the Northern Hemisphere, since it consumes $\mathrm{ClO}$.

There is a striking difference in $\mathrm{ClONO}_{2}$ production in spring between the Northern and Southern hemispheres (Fig. 5). While $\mathrm{ClONO}_{2}$ increases to $2 \mathrm{ppb}$ in the Northern Hemisphere, it stays below $0.1 \mathrm{ppb}$ in the Southern Hemisphere due to the strongly denitrified conditions there. The hindrance of the deactivation path via $\mathrm{ClONO}_{2}$ under denitrified conditions prolongs the period of ozone loss, since the other deactivation path via the reaction $\mathrm{Cl}+\mathrm{CH}_{4}$ is only effective under low ozone levels (e.g., Douglass et al., 1995; Portmann et al., 1996); see Sect. 4.3.2. $\mathrm{ClONO}_{2}$ stays relatively constant in March 2005 in the Northern Hemisphere after the initial increase, since the decrease in $\mathrm{ClO}$ is compensated by an increase in $\mathrm{NO}_{2}$.

The mixing ratio of $\mathrm{N}_{2} \mathrm{O}_{5}$ is governed by

$$
\begin{aligned}
& \mathrm{NO}_{2}+\mathrm{NO}_{3}+\mathrm{M} \rightarrow \mathrm{N}_{2} \mathrm{O}_{5}+\mathrm{M} \\
& \mathrm{N}_{2} \mathrm{O}_{5}+h v \rightarrow \mathrm{NO}_{2}+\mathrm{NO}_{3} \\
& \mathrm{~N}_{2} \mathrm{O}_{5}+\mathrm{H}_{2} \mathrm{O} \rightarrow \mathrm{HNO}_{3}+\mathrm{HNO}_{3} .
\end{aligned}
$$

At night, $\mathrm{N}_{2} \mathrm{O}_{5}$ is produced slowly by Reaction (R13), with $\mathrm{NO}_{3}$ produced by

$\mathrm{NO}_{2}+\mathrm{O}_{3} \rightarrow \mathrm{NO}_{3}+\mathrm{O}_{2}$.

During daytime, no $\mathrm{N}_{2} \mathrm{O}_{5}$ is produced, since the $\mathrm{NO}_{3}$ produced by Reactions (R10) and (R15) is easily photolyzed. However, $\mathrm{N}_{2} \mathrm{O}_{5}$ is only slowly depleted during daytime, so that $\mathrm{N}_{2} \mathrm{O}_{5}$ levels during daytime and at night are comparable in the Northern Hemisphere (up to $30 \%$ of classical $\mathrm{NO}_{\mathrm{x}}$ is in $\mathrm{N}_{2} \mathrm{O}_{5}$ ). In the Southern Hemisphere, low ozone levels hinder the production of $\mathrm{N}_{2} \mathrm{O}_{5}$. The produced $\mathrm{N}_{2} \mathrm{O}_{5}$ can react back to the reservoir $\mathrm{HNO}_{3}$ via Reaction (R3) (see Fig. 4).

\subsection{Hydrogen species}

The sources for $\mathrm{HO}_{\mathrm{x}}=\mathrm{OH}+\mathrm{HO}_{2}$ are mainly $\mathrm{H}_{2} \mathrm{O}, \mathrm{CH}_{4}$ and $\mathrm{HNO}_{3}$. The source for stratospheric water is humid tropospheric air "freeze-dried" at the tropopause and sources for $\mathrm{CH}_{4}$ are both natural (e.g., wetlands) and anthropogenic (e.g., WMO, 2011; Montzka, 2012). $\mathrm{CH}_{4}$ is slowly oxidized to $\mathrm{H}_{2} \mathrm{O}$ in the stratosphere (e.g., Hanisco, 2003; see also below). Figure 7 shows that the mixing ratio for $\mathrm{H}_{2} \mathrm{O}$ is between 2 and $6 \mathrm{ppm}$ at $54 \mathrm{hPa}$ and that $\mathrm{CH}_{4}$ has a mixing ratio 

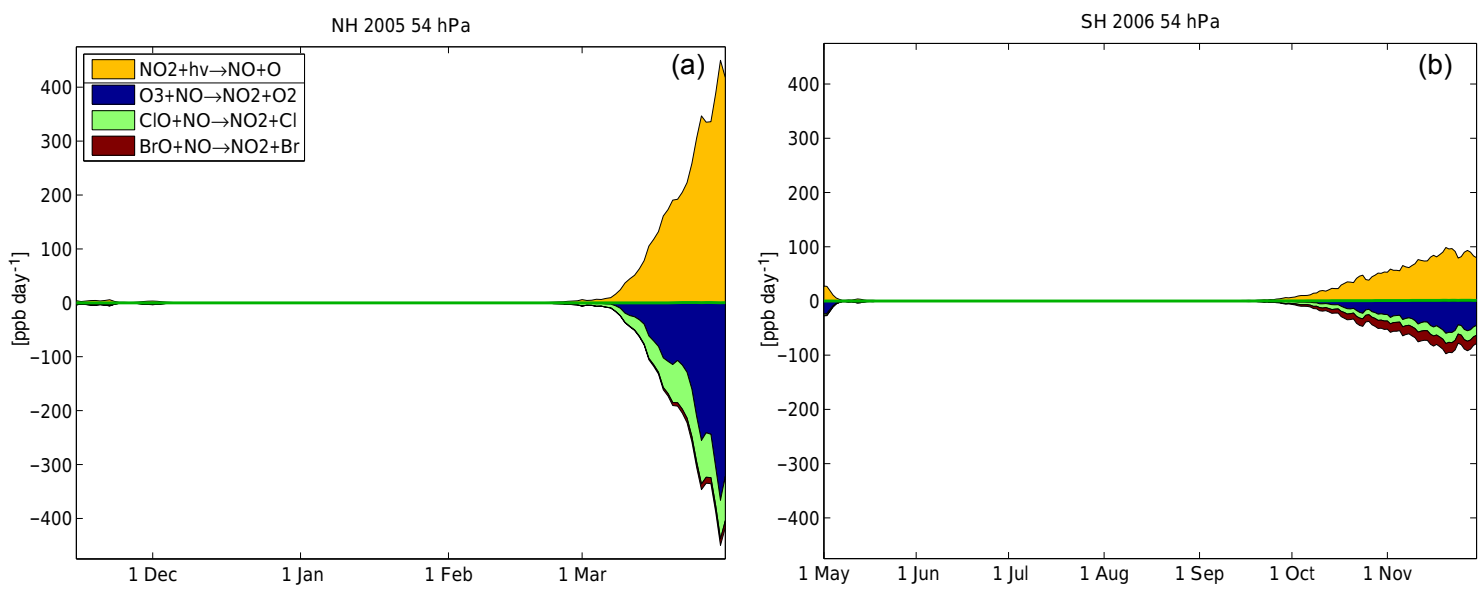

Figure 6. Vortex-averaged chemical reaction rates of reactions changing NO for the Arctic winter 2004-2005 (a) and the Antarctic winter 2006 (b) at $54 \mathrm{hPa}$ to illustrate $\mathrm{NO}_{\mathrm{x}}$ partitioning. Production reactions are shown as positive and are separated by a line in the legend from the loss reactions, which are shown as negative. The net change of NO is shown as a green line.
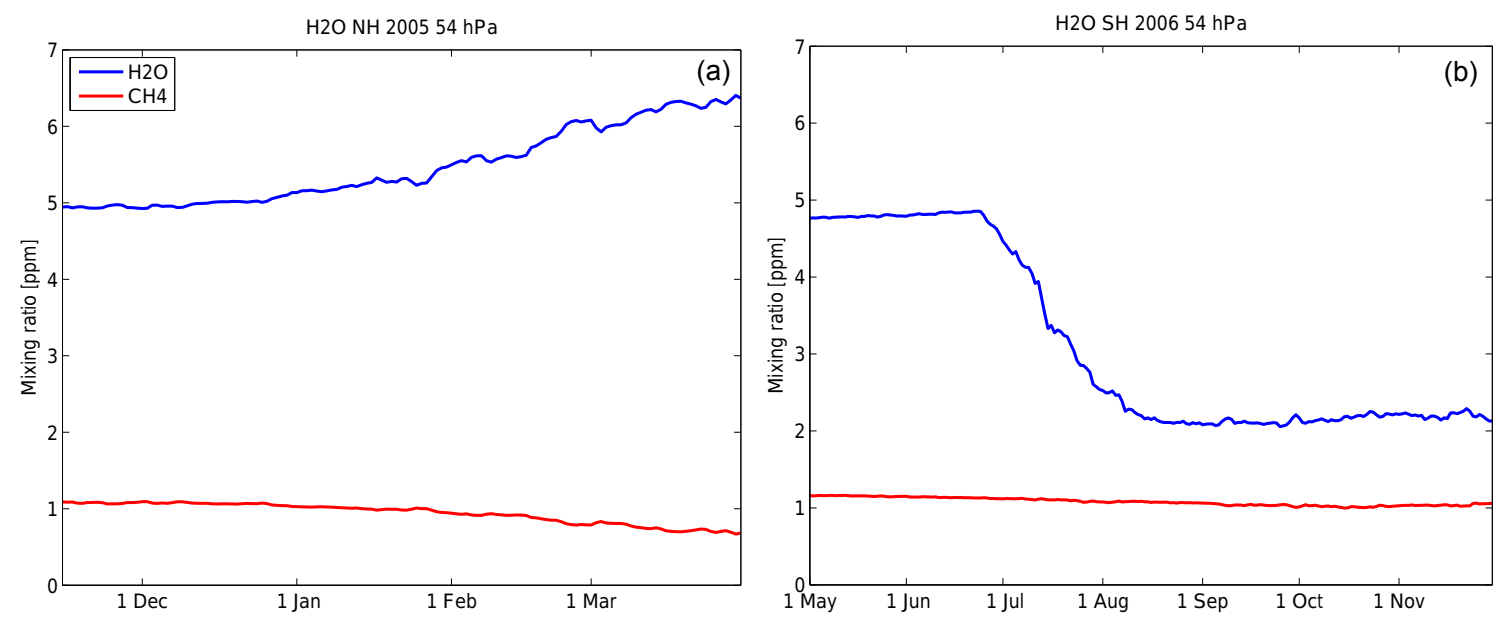

Figure 7. Vortex-averaged mixing ratios of $\mathrm{H}_{2} \mathrm{O}$ and $\mathrm{CH}_{4}$ for the Arctic winter 2004-2005 and the Antarctic winter 2006 at $54 \mathrm{hPa}$.

of about $1 \mathrm{ppm}$. The decrease of $\mathrm{H}_{2} \mathrm{O}$ in July 2006 in the Southern Hemisphere is caused by dehydration by sedimenting cloud particles, similar to the situation for $\mathrm{HNO}_{3}$. The Northern Hemisphere in 2005 is not cold enough for the formation of a significant amount of ice clouds (Fig. 1).

Production and loss processes of $\mathrm{HO}_{\mathrm{x}}$ are fairly complicated (Hanisco, 2003). Figure 8 shows the production and loss rates of an extended $\mathrm{HO}_{\mathrm{x}}$ at $54 \mathrm{hPa}$, where we have included some species that are not a net source or sink of $\mathrm{HO}_{\mathrm{x}}$ over a diurnal cycle (extended $\mathrm{HO}_{\mathrm{x}}=\mathrm{OH}+\mathrm{HO}_{2}+\mathrm{H}+$ $\mathrm{HOCl}+\mathrm{HOBr}+\mathrm{HO}_{2} \mathrm{NO}_{2}$ ). Particularly in the Southern Hemisphere, $\mathrm{CH}_{4}$ oxidation plays an important role. Production from $\mathrm{CH}_{4}$ oxidation can be initiated by

$\mathrm{X}+\mathrm{CH}_{4} \rightarrow \mathrm{XH}+\mathrm{CH}_{3}$,

with $\mathrm{X}=\mathrm{Cl}, \mathrm{O}\left({ }^{1} \mathrm{D}\right)$ or $\mathrm{OH}$, and then continue with a complicated chain of reactions involving $\mathrm{CH}_{2} \mathrm{O}$ (see Hanisco, 2003 for more details). The maximum yield of this reaction chain is $4 \mathrm{HO}_{\mathrm{x}}$ per $\mathrm{CH}_{4}$, but the yield is normally lower (Hanisco, 2003). For example, the $\mathrm{HCl}$ formed by Reaction (R16) with $\mathrm{X}=\mathrm{Cl}$ lowers the yield of the reaction chain starting with this reaction because of the reaction

$\mathrm{HCl}+\mathrm{OH} \rightarrow \mathrm{H}_{2} \mathrm{O}+\mathrm{Cl}$.

Reaction of water with $\mathrm{O}\left({ }^{1} \mathrm{D}\right)$,

$\mathrm{H}_{2} \mathrm{O}+\mathrm{O}\left({ }^{1} \mathrm{D}\right) \rightarrow \mathrm{OH}+\mathrm{OH}$,

and photolysis of $\mathrm{HNO}_{3}$,

$\mathrm{HNO}_{3}+h v \rightarrow \mathrm{NO}_{2}+\mathrm{OH}$,

can also produce $\mathrm{HO}_{\mathrm{x}}$. Sinks are the recombination into water

$\mathrm{OH}+\mathrm{HO}_{2} \rightarrow \mathrm{H}_{2} \mathrm{O}+\mathrm{O}_{2}$ 

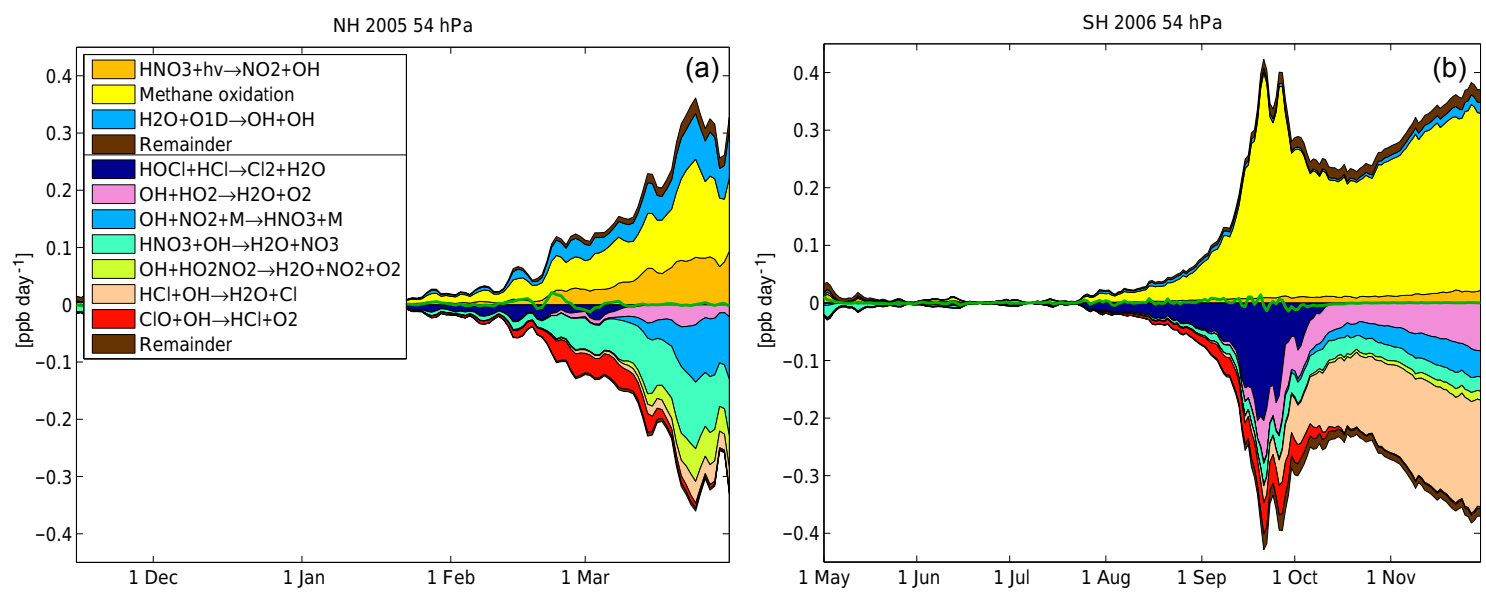

Figure 8. Vortex-averaged chemical reaction rates of reactions changing extended $\mathrm{HO}_{\mathrm{x}}\left(\mathrm{OH}+\mathrm{HO}_{2}+\mathrm{H}+\mathrm{HOCl}+\mathrm{HOBr}+\mathrm{HO} \mathrm{NO}_{2}\right)$ for the Arctic winter 2004-2005 (a) and the Antarctic winter 2006 (b) at $54 \mathrm{hPa}$. Production reactions are shown as positive and are separated by a line in the legend from the loss reactions, which are shown as negative. The net change of extended $\mathrm{HO}_{\mathrm{x}}$ is shown as a green line. Methane oxidation is modeled by simplified net reactions in ATLAS, the reactions denoted as methane oxidation in the legend are $\mathrm{Cl}+\mathrm{CH}_{4} \rightarrow$ $\mathrm{HCl}+\mathrm{CH}_{2} \mathrm{O}+\mathrm{HO}_{2}$ and $\mathrm{Cl}+\mathrm{CH}_{2} \mathrm{O} \rightarrow \mathrm{HCl}+\mathrm{CO}+\mathrm{HO}_{2}$.

and the reactions

$$
\begin{aligned}
& \mathrm{OH}+\mathrm{NO}_{2}+\mathrm{M} \rightarrow \mathrm{HNO}_{3}+\mathrm{M} \\
& \mathrm{HNO}_{3}+\mathrm{OH} \rightarrow \mathrm{H}_{2} \mathrm{O}+\mathrm{NO}_{3} \\
& \mathrm{ClO}+\mathrm{OH} \rightarrow \mathrm{HCl}+\mathrm{O}_{2} .
\end{aligned}
$$

$\mathrm{HO}_{\mathrm{x}}$ is in equilibrium with $\mathrm{HOCl}$ under sunlit conditions and when chlorine is activated (e.g., Portmann et al., 1996):

$\mathrm{HOCl}+h v \rightarrow \mathrm{Cl}+\mathrm{OH}$

$\mathrm{ClO}+\mathrm{HO}_{2} \rightarrow \mathrm{HOCl}+\mathrm{O}_{2}$.

Hence, the heterogeneous reaction,

$\mathrm{HOCl}+\mathrm{HCl} \rightarrow \mathrm{Cl}_{2}+\mathrm{H}_{2} \mathrm{O}$,

is also a sink for $\mathrm{HO}_{\mathrm{x}}$. The rates of the reactions changing extended $\mathrm{HO}_{\mathrm{x}}$ increase by up to a factor of 4 from 70 to $32 \mathrm{hPa}$ (Figs. S10, S34, 58 and S82 of the Supplement). The relative importance of the reactions does not change with the exception of methane oxidation, which becomes less important with increasing height.

$\mathrm{HO}_{\mathrm{x}}$ levels are about 1 to $4 \mathrm{ppt}$ at $54 \mathrm{hPa}$ under sunlit conditions in both hemispheres (Fig. 9). Maximum values typically increase from $3 \mathrm{ppt}$ at $70 \mathrm{hPa}$ to $7 \mathrm{ppt}$ at $32 \mathrm{hPa}$ (Figs. S11, S35, S59 and S82 in the Supplement). At night, no $\mathrm{HO}_{\mathrm{x}}$ is present, since there is no production and $\mathrm{HO}_{\mathrm{x}}$ recombines into water and $\mathrm{HNO}_{3}$ (Fig. 8). $\mathrm{HOCl}$ can reach mixing ratios of up to $0.15 \mathrm{ppb}$ at $54 \mathrm{hPa}$ in both hemispheres, as long as chlorine is activated (see Fig. 11). Figure 9 shows that $\mathrm{HO}_{\mathrm{x}}$ does not simply scale with the amount of sunlight, $\mathrm{HNO}_{3}, \mathrm{H}_{2} \mathrm{O}$ and $\mathrm{CH}_{4}$ : in the Southern Hemisphere, $\mathrm{HO}_{\mathrm{x}}$ shows a peak under conditions of both chlorine activation and sunlight, related to the fact that reactions like $\mathrm{Cl}+\mathrm{CH}_{4}$ and $\mathrm{HOCl}+\mathrm{HCl}$ play a role in $\mathrm{HO}_{\mathrm{x}}$ chemistry (Fig. 8; see also the discussion in Sect. 4.3.2 related to $\mathrm{HCl}$ ).

Figure 9 also shows the partitioning of $\mathrm{HO}_{\mathrm{x}}$. Similar to $\mathrm{NO}_{\mathrm{x}}$, there is a fast equilibrium between $\mathrm{OH}$ and $\mathrm{HO}_{2}$. The partitioning between the $\mathrm{HO}_{\mathrm{x}}$ species is determined mainly by

$$
\begin{aligned}
& \mathrm{HOCl}+h v \rightarrow \mathrm{Cl}+\mathrm{OH} \\
& \mathrm{ClO}+\mathrm{HO}_{2} \rightarrow \mathrm{HOCl}+\mathrm{O}_{2} \\
& \mathrm{ClO}+\mathrm{OH} \rightarrow \mathrm{Cl}+\mathrm{HO}_{2} \\
& \mathrm{O}_{3}+\mathrm{HO}_{2} \rightarrow \mathrm{OH}+2 \mathrm{O}_{2} \\
& \mathrm{O}_{3}+\mathrm{OH} \rightarrow \mathrm{HO}_{2}+\mathrm{O}_{2} \\
& \mathrm{NO}+\mathrm{HO}_{2} \rightarrow \mathrm{NO}_{2}+\mathrm{OH} .
\end{aligned}
$$

Figure 10 shows the rates of $\mathrm{HO}_{2}$ production and loss (the corresponding plots for $\mathrm{OH}$ look similar but mirrored, with $\mathrm{ClO}+\mathrm{HO}_{2}$ replaced by $\left.\mathrm{HOCl}+h v\right)$.

The rates of the reactions partitioning $\mathrm{HO}_{\mathrm{x}}$ increase by up to a factor of 4 from 70 to $32 \mathrm{hPa}$ (Figs. S13, S37, S61 and S85 of the Supplement), but the relative importance of the reactions does not change except for the Reaction (R24) becoming less important with increasing altitude. The production and loss rates of $\mathrm{HO}_{\mathrm{x}}$ proper are dominated by the Reactions (R21) and (R22) which form the equilibrium with $\mathrm{HOCl}$ (not shown).

The equilibrium is mainly on the side of $\mathrm{HO}_{2}$ in both hemispheres (see Fig. 9; e.g., Hanisco and 2003). The fraction of $\mathrm{OH}$ is somewhat higher in the Southern Hemisphere (about 20-40\%) than in the Northern Hemisphere (about 10-20\%); see also Figs. S12, S36, S60 and S84 in the Supplement. The relative partitioning is approximately constant with altitude (see the Supplement). Absolute $\mathrm{OH}$ levels are of 

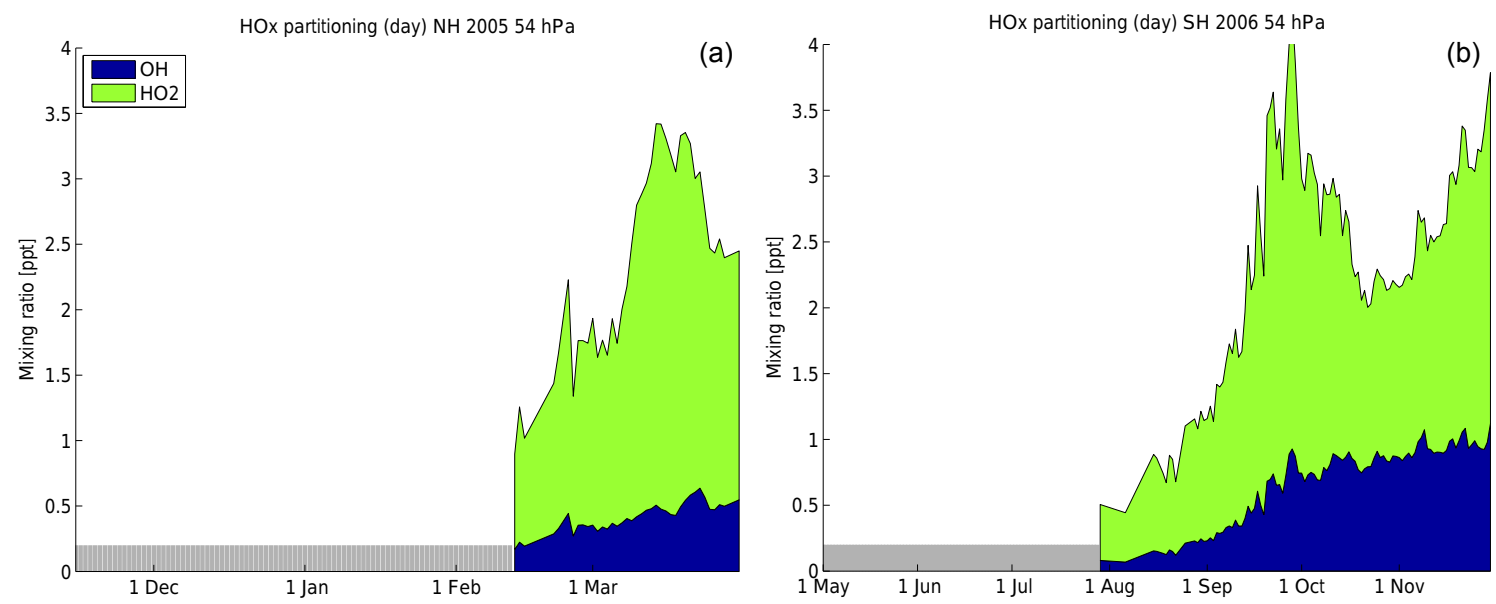

Figure 9. Vortex-averaged partitioning of $\mathrm{HO}_{\mathrm{x}}$ species for the Arctic winter 2004-2005 (a) and the Antarctic winter 2006 (b) at $54 \mathrm{hPa}$. The plots show daytime averages (parts of the vortex where the solar zenith angle is smaller than $80^{\circ}$ ). Nighttime averages are near zero and not shown. Days without sufficient data for averaging are not shown (grey bars).
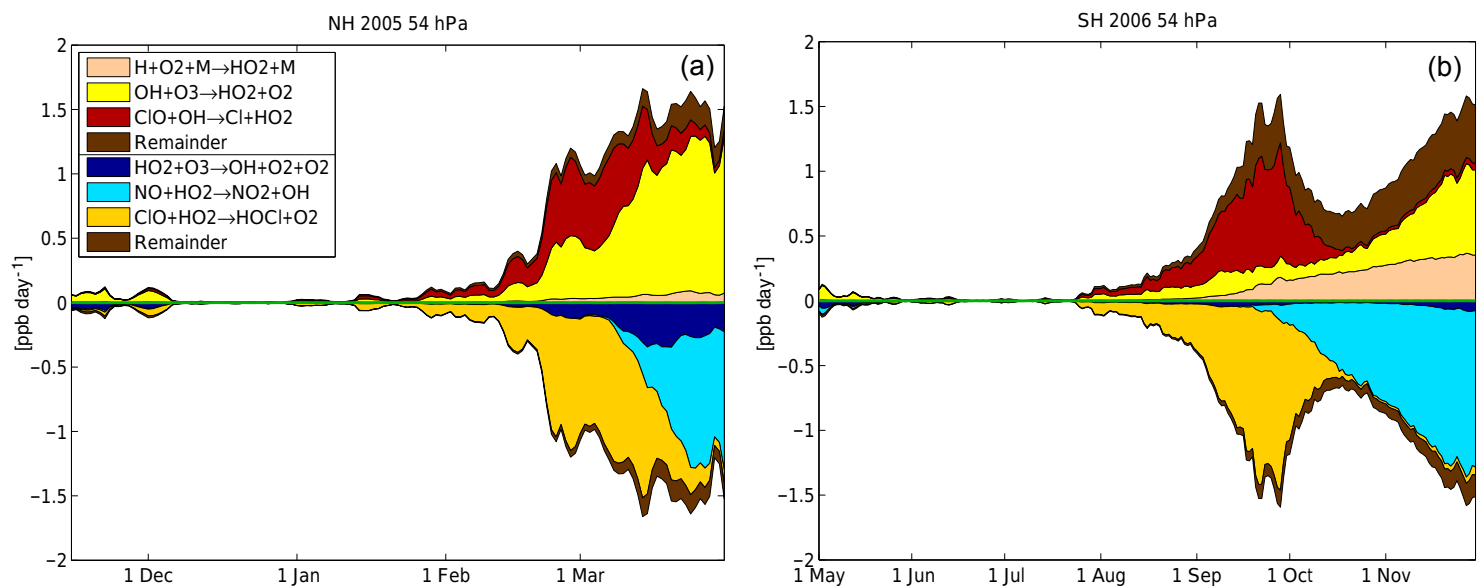

Figure 10. Vortex-averaged chemical reaction rates of reactions changing $\mathrm{HO}_{2}$ for the Arctic winter 2004-2005 (a) and the Antarctic winter 2006 (b) at $54 \mathrm{hPa}$ to illustrate $\mathrm{HO}_{\mathrm{x}}$ partitioning. Production reactions are shown as positive and are separated by a line in the legend from the loss reactions, which are shown as negative. The net change of $\mathrm{HO}_{2}$ is shown as a green line.

relatively similar magnitude in both hemispheres (up to $1 \mathrm{ppt}$ in the Southern Hemisphere and up to $0.5 \mathrm{ppt}$ in the Northern Hemisphere).

Equations for the equilibrium values of $\mathrm{OH}, \mathrm{HO}_{2}$ and $\mathrm{HOCl}$ can be derived from Reactions (R21) to (R27). The ratio of $\mathrm{OH}$ and $\mathrm{HO}_{2}$ under sunlit conditions in the Northern Hemisphere and in the Southern Hemisphere before midSeptember is to a good approximation given by

$\frac{[\mathrm{OH}]}{\left[\mathrm{HO}_{2}\right]}=\frac{k_{\mathrm{R} 25}\left[\mathrm{O}_{3}\right]+k_{\mathrm{R} 22}[\mathrm{ClO}]+k_{\mathrm{R} 27}[\mathrm{NO}]}{k_{\mathrm{R} 26}\left[\mathrm{O}_{3}\right]+k_{\mathrm{R} 24}[\mathrm{ClO}]}$.

That is, the ratio depends only on $\mathrm{O}_{3}, \mathrm{ClO}$ and NO. The equation can be simplified to
$\frac{[\mathrm{OH}]}{\left[\mathrm{HO}_{2}\right]}=\frac{k_{\mathrm{R} 25}\left[\mathrm{O}_{3}\right]+k_{\mathrm{R} 22}[\mathrm{ClO}]}{k_{\mathrm{R} 26}\left[\mathrm{O}_{3}\right]+k_{\mathrm{R} 24}[\mathrm{ClO}]}$

under conditions when chlorine is activated and no NO is present (see Fig. 5, before March 2005 and midSeptember 2006 in the Northern and Southern hemispheres, respectively) and to

$\frac{[\mathrm{OH}]}{\left[\mathrm{HO}_{2}\right]}=\frac{k_{\mathrm{R} 25}\left[\mathrm{O}_{3}\right]+k_{\mathrm{R} 27}[\mathrm{NO}]}{k_{\mathrm{R} 26}\left[\mathrm{O}_{3}\right]}$

in spring in the Northern Hemisphere (end of March 2005), after chlorine is deactivated. In the Southern Hemisphere, the change between conditions rich in $\mathrm{ClO}_{\mathrm{x}}$ and rich in $\mathrm{NO}_{\mathrm{x}}$ is marked by a change in the relative contribution of $\mathrm{OH}$ to $\mathrm{HO}_{\mathrm{x}}$ from about $20 \%$ to about $40 \%$ at the start of October (see 
Figs. S60 and S84 in the Supplement). A similar discussion and expressions for midlatitudes can be found in Cohen et al. (1994).

Under sunlit conditions and when chlorine is activated, the equilibrium of $\mathrm{HOCl}$ is given by

$[\mathrm{HOCl}]=\frac{k_{\mathrm{R} 22}}{k_{\mathrm{R} 21}}[\mathrm{ClO}]\left[\mathrm{HO}_{2}\right]$.

At night, $\mathrm{HOCl}$ remains constant (except for heterogeneous processing), since neither the photolysis reaction nor the $\mathrm{ClO}+\mathrm{HO}_{2}$ reaction can proceed.

$\mathrm{HO}_{\mathrm{x}}$ is relevant for ozone depletion, since the reactions $\mathrm{HCl}+\mathrm{OH} \rightarrow \mathrm{H}_{2} \mathrm{O}+\mathrm{Cl}$ (Reaction $\mathrm{R} 17$ ) and $\mathrm{ClO}+\mathrm{OH} \rightarrow$ $\mathrm{HCl}+\mathrm{O}_{2}$ (Reaction $\mathrm{R} 20$ ) play a role in chlorine activation and deactivation (note that the second reaction differs from Reaction (R24) in the products). In addition, chlorine can be activated by the heterogeneous $\mathrm{HOCl}+\mathrm{HCl}$ (Reaction $\mathrm{R} 23$ ) reaction.

\subsection{Chlorine species}

\subsubsection{Overview and partitioning}

When the polar vortex forms, the majority of chlorine is present in the form of $\mathrm{HCl}$ and the remainder is present in the other important reservoir gas $\mathrm{ClONO}_{2}$ (e.g., Solomon, 1999; Santee et al., 2008). Figure 11 shows the partitioning between the various inorganic chlorine species $\left(\mathrm{Cl}_{\mathrm{y}}\right)$. The available amount of $\mathrm{Cl}_{\mathrm{y}}$ is about 2.7 to $3.3 \mathrm{ppb}$ at $54 \mathrm{hPa}$. The increase of $\mathrm{Cl}_{\mathrm{y}}$ over the winter is due to transport from above. Due to stronger descent in the model in the Northern Hemisphere, $\mathrm{Cl}_{\mathrm{y}}$ increases to values that are about $0.3 \mathrm{ppb}$ higher in the Northern Hemisphere in 2005 than in the Southern Hemisphere in spring 2006, although the initial values are similar. Thus, the chlorine potentially available for ozone depletion in the Northern Hemisphere is increased compared to the Southern Hemisphere. In both hemispheres, the initial mixing ratio of $\mathrm{HCl}$ is about $2 \mathrm{ppb}$ at $54 \mathrm{hPa}(75 \%$ of $\mathrm{Cl}_{\mathrm{y}}$ ) and the initial mixing ratio of $\mathrm{ClONO}_{2}$ is about $0.7 \mathrm{ppb}$ (see also Santee et al., 2008). $\mathrm{Cl}_{\mathrm{y}}$ is produced by photolysis and reaction with $\mathrm{O}\left({ }^{1} \mathrm{D}\right)$ from chlorofluorocarbons (CFCs), hydrochlorofluorocarbons (HCFCs) and similar species of mainly anthropogenic origin (e.g., WMO, 2011; Montzka, 2012). The relative partitioning within $\mathrm{Cl}_{\mathrm{y}}$ is approximately constant between 70 and $32 \mathrm{hPa}$ (with only a slight increase in $\mathrm{Cl}_{\mathrm{y}}$ with altitude; see Figs. S14, S38, S62 and S86 of the Supplement), so that most of the following discussion applies to the entire altitude range.

In early winter, passive reservoir gases $\mathrm{HCl}$ and $\mathrm{ClONO}_{2}$ are transformed to $\mathrm{Cl}_{2}$ through heterogeneous reactions on the surface of polar stratospheric clouds (e.g., Solomon et al., 1986), starting in December 2004 in the Northern Hemisphere and in May 2006 in the Southern Hemisphere. Since the major reaction that transforms the reservoir gases to $\mathrm{Cl}_{2}$ is $\mathrm{HCl}+\mathrm{ClONO}_{2}$ (e.g., Solomon et al., 1986; see also
Sect. 4.3.2), the amount of chlorine that can be activated is limited by the mixing ratio of the less abundant $\mathrm{ClONO}_{2}$ (e.g., Portmann et al., 1996). While some $\mathrm{ClONO}_{2}$ can be regenerated by the reaction $\mathrm{ClO}+\mathrm{NO}_{2}+\mathrm{M}$ and some $\mathrm{HCl}$ can be activated by the reaction $\mathrm{HOCl}+\mathrm{HCl}$, this is not sufficient to remove all $\mathrm{HCl}$ over the course of the winter, and total $\mathrm{HCl}$ mixing ratios consistently stay larger than $0.5 \mathrm{ppb}$ in our model runs, while $\mathrm{ClONO}_{2}$ decreases to near-zero values. Due to the applied adjustment to the $\mathrm{HCl}$ solubility (see Sect. 6), up to $0.5 \mathrm{ppb}$ of $\mathrm{HCl}$ is dissolved in STS droplets in the Southern Hemisphere at $54 \mathrm{hPa}$ (more with increasing altitude).

When sunlight starts to come back, $\mathrm{Cl}_{2}$ is quickly transformed to the active chlorine species $\mathrm{ClO}$ and its dimer $\mathrm{Cl}_{2} \mathrm{O}_{2}$ by photolysis of $\mathrm{Cl}_{2}$

$\mathrm{Cl}_{2}+h v \rightarrow \mathrm{Cl}+\mathrm{Cl}$,

immediately followed by the reaction

$\mathrm{Cl}+\mathrm{O}_{3} \rightarrow \mathrm{ClO}+\mathrm{O}_{2}$

to produce $\mathrm{ClO}$. The time between first activation and the first sunlight becomes apparent in a $\mathrm{Cl}_{2}$ peak in December 2004 and May 2006 in Fig. 11.

Under polar conditions, the dimer of $\mathrm{ClO}$ plays an important role. Reactions that determine the ratio of $\mathrm{ClO}$ and its dimer $\mathrm{Cl}_{2} \mathrm{O}_{2}$ are

$\mathrm{ClO}+\mathrm{ClO}+\mathrm{M} \rightarrow \mathrm{Cl}_{2} \mathrm{O}_{2}+\mathrm{M}$

$\mathrm{Cl}_{2} \mathrm{O}_{2}+h v+\mathrm{M} \rightarrow 2 \mathrm{Cl}+\mathrm{O}_{2}+\mathrm{M}$

$\mathrm{Cl}_{2} \mathrm{O}_{2}+\mathrm{M} \rightarrow \mathrm{ClO}+\mathrm{ClO}+\mathrm{M}$.

Reactions (R30) and (R31) are part of the ClO dimer ozone loss cycle and play an important role in ozone depletion (see Sect. 4.5). Note that Reaction (R31) includes an intermediate step over $\mathrm{ClOO}$ not shown here. Figure 12 shows the partitioning of $\mathrm{ClO}_{\mathrm{x}}=\mathrm{ClO}+2 \mathrm{Cl}_{2} \mathrm{O}_{2}$ at $54 \mathrm{hPa}$. Active chlorine is mainly present in the form of $\mathrm{Cl}_{2} \mathrm{O}_{2}$ at night and in the form of $\mathrm{ClO}$ during daytime (e.g., Stimpfle et al., 2004; WMO, 2011). At night, only small levels of $\mathrm{ClO}\left(10 \%\right.$ of $\mathrm{ClO}_{\mathrm{x}}$ in our model) are maintained by the interplay between the forward Reaction (R32) (thermal dissociation) and backward Reaction (R30) (e.g., Stimpfle et al., 2004; WMO, 2011). The nighttime equilibrium is highly temperature dependent (e.g., Stimpfle et al., 2004), and higher temperatures shift the equilibrium towards $\mathrm{ClO}$ at night (see Fig. 12). During daytime, most $\mathrm{Cl}_{2} \mathrm{O}_{2}$ is photolyzed into $\mathrm{Cl}$, which reacts to $\mathrm{ClO}$, and equilibrium between $\mathrm{ClO}$ and $\mathrm{Cl}_{2} \mathrm{O}_{2}$ is maintained through the photolysis Reaction (R31) and Reaction (R30) (e.g., WMO, 2011). About $70 \%$ of $\mathrm{ClO}_{\mathrm{x}}$ is present as $\mathrm{ClO}$ during daytime at all altitudes in our model (Fig. 12 and Figs. S16, S40, S64 and S88 of the Supplement). This is in good agreement with the $60-70 \%$ inferred from direct aircraft observations of $\mathrm{ClO}$ and $\mathrm{ClOOCl}$ by Stimpfle et al. (2004). 
(a)

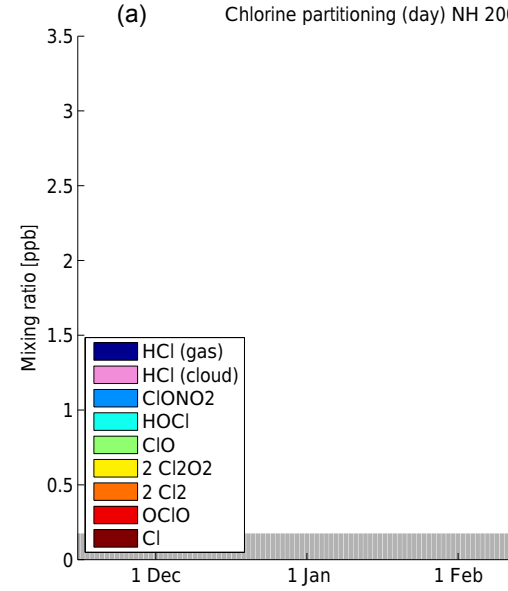

(c)

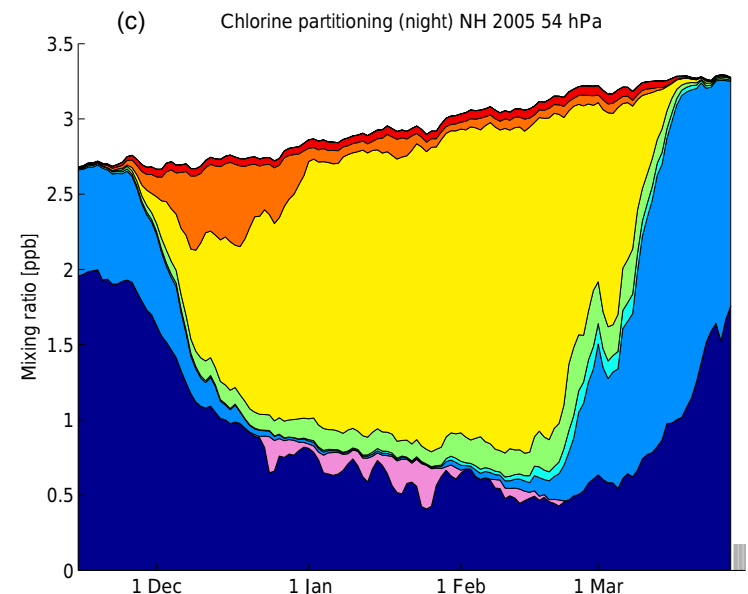

(b)

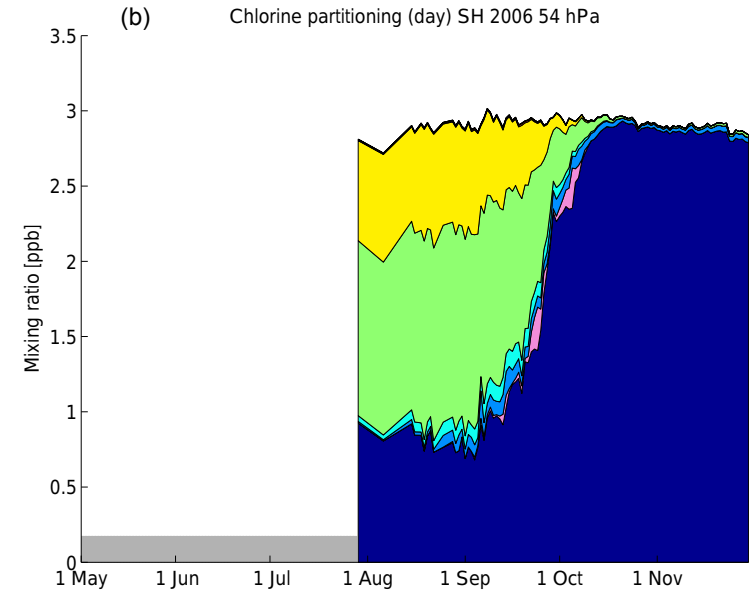

(d)

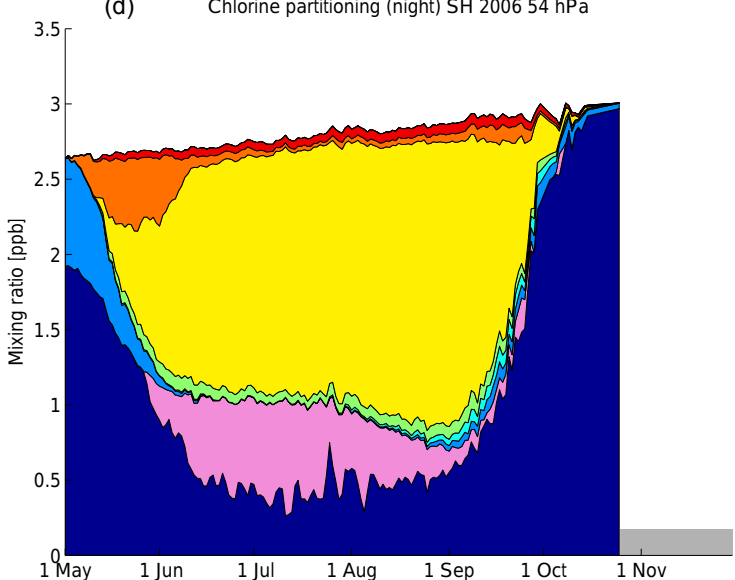

Figure 11. Vortex-averaged partitioning of inorganic chlorine species $\left(\mathrm{Cl}_{\mathrm{y}}\right)$ for the Arctic winter 2004-2005 (a, c) and the Antarctic winter $2006(\mathbf{b}, \mathbf{d})$ at $54 \mathrm{hPa}$. Panels $(\mathbf{a}, \mathbf{b})$ show daytime averages (parts of the vortex where the solar zenith angle is smaller than $\left.80^{\circ}\right)$. Panels $(\mathbf{c}$, d) show nighttime averages (parts of the vortex where the solar zenith angle is larger than $100^{\circ}$ ). Days without sufficient data for averaging are not shown (grey bars). Species $\mathrm{ClNO}_{2}$ and $\mathrm{BrCl}$ are not shown due to their small mixing ratios. The area labeled "HCl (cloud)" shows $\mathrm{HCl}$ dissolved in STS droplets due to the applied adjustment to the $\mathrm{HCl}$ solubility (see Sect. 6).

There is a long history of studies investigating the Reactions (R30) to (R32), which are central for polar ozone depletion and have been uncertain for a long time (e.g., Molina and Molina, 1987; Burkholder et al., 1990; Stimpfle et al., 2004; Frieler et al., 2006; Schofield et al., 2008; Kremser et al., 2011; Canty et al., 2016). Recently, a study of the photolysis cross section of $\mathrm{Cl}_{2} \mathrm{O}_{2}$ challenged the understanding of polar ozone depletion and motivated a thorough reinvestigation of the chemistry of ozone depletion (see WMO, 2011, Sect. 2.2.2 and references therein). The uncertainties have been resolved (Kawa et al., 2009; WMO, 2011; von Hobe and Stroh, 2012; Canty et al., 2016), but the $\mathrm{Cl}_{2} \mathrm{O}_{2}$ photolysis is still one of the reactions that causes the largest uncertainties in ozone depletion (Kawa et al., 2009). In addition, there is some uncertainty in the nighttime equilibrium between $\mathrm{ClO}$ and $\mathrm{Cl}_{2} \mathrm{O}_{2}$ (Kawa et al., 2009; Canty et al., 2016), but this is not relevant for the amount of ozone depletion.
When chlorine is activated (from December 2004 to the beginning of March 2005 in the Northern Hemisphere and from May to the beginning of October 2006 in the Southern Hemisphere), ozone is removed by the $\mathrm{ClO}$ dimer cycle and the $\mathrm{ClO}-\mathrm{BrO}$ cycle (e.g., Solomon and 1999; see also Sect. 4.5). $\mathrm{ClO}_{\mathrm{x}}$ peaks at about $2.4 \mathrm{ppb}$ in the Northern Hemisphere and at about $2.0 \mathrm{ppb}$ in the Southern Hemisphere at $54 \mathrm{hPa}$, with little variation from 70 to $32 \mathrm{hPa}$ (see Figs. S15, S39, S63 and S87 of the Supplement).

Modeled $\mathrm{ClO}$ values are in reasonable agreement with MLS measurements in the Northern Hemisphere in 2005 but are underestimated by $0.2-0.4 \mathrm{ppb}$ in the Southern Hemisphere in 2006 (Figs. S145, S147, .., S163 of the Supplement). In the measurements, the highest peak values of $\mathrm{ClO}$ are typically about $2.0 \mathrm{ppb}$ in both hemispheres, but in the model in the Southern Hemisphere, only 1.6-1.8 ppb are reached. This is consistent with an overestimation of gasphase $\mathrm{HCl}$ compared to MLS of the same order of magni- 
tude (see Sect. 6), which means that the discrepancy in $\mathrm{ClO}$ is directly related to the difficulty to model $\mathrm{HCl}$ correctly.

In the model, the higher peak values of $\mathrm{ClO}_{\mathrm{x}}$ in the Northern Hemisphere are caused not only by the higher $\mathrm{Cl}_{\mathrm{y}}$ values (Fig. 11) but also by the more efficient activation of $\mathrm{HCl}$ into $\mathrm{ClO}_{\mathrm{x}}$ by reformation of $\mathrm{ClONO}_{2}$ in the Northern Hemisphere, which provides about $0.1-0.2 \mathrm{ppb}$ additional chlorine from $\mathrm{HCl}$ compared to the Southern Hemisphere (see discussion in the Sect. "HCl loss (chlorine activation)"). However, the underestimation of $\mathrm{ClO}$ and overestimation of $\mathrm{HCl}$ by ATLAS compared to MLS in the Southern Hemisphere point at an underestimation of chlorine activation in the Southern Hemisphere. Taking this into account, similar $\mathrm{ClO}_{\mathrm{x}}$ levels are expected in the real atmosphere in both hemispheres, and more efficient chlorine activation in the Southern Hemisphere compared to the Northern Hemisphere in the real atmosphere would be countered by higher $\mathrm{Cl}_{\mathrm{y}}$ levels in the Northern Hemisphere to give similar $\mathrm{ClO}_{\mathrm{x}}$ levels.

\subsubsection{Reservoir $\mathrm{HCl}$}

Figure 13 shows the time evolution of the vortex-averaged reaction rates of all relevant reactions that change $\mathrm{HCl}$ at $54 \mathrm{hPa}$. The Supplement shows that the rates and relative importance of the reactions are similar from 70 to $32 \mathrm{hPa}$, so that the following discussion applies to the entire altitude range (Figs. S17, S41, S65 and S89 of the Supplement). In early winter (up to the end of December 2004 in the Northern Hemisphere and up to the end of July 2006 in the Southern Hemisphere), $\mathrm{HCl}$ is removed by heterogeneous reactions on polar stratospheric clouds and active chlorine is produced. When sunlight returns, this is followed by a phase of competition between $\mathrm{HCl}$ removal by heterogeneous reactions and deactivation of $\mathrm{ClO}_{\mathrm{x}}$ into $\mathrm{HCl}$ by gas-phase reactions (e.g., Portmann et al., 1996; Solomon et al., 2015), most pronounced in August 2006 in the Southern Hemisphere. In the Southern Hemisphere, this is followed by a phase of deactivation of active chlorine into $\mathrm{HCl}$ by the $\mathrm{Cl}+\mathrm{CH}_{4}$ reaction from September to October (e.g., Douglass et al., 1995). Finally, when sunlight comes back, the gas-phase loss reaction $\mathrm{HCl}+\mathrm{OH}$ becomes important and competes with the production by $\mathrm{Cl}+\mathrm{CH}_{4}$. In the Southern Hemisphere, $\mathrm{HCl}$ is near equilibrium during this time, while in the Northern Hemisphere, chlorine that was initially deactivated into $\mathrm{ClONO}_{2}$ is slowly transformed into $\mathrm{HCl}$.

\section{HCl loss (chlorine activation)}

The most important heterogeneous loss reaction for $\mathrm{HCl}$ is

$\mathrm{ClONO}_{2}+\mathrm{HCl} \rightarrow \mathrm{Cl}_{2}+\mathrm{HNO}_{3}$.

Another heterogeneous activation channel for $\mathrm{HCl}$ is

$\mathrm{HOCl}+\mathrm{HCl} \rightarrow \mathrm{Cl}_{2}+\mathrm{H}_{2} \mathrm{O}$.

While this reaction plays a smaller role in the Northern Hemisphere in 2005, the reaction is important in the South- ern Hemisphere in the months August and September 2006. In the Southern Hemisphere, the $\mathrm{HOCl}+\mathrm{HCl}$ reaction accounts for about $70 \%$ of the $\mathrm{HCl}$ activation by heterogeneous reactions (integrated over the winter) and in the Northern Hemisphere it accounts for about $30 \%$. HOCl only exists in significant amounts when chlorine is activated. In the Southern Hemisphere, there is a shift from activation by $\mathrm{ClONO}_{2}+\mathrm{HCl}$ in early winter to activation dominated by $\mathrm{HOCl}+\mathrm{HCl}$ later in spring. The reason for this is the deactivation of chlorine by the reaction $\mathrm{Cl}+\mathrm{CH}_{4}$ in the Southern Hemisphere (caused by the low ozone values; see next section), which provides $\mathrm{HCl}$ and produces $\mathrm{HO}_{\mathrm{x}}$ and in turn $\mathrm{HOCl}$ (for a detailed discussion, see Crutzen et al., 1992; Portmann et al., 1996). This can clearly be seen in the rising $\mathrm{HCl}$ levels in September in the Southern Hemisphere (Fig. 11) and in the increased $\mathrm{HO}_{\mathrm{x}}$ levels (Fig. 9). In contrast, deactivation occurs mainly by conversion to $\mathrm{ClONO}_{2}$ in the Northern Hemisphere, keeping $\mathrm{HCl}$ levels low. Since the Southern Hemisphere is more denitrified, activation by $\mathrm{ClONO}_{2}+\mathrm{HCl}$ is hindered. Note that the net effect of $\mathrm{Cl}+$ $\mathrm{CH}_{4}$ and $\mathrm{HOCl}+\mathrm{HCl}$ is a net chlorine deactivation in the Southern Hemisphere (green line in Fig. 13).

It is evident that about $0.1-0.2 \mathrm{ppb}$ more $\mathrm{HCl}$ is removed in the Northern Hemisphere in December 2005 than in the Southern Hemisphere in May 2006 (Fig. 11), although the temperatures are lower in the Southern Hemisphere and the initial values of $\mathrm{HCl}$ and $\mathrm{ClONO}_{2}$ are similar. Figure 13 shows that the reason is that the $\mathrm{ClONO}_{2}+\mathrm{HCl}$ reaction activates more $\mathrm{HCl}$ in the Northern Hemisphere. This is caused by reformation of $\mathrm{ClONO}_{2}$ after the initial depletion in the Northern Hemisphere (see Fig. 17 below), which is much smaller in the Southern Hemisphere.

The only other reaction that removes $\mathrm{HCl}$ in relevant quantities is the gas-phase reaction with $\mathrm{OH}$, which is only important under sunlit conditions:

$\mathrm{HCl}+\mathrm{OH} \rightarrow \mathrm{H}_{2} \mathrm{O}+\mathrm{Cl}$

In the Northern Hemisphere, the reaction is relevant in March in 2005. For the Southern Hemisphere, the reaction is relevant in October 2006 and later.

\section{HCl production (chlorine deactivation)}

$\mathrm{HCl}$ is only produced by reactions that are indirectly dependent on sunlight. Deactivation of active chlorine occurs mainly by conversion to $\mathrm{HCl}$ in the Southern Hemisphere but predominantly by conversion to $\mathrm{ClONO}_{2}$ in the Northern Hemisphere. The reason for this is that deactivation of $\mathrm{ClONO}_{2}$ is hindered in the Southern Hemisphere by strong denitrification (absence of $\mathrm{NO}_{2}$ ), while normally it would be the preferred pathway of deactivation (e.g., Douglass et al., 1995; Portmann et al., 1996).

In the long term, the partitioning of $\mathrm{HCl}$ and $\mathrm{ClONO}_{2}$ in spring and summer favors $\mathrm{HCl}$ (e.g., Portmann et al., 1996; Santee et al., 2008). This can be seen in the fact that in 

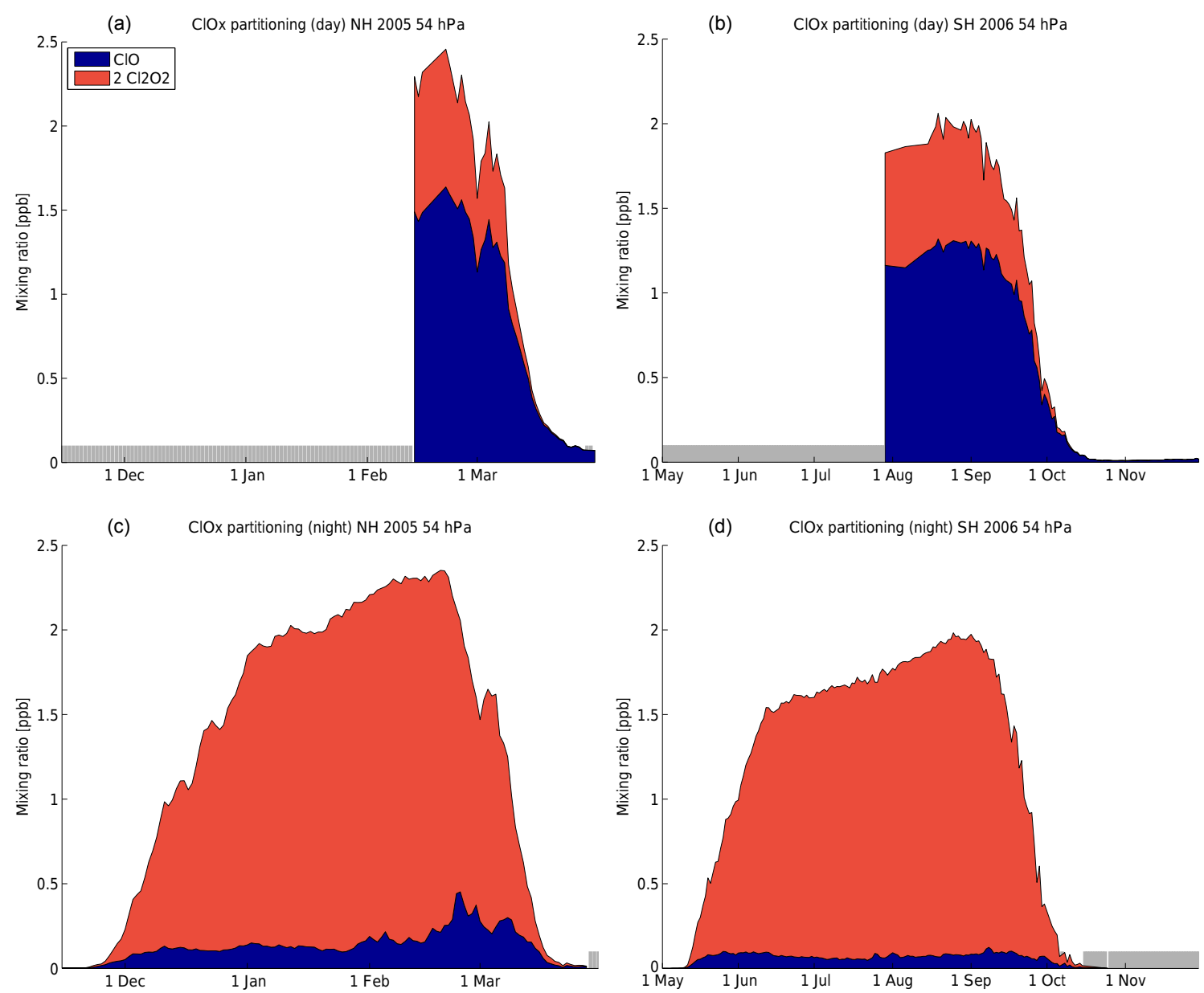

Figure 12. Vortex-averaged partitioning of $\mathrm{ClO}_{\mathrm{x}}$ for the Arctic winter 2004-2005 (a) and the Antarctic winter 2006 (b) at $54 \mathrm{hPa}$. Panels (a, b) show daytime averages (parts of the vortex where the solar zenith angle is smaller than $80^{\circ}$ ). Panels (c, d) show nighttime averages (parts of the vortex where the solar zenith angle is larger than $100^{\circ}$ ). Days without sufficient data for averaging are not shown (grey bars).
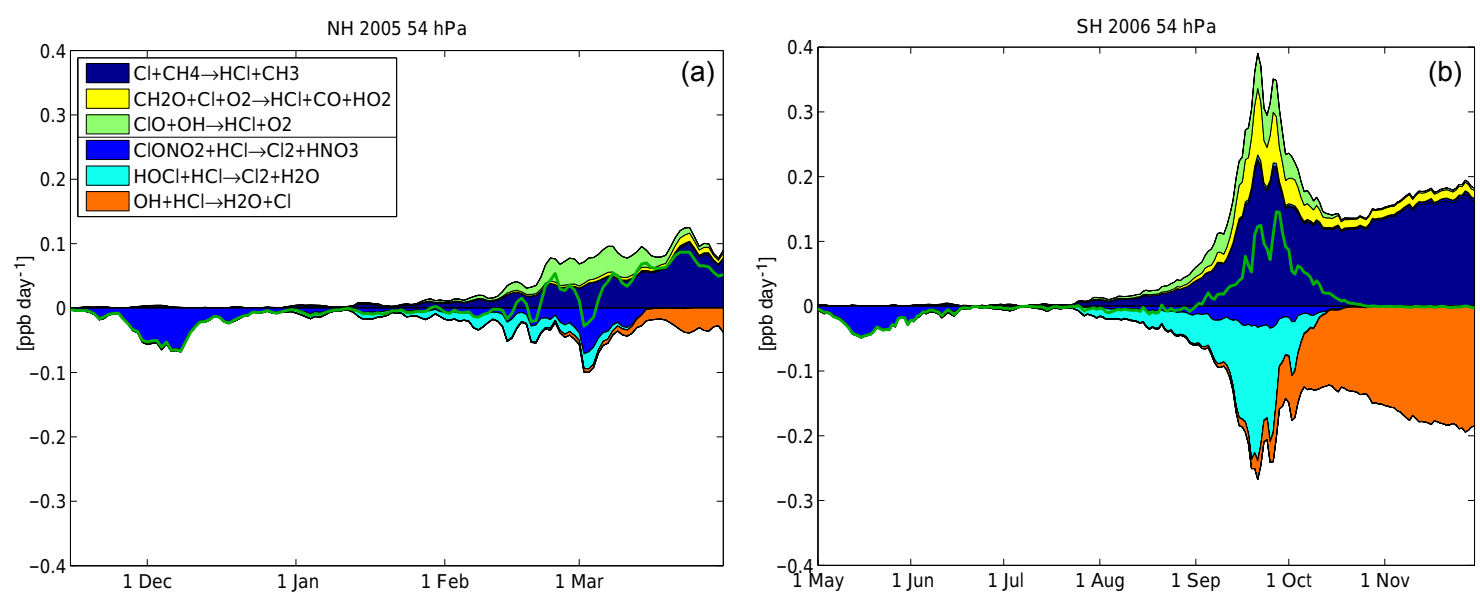

Figure 13. Vortex-averaged chemical reaction rates of reactions involving $\mathrm{HCl}$ for the Arctic winter 2004-2005 (a) and the Antarctic winter 2006 (b) at $54 \mathrm{hPa}$. Production reactions are shown as positive and are separated by a line in the legend from the loss reactions, which are shown as negative. The net change of $\mathrm{HCl}$ is shown as a green line. Reactions with rates which cannot be distinguished from the zero line at plot resolution are not shown. 
the Northern Hemisphere, $\mathrm{HCl}$ is produced from $\mathrm{ClONO}_{2}$ in spring after $\mathrm{ClO}_{\mathrm{x}}$ has been deactivated into $\mathrm{ClONO}_{2}$ some time earlier (see also Sect. 4.3.3 and Fig. 17), while in the Southern Hemisphere, active chlorine is deactivated mainly into $\mathrm{HCl}$. The chemical change rates of both $\mathrm{HCl}$ and $\mathrm{ClONO}_{2}$ decrease to zero in November in the Southern Hemisphere (green lines in Figs. 13, 16 and 17). The reaction

$\mathrm{Cl}+\mathrm{CH}_{4} \rightarrow \mathrm{HCl}+\mathrm{CH}_{3}$

is the main production reaction for $\mathrm{HCl}$ in both hemispheres (e.g., Portmann et al., 1996). In addition, it is responsible for deactivation under ozone hole conditions in the Southern Hemisphere. The reaction

$\mathrm{ClO}+\mathrm{OH} \rightarrow \mathrm{HCl}+\mathrm{O}_{2}$

becomes similar in importance to $\mathrm{Cl}+\mathrm{CH}_{4}$ as a production process for $\mathrm{HCl}$ around late February 2005 in the Northern Hemisphere and plays a smaller role earlier and later in winter. In the Southern Hemisphere, the reaction is not negligible around September and October 2006. The reaction is responsible for part of the chlorine deactivation in both hemispheres. The reaction $\mathrm{ClO}+\mathrm{OH}$ has two product channels. The channel into $\mathrm{HCl}$ yields about $8 \%$ of the products (the other channel is into $\mathrm{Cl}$ ).

\section{The role of $\mathrm{Cl}$ in $\mathrm{HCl}$ production}

The rate of the $\mathrm{Cl}+\mathrm{CH}_{4}$ reaction is proportional to the mixing ratio of $\mathrm{Cl}$. Figure 14 shows the mixing ratio of $\mathrm{Cl}$ for both hemispheres. Figure 15 shows that $\mathrm{Cl}$ is determined by the two source reactions:

$$
\begin{aligned}
& \mathrm{Cl}_{2} \mathrm{O}_{2}+h v+\mathrm{M} \rightarrow 2 \mathrm{Cl}+\mathrm{O}_{2}+\mathrm{M} \\
& \mathrm{ClO}+\mathrm{NO} \rightarrow \mathrm{Cl}+\mathrm{NO}_{2},
\end{aligned}
$$

and a reaction that removes $\mathrm{Cl}$,

$$
\mathrm{Cl}+\mathrm{O}_{3} \rightarrow \mathrm{ClO}+\mathrm{O}_{2} .
$$

Reaction (R31) is coupled to the catalytic $\mathrm{ClO}$ dimer cycle. $\mathrm{Cl}$ levels are considerably higher in the Southern Hemisphere due to a lack of ozone, which hinders the recombination to $\mathrm{ClO}$ (e.g., Douglass et al., 1995). This favors the deactivation of active chlorine via the $\mathrm{Cl}+\mathrm{CH}_{4}$ reaction (e.g., Portmann et al., 1996). Cl shows a very distinct behavior in the Southern Hemisphere. It does not just increase with the amount of sunlight, but shows a peak in September, followed by a near-constant plateau. This curve shape is approximately repeated in the curves of the reaction rate of the $\mathrm{Cl}+\mathrm{CH}_{4}$ reaction (Fig. 13), since $\mathrm{CH}_{4}$ is relatively constant. Figure 15 shows that the peak in $\mathrm{Cl}$ mixing ratios in the Southern Hemisphere is related to Reaction (R31), i.e., the catalytic ozone destruction. In contrast, the plateau is related to the $\mathrm{NO}_{\mathrm{x}} \mathrm{Re}-$ action (R7) (see also Wayne et al., 1995, p. 2836).

\subsubsection{Reservoir $\mathrm{ClONO}_{2}$}

Figure 16 shows the reaction rates of the most important reactions changing $\mathrm{ClONO}_{2}$. The reaction rates increase by a factor of 2 from 70 to $32 \mathrm{hPa}$ in 2004-2005 but are more constant in 2009-2010 (Figs. S20 and S44 of the Supplement). As discussed in Sect. 4.1, the gross change rates of $\mathrm{ClONO}_{2}$ are dominated by a near equilibrium between the reactions

$$
\begin{aligned}
& \mathrm{ClONO}_{2}+h v \rightarrow \mathrm{Cl}+\mathrm{NO}_{3} \\
& \mathrm{ClONO}_{2}+h v \rightarrow \mathrm{ClO}+\mathrm{NO}_{2}
\end{aligned}
$$

and

$\mathrm{ClO}+\mathrm{NO}_{2}+\mathrm{M} \rightarrow \mathrm{ClONO}_{2}+\mathrm{M}$

under sunlit conditions (e.g., Portmann et al., 1996). Net changes of $\mathrm{ClONO}_{2}$ are induced by changes in $\mathrm{NO}_{\mathrm{x}}$ which shift the equilibrium (e.g., Portmann et al., 1996).

The net change of $\mathrm{ClONO}_{2}$ is 1 order of magnitude smaller than the gross rates. Figure 17 shows the net effect of Reactions (R10)-(R12) and all other reactions that play a role in changing $\mathrm{ClONO}_{2}$. These reactions, which are all loss reactions, remove $\mathrm{ClONO}_{2}$ either by heterogeneous reactions or gas-phase reactions of $\mathrm{ClONO}_{2}$ with a radical. The most important heterogeneous reaction is the same as for $\mathrm{HCl}$ :

$\mathrm{ClONO}_{2}+\mathrm{HCl} \rightarrow \mathrm{Cl}_{2}+\mathrm{HNO}_{3}$.

The reactions of $\mathrm{ClONO}_{2}$ with a radical are of the type

$\mathrm{ClONO}_{2}+\mathrm{X} \rightarrow \mathrm{XCl}+\mathrm{NO}_{3}$,

where $\mathrm{X}$ is $\mathrm{X}=\mathrm{O}, \mathrm{Cl}$ or $\mathrm{OH}$. The reaction with $\mathrm{Cl}$ is the dominant reaction. The relative importance of these reactions is approximately constant from 70 to $32 \mathrm{hPa}$ (Figs. S21, S45, S69 and S93 of the Supplement).

In early winter in the polar night (December 2004 in the Northern Hemisphere; May and June 2006 in the Southern Hemisphere), the loss of $\mathrm{ClONO}_{2}$ by heterogeneous reactions dominates, leading to the activation of chlorine. After the complete depletion of $\mathrm{ClONO}_{2}$, this is followed by a phase with only small production and loss, due to near-zero levels of both $\mathrm{NO}_{\mathrm{x}}$ and $\mathrm{ClONO}_{2}$. The peak in production in early spring in the Northern Hemisphere (end of February and beginning of March 2005) is caused by the net production of extended $\mathrm{NO}_{\mathrm{x}}$ from $\mathrm{HNO}_{3}$ and is the main deactivation pathway for active chlorine in the Northern Hemisphere (e.g., Douglass et al., 1995; Portmann et al., 1996). At that time, $\mathrm{ClONO}_{2}$ is out of equilibrium and more $\mathrm{ClONO}_{2}$ is produced by $\mathrm{ClO}+\mathrm{NO}_{2}$ than is lost by photolysis. In the Southern Hemisphere, the rates are much lower due to the strongly denitrified conditions. In late March 2005, $\mathrm{ClONO}_{2}$ is lost in the Northern Hemisphere and finally converted to $\mathrm{HCl}$, which is the favored reservoir under summer conditions (e.g., Portmann et al., 1996; Santee et al., 2008). In the Southern Hemisphere, the rates of change are low in late October and November, since the deactivation already occurred directly to $\mathrm{HCl}$. 

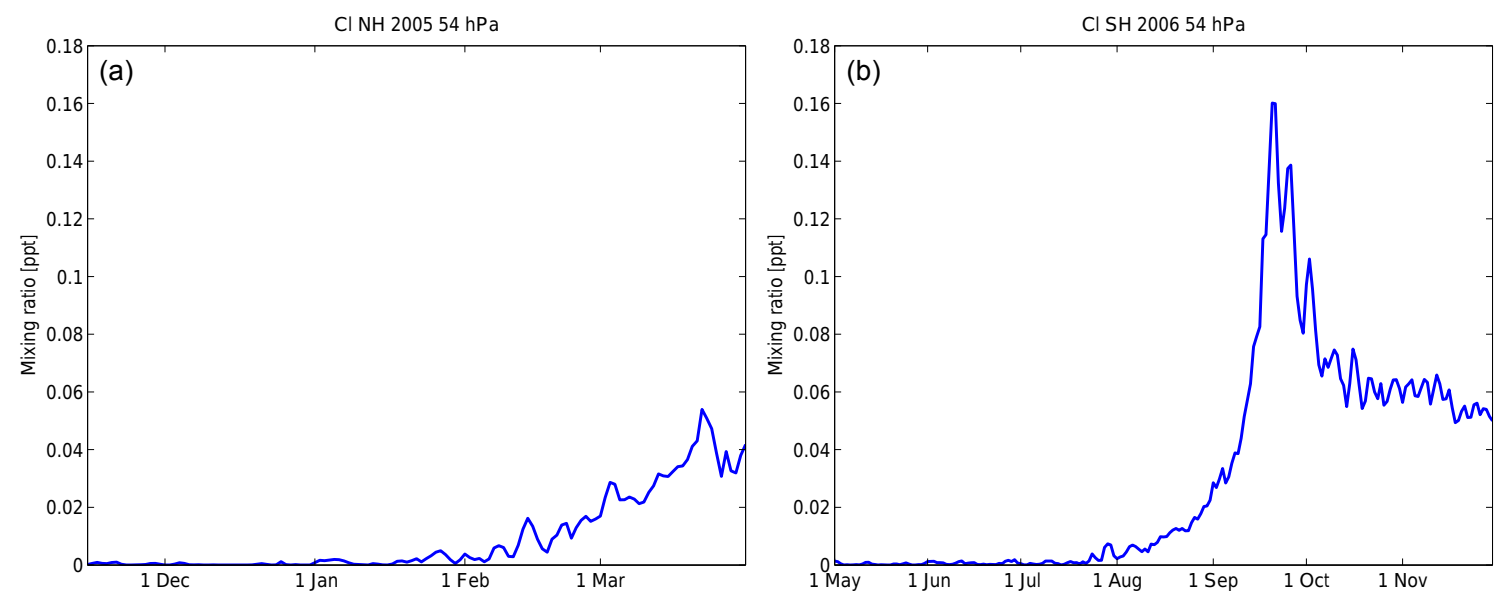

Figure 14. Vortex-averaged $\mathrm{Cl}$ mixing ratios for the Arctic winter 2004-2005 (a) and the Antarctic winter 2006 (b) at $54 \mathrm{hPa}$.
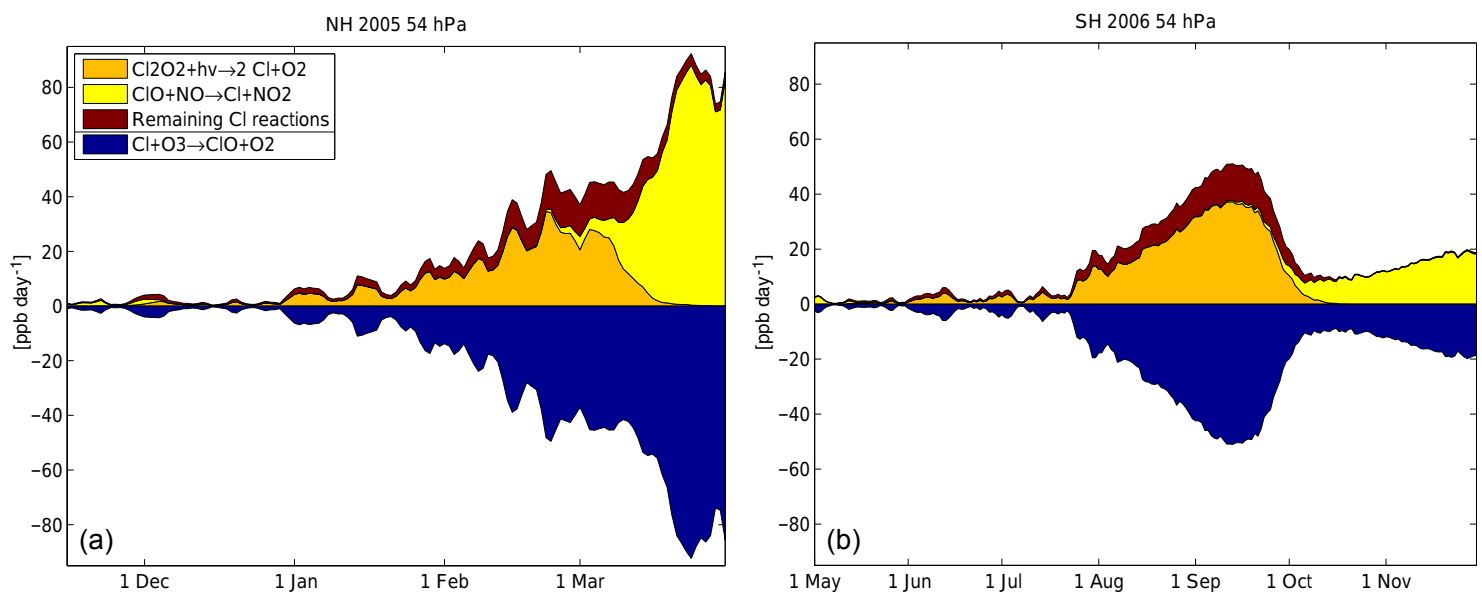

Figure 15. Vortex-averaged chemical reaction rates of reactions involving $\mathrm{Cl}$ for the Arctic winter 2004-2005 (a) and the Antarctic winter 2006 (b) at $54 \mathrm{hPa}$. Production reactions are shown as positive and are separated by a line in the legend from the loss reactions, which are shown as negative.

\subsection{Bromine species}

Sources of inorganic bromine, which has both natural and anthropogenic sources, are mainly halons and methyl bromide, but also some short-lived species (e.g., WMO, 2011; Montzka, 2012). Inorganic bromine $\left(\mathrm{Br}_{\mathrm{y}}\right)$ levels in the stratosphere are about $20 \mathrm{ppt}$ at maximum (e.g., WMO, 2011), with marginally lower levels in the altitude range considered here. Bromine chemistry is still somewhat uncertain due to uncertainties in the reaction coefficients (Sander et al., 2011; von Hobe and Stroh, 2012).

Atomic bromine is released from the source gases mainly by photolysis. Under sunlit conditions, it is in equilibrium with $\mathrm{BrO}$. The relevant reactions are

$$
\begin{aligned}
& \mathrm{Br}+\mathrm{O}_{3} \rightarrow \mathrm{BrO}+\mathrm{O}_{2} \\
& \mathrm{BrO}+h v \rightarrow \mathrm{Br}+\mathrm{O} \\
& \mathrm{BrO}+\mathrm{NO} \rightarrow \mathrm{NO}_{2}+\mathrm{Br}
\end{aligned}
$$

$\mathrm{BrO}+\mathrm{ClO}+\mathrm{M} \rightarrow \mathrm{Br}+\mathrm{Cl}+\mathrm{O}_{2}+\mathrm{M}$.

Reactions (R35) and (R38) are directly involved in the ClOBrO cycle; see Sect. 4.5.

Figure 18 shows the partitioning between the various inorganic bromine species at $54 \mathrm{hPa}$, which is very similar from 70 to $32 \mathrm{hPa}$ (Figs. S22, S46, S70 and S94 of the Supplement). Bromine is mostly present in the form of $\mathrm{HOBr}$ and $\mathrm{BrONO}_{2}$ at night before chlorine activation starts. In contrast to the less reactive chlorine, these are not real reservoir gases, since they easily photolyze into $\mathrm{Br}$ and react further to $\mathrm{BrO}$ during daytime, which gives bromine a great potential to destroy ozone despite the low mixing ratios (e.g., Lary, 1996; Solomon, 1999). BrO is a dominant species during daytime (e.g., Lary, 1996), except in October and November in the Southern Hemisphere, when the reaction $\mathrm{Br}+\mathrm{O}_{3}$ is hindered by the low ozone levels and $\mathrm{Br}$ mixing ratios are significant. Heterogeneous reactions play only a minor role and are not 

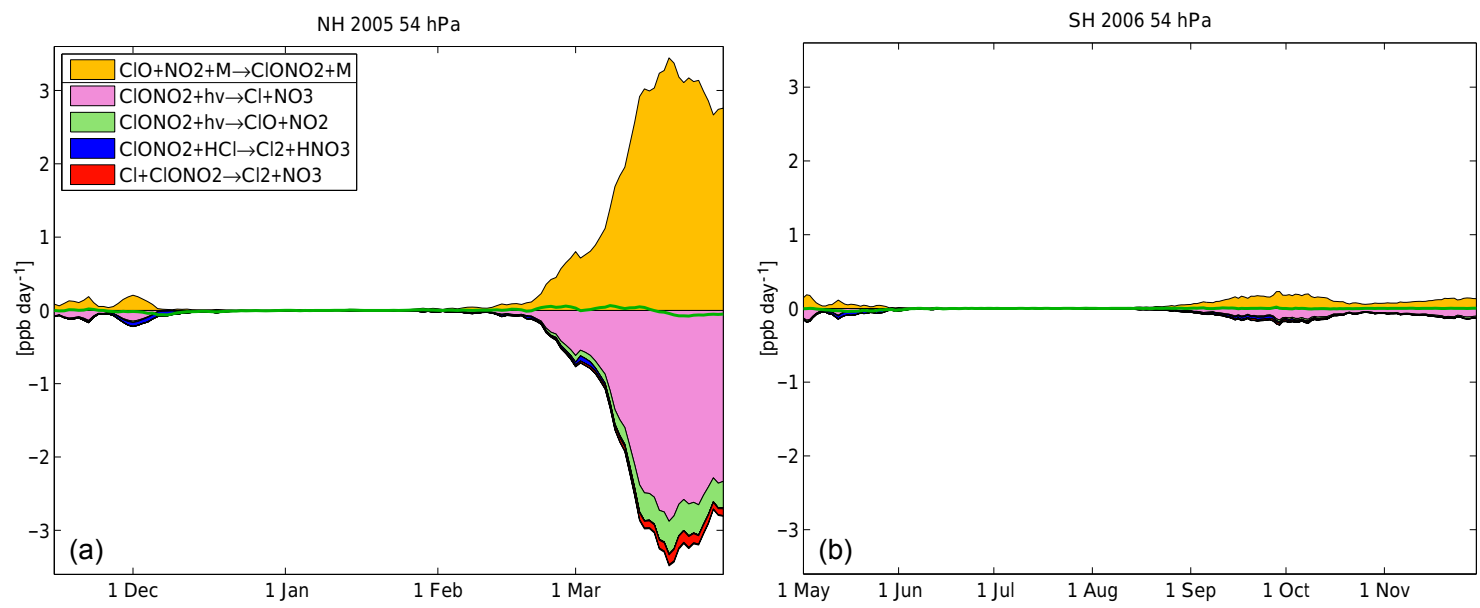

Figure 16. Vortex-averaged chemical reaction rates involving $\mathrm{ClONO}_{2}$ for the Arctic winter 2004-2005 and the Antarctic winter 2006 at $54 \mathrm{hPa}$. Production reactions are shown as positive and are separated by a line in the legend from the loss reactions, which are shown as negative. The net change of $\mathrm{ClONO}_{2}$ is shown as a green line. Reactions with rates which cannot be distinguished from the zero line at plot resolution are not shown.
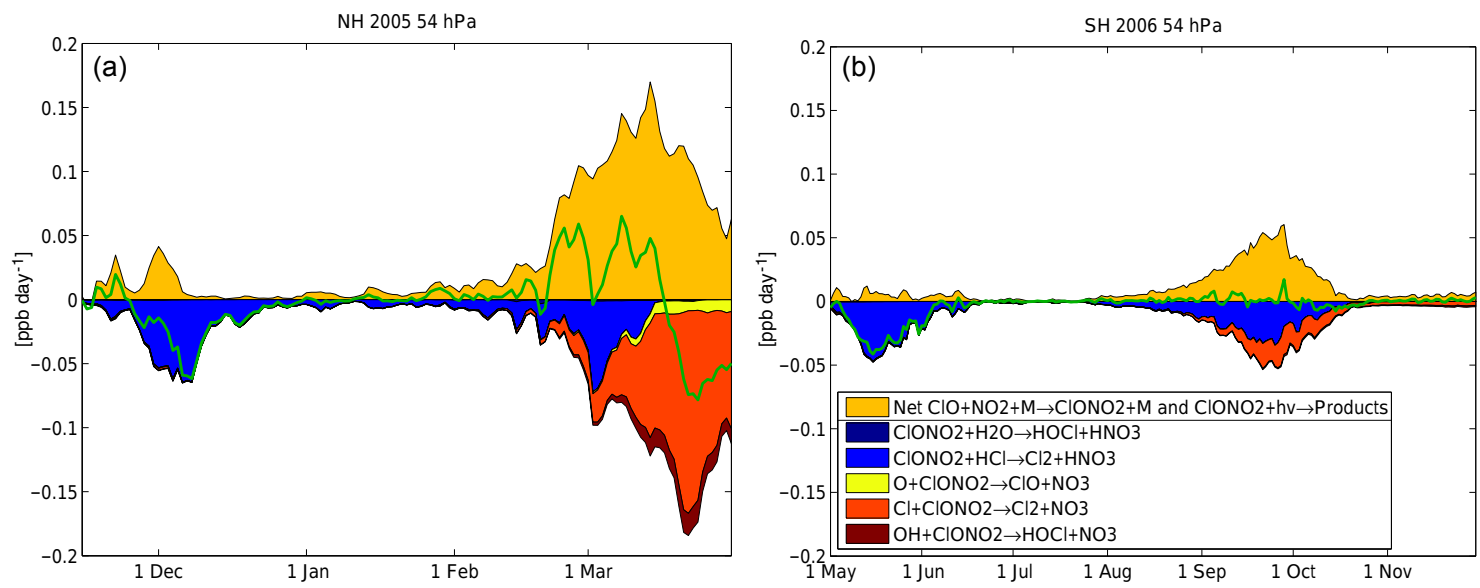

Figure 17. Vortex-averaged chemical reaction rates involving $\mathrm{ClONO}_{2}$ for the Arctic winter 2004-2005 (a) and the Antarctic winter 2006 (b) at $54 \mathrm{hPa}$. In contrast to Fig. 16, the net production rate of the fast cycle $\mathrm{ClONO}_{2}+h v \rightarrow$ products $/ \mathrm{ClO}+\mathrm{NO}_{2}+\mathrm{M} \rightarrow \mathrm{ClONO}_{2}+\mathrm{M}$ is shown. This cycle is separated by a line in the legend from the loss reactions. The green line shows the net change of $\mathrm{ClONO}_{2}$ by chemistry. Reactions with rates which cannot be distinguished from the zero line at plot resolution are not shown.

needed for activation (e.g., Lary et al., 1996; Wayne et al., 1995). As long as chlorine is activated, almost all bromine is in the form of $\mathrm{BrCl}$ at night (e.g., Lary et al., 1996; von Hobe and $\mathrm{Stroh}, 2012) . \mathrm{BrCl}$ is produced by the reaction

$\mathrm{BrO}+\mathrm{ClO} \rightarrow \mathrm{BrCl}+\mathrm{O}_{2}$.

During daytime, most of this $\mathrm{BrCl}$ is transformed to $\mathrm{Br}$ by photolysis:

$\mathrm{BrCl}+h v \rightarrow \mathrm{Br}+\mathrm{Cl}$,

followed by transformation to $\mathrm{BrO}$ by Reaction (R35).

\subsection{Oxygen species}

Figure 19 shows the vortex-averaged mixing ratios of ozone for the Northern and Southern hemispheres. Ozone stays more constant in the Northern Hemisphere in 2005 (where values range from 1.5 to $2.5 \mathrm{ppm}$ at $54 \mathrm{hPa}$ ) compared to the Southern Hemisphere in 2006, since the change by ozone depletion is nearly canceled by transport of air rich in ozone from above and over the vortex edge. In contrast, ozone values decrease from $2.5 \mathrm{ppm}$ to less than $0.5 \mathrm{ppm}$ at $54 \mathrm{hPa}$ in the Southern Hemisphere in 2006, both due to weaker transport and larger ozone depletion. While the initial ozone value of $2.5 \mathrm{ppm}$ in the Northern Hemisphere in 2004-2005 is relatively constant with height, the value at the end of 

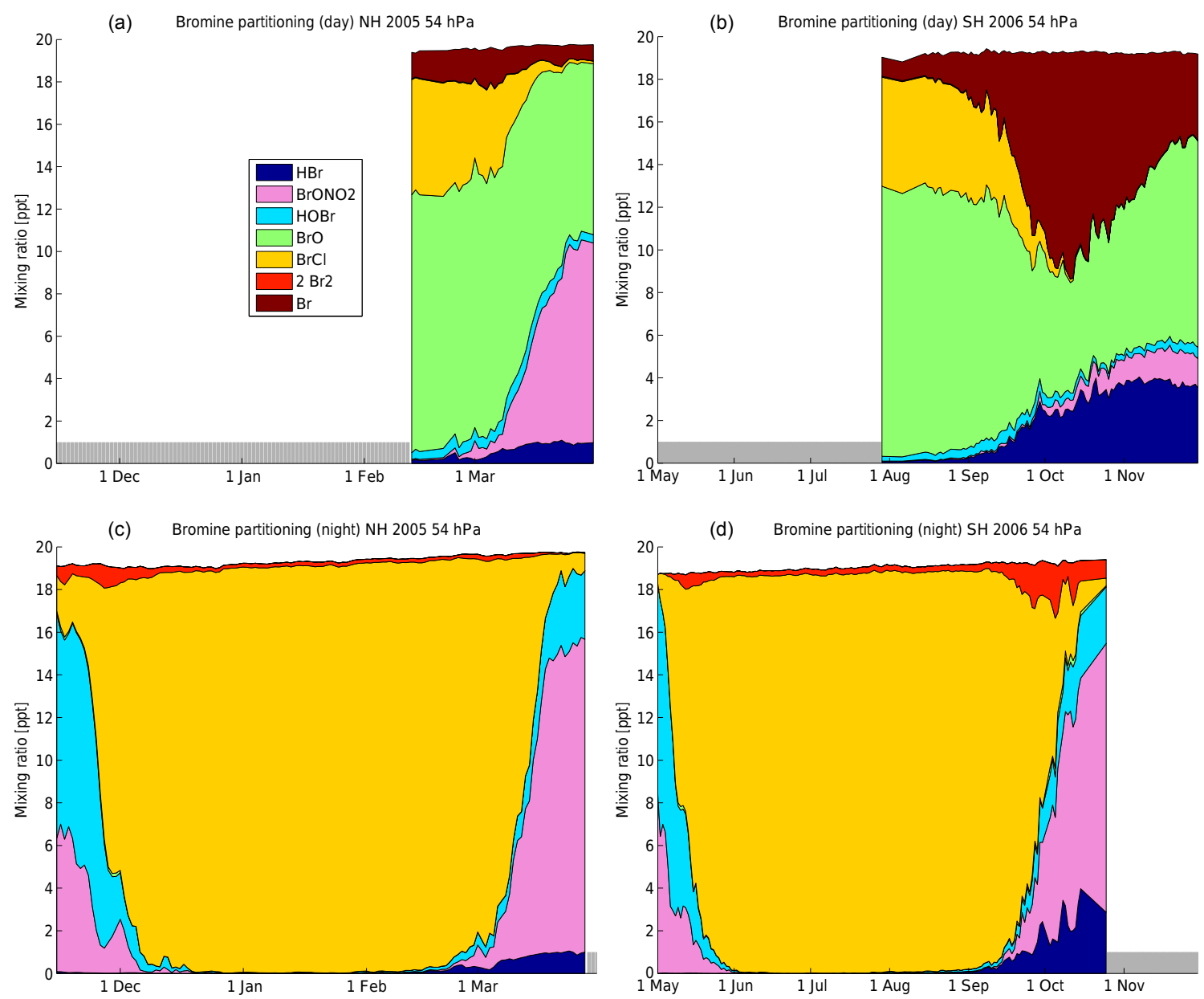

Figure 18. Vortex-averaged partitioning of inorganic bromine species for the Arctic winter 2004-2005 (a, c) and the Antarctic winter 2006 (b, d) at $54 \mathrm{hPa}$. Panels (a, b) show daytime averages (parts of the vortex where the solar zenith angle is smaller than $80^{\circ}$ ). Panels $(\mathbf{c}, \mathbf{d})$ show nighttime averages (parts of the vortex where the solar zenith angle is larger than $100^{\circ}$ ). Days without sufficient data for averaging are not shown (grey bars).

the winter varies from $1 \mathrm{ppm}$ at $70 \mathrm{hPa}$ to $3 \mathrm{ppm}$ at $32 \mathrm{hPa}$ due to changes in ozone depletion, production and transport (Fig. S23 of the Supplement). In the warmer winter 20092010, values are more similar at the end of the winter and less ozone depletion is observed (Fig. S47 of the Supplement).

$\mathrm{O}_{3}$ is in very fast equilibrium with $\mathrm{O}$. The dominant cycle is part of the well-known Chapman chemistry (Chapman, 1930):

$\mathrm{O}_{3}+h v \rightarrow \mathrm{O}+\mathrm{O}_{2}$

$\mathrm{O}+\mathrm{O}_{2}+\mathrm{M} \rightarrow \mathrm{O}_{3}+\mathrm{M}$.

We follow the usual convention here to treat $\mathrm{O}_{3}$ and $\mathrm{O}$ together as odd oxygen $\mathrm{O}_{\mathrm{x}}$ (e.g., Brasseur and Solomon, 2005; Solomon, 1999). Since O mixing ratios are low, the chemical rate of change of $\mathrm{O}_{\mathrm{x}}$ is nearly the same as the rate of change of ozone.

Odd oxygen is destroyed by several catalytic cycles. It is well known (e.g., Solomon, 1999) that the two dominant cy- cles in anthropogenic polar ozone depletion by halogens are the $\mathrm{ClO}$ dimer cycle (first proposed by Molina and Molina, 1987):

$$
\begin{aligned}
& 2\left(\mathrm{Cl}+\mathrm{O}_{3} \rightarrow \mathrm{ClO}+\mathrm{O}_{2}\right) \\
& \mathrm{ClO}+\mathrm{ClO}+\mathrm{M} \rightarrow \mathrm{Cl}_{2} \mathrm{O}_{2}+\mathrm{M} \\
& \mathrm{Cl}_{2} \mathrm{O}_{2}+h v+\mathrm{M} \rightarrow 2 \mathrm{Cl}+\mathrm{O}_{2}+\mathrm{M} \\
& 2 \mathrm{O}_{3} \rightarrow 3 \mathrm{O}_{2},
\end{aligned}
$$

and the $\mathrm{ClO}-\mathrm{BrO}$ cycle (first proposed by McElroy et al., 1986):

$$
\begin{aligned}
& \mathrm{Cl}+\mathrm{O}_{3} \rightarrow \mathrm{ClO}+\mathrm{O}_{2} \\
& \mathrm{Br}+\mathrm{O}_{3} \rightarrow \mathrm{BrO}+\mathrm{O}_{2} \\
& \mathrm{BrO}+\mathrm{ClO}+\mathrm{M} \rightarrow \mathrm{Br}+\mathrm{Cl}+\mathrm{O}_{2}+\mathrm{M} \\
& 2 \mathrm{O}_{3} \rightarrow 3 \mathrm{O}_{2} .
\end{aligned}
$$

The $\mathrm{ClO}$ dimer cycle is effective because $\mathrm{Cl}_{2} \mathrm{O}_{2}$ photolysis, which produces $\mathrm{Cl}$ and not $\mathrm{ClO}$, is fast compared to the com- 
peting $\mathrm{Cl}_{2} \mathrm{O}_{2}$ loss reaction $\mathrm{Cl}_{2} \mathrm{O}_{2}+\mathrm{M}$ (Wayne et al., 1995, p. 2836). The uncertainty of the rate coefficient of $\mathrm{Cl}_{2} \mathrm{O}_{2}$ photolysis (Reaction R31) and the rate coefficient of the $\mathrm{BrO}+\mathrm{ClO}$ Reaction (R38) are two of the parameters which produce the largest uncertainties with respect to ozone loss in models (e.g., Frieler et al., 2006; WMO, 2011), although much of the uncertainty in the photolysis rate coefficient has been resolved recently (Kawa et al., 2009; von Hobe and Stroh, 2012; Canty et al., 2016).

Figure 20 shows the contribution of the different catalytic cycles to the net chemical rate of change of ozone. For this purpose, the reaction rates of the rate-limiting step of the reaction cycles have been used. This is possible here without ambiguities, since all rate-limiting reactions are only involved in one cycle.

Typical peak loss rates vary between 40 and 60 ppb per day and are similar in both hemispheres in the altitude range 70 to $32 \mathrm{hPa}$ for these two winters (compare also the peak values of $\mathrm{ClO}_{\mathrm{x}}$ discussed earlier and Figs. S24 and S72 of the Supplement). Somewhat higher values of up to $70 \mathrm{ppb}$ per day are only seen at 42 and $32 \mathrm{hPa}$ in the Southern Hemisphere. Note, however, the underestimation of $\mathrm{ClO}$ in the Southern Hemisphere in ATLAS compared to MLS mentioned earlier. Hence, the higher ozone depletion in the Southern Hemisphere is mainly caused by the much longer time period in which $\mathrm{ClO}_{\mathrm{x}}$ is activated in our model. Photochemical production of ozone is evident in March 2005 in the Northern Hemisphere and in October and November 2006 in the Southern Hemisphere and increases with altitude (Figs. S24, S48, S72 and S96 of the Supplement).

As long as appreciable amounts of $\mathrm{ClO}$ exist (January to February 2005 in the Northern Hemisphere; June to September 2006 in the Southern Hemisphere), the $\mathrm{ClO}-\mathrm{ClO}$ cycle contributes about $50 \%$ to the net ozone loss and the $\mathrm{ClO}-\mathrm{BrO}$ cycle contributes about $30-40 \%$ at all altitudes (Figs. S24, S48, S72 and S96 of the Supplement). These values compare well with the results of Kuttippurath et al. (2010) at $475 \mathrm{~K}$ for $2005(50 \% \mathrm{ClO}-\mathrm{ClO}$ to $30 \% \mathrm{ClO}-\mathrm{BrO})$ and with the results of Frieler et al. (2006) (50\% ClO-ClO to $30-50 \% \mathrm{ClO}-\mathrm{BrO}$ but for years different from 2005). See also Grenfell et al., 2006, for case studies.

Loss cycles of the form

$\mathrm{X}+\mathrm{O}_{3} \rightarrow \mathrm{XO}+\mathrm{O}_{2}$

$\underline{\mathrm{XO}+\mathrm{O} \rightarrow \mathrm{X}+\mathrm{O}_{2}}$

$\mathrm{O}+\mathrm{O}_{3} \rightarrow \mathrm{O}_{2}+\mathrm{O}_{2}$,

where $\mathrm{X}=\mathrm{OH}, \mathrm{H}, \mathrm{NO}, \mathrm{Cl}$ or $\mathrm{Br}$, which dominate in most latitudes and seasons, only play a minor role in the polar lower stratosphere due to the relatively low production of atomic oxygen by photolysis (e.g., von Hobe and Stroh, 2012). The $\mathrm{ClO}-\mathrm{O}$ cycle contributes about $10 \%$ at $54 \mathrm{hPa}$ and increases in importance with altitude, in agreement with, e.g., Kuttippurath et al. (2010).
The most important null cycle acting on odd oxygen apart from Reactions (R41) and (R42) is the nitrogen cycle

$$
\begin{aligned}
& \mathrm{O}_{3}+\mathrm{NO} \rightarrow \mathrm{NO}_{2}+\mathrm{O}_{2} \\
& \frac{\mathrm{NO}_{2}+h v \rightarrow \mathrm{NO}+\mathrm{O}}{\mathrm{O}_{3} \rightarrow \mathrm{O}_{2}+\mathrm{O} .}
\end{aligned}
$$

\section{Interannual variability}

In addition to the runs for the Arctic winter 2004-2005 and the Antarctic winter 2006, we performed model runs for the Arctic winter 2009-2010 and the Antarctic winter 2011 to get at least an idea of the interannual variability of the reaction rates and partitioning, and to assess if the results can be generalized. Figures for the additional years can be found in the Supplement.

Since meteorological conditions are usually very similar in the Southern Hemisphere from year to year, the results do not change significantly for the Antarctic winter 2011 compared to 2006, and the same discussion as for the winter 2006 applies. Except for rare cases, such as the vortex split in 2002, the dates, magnitudes of the values and the relative partitioning will also be applicable to other southern winters.

The northern winters 2004-2005 and 2009-2010 were taken as examples for a colder and a warmer winter, respectively, and reflect the larger meteorological variability in the Northern Hemisphere. The main differences are in the timing of the changes in reaction rates and mixing ratios. The first main difference is a later activation of chlorine (end of December 2009 compared to start of December 2004) reflected, e.g., in the timing of the heterogeneous reaction rates. The second main difference is an earlier deactivation by an earlier stratospheric warming in February. That means an earlier increase in, e.g., $\mathrm{ClONO}_{2}, \mathrm{NO}_{\mathrm{x}}$ or $\mathrm{HO}_{\mathrm{x}}$ and the associated reaction rates, and an earlier decrease in $\mathrm{ClO}_{\mathrm{x}}$. The timing of activation and deactivation can vary greatly between different northern winters, from winters with no chlorine activation or heterogeneous ozone depletion at all to winters that stay cold until April and experience severe ozone loss (e.g., Santee et al., 2008).

The absolute values of the reaction rates and mixing ratios, the relative partitioning inside the chemical families and the relative importance of reactions remain similar for most species for these two northern winters. One of the notable exceptions is of course ozone, which shows less depletion in a warm winter like 2009-2010. This comparison suggests that the relative partitioning and the relative importance of reactions can be generalized to other northern winters, but that the absolute values of ozone depletion and of several reaction rates will differ. 

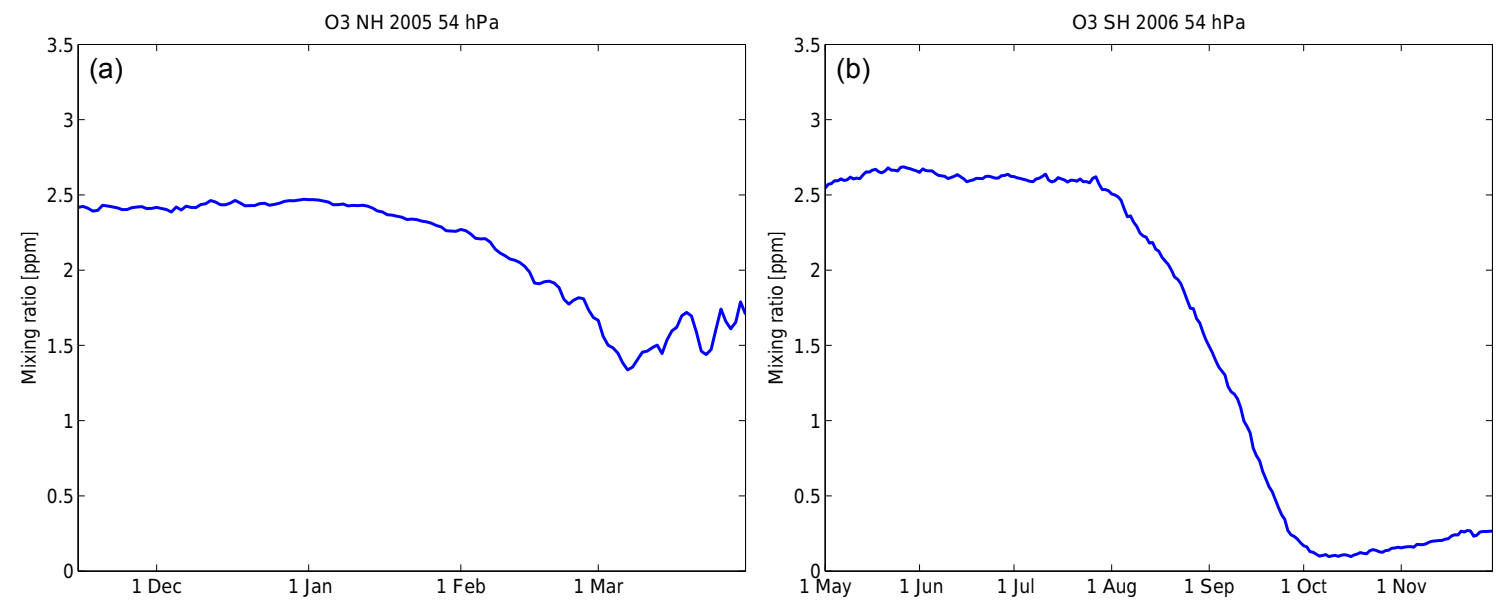

Figure 19. Vortex-averaged ozone mixing ratios for the Arctic winter 2004-2005 (a) and the Antarctic winter 2006 (b) at $54 \mathrm{hPa}$
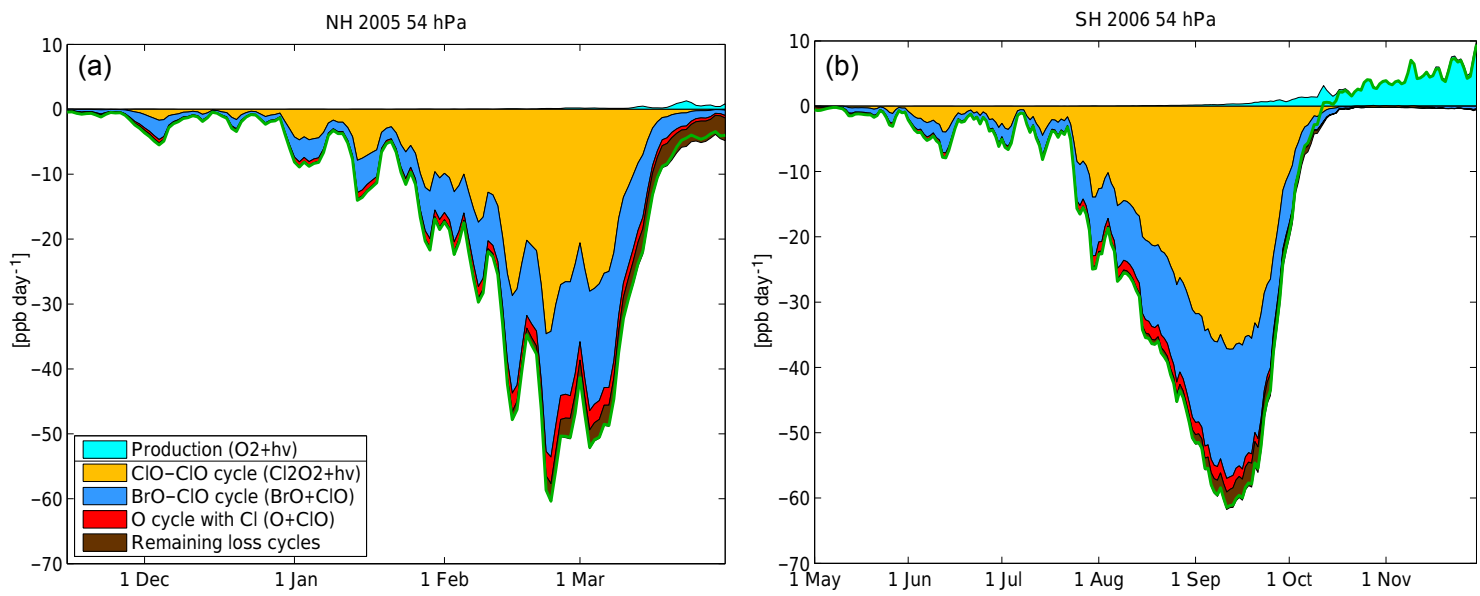

Figure 20. Vortex-averaged net chemical change of odd oxygen. The green line shows the net chemical change rate of ozone, which nearly equals the change rate of odd oxygen at this altitude. The contribution of different catalytic cycles to the ozone loss is shown by the reaction rates of their rate-limiting step. Only the three most important cycles are shown; the contribution of other cycles is small. Ozone production, which is almost exclusively by the $\mathrm{O}_{2}+h v$ reaction, is shown in cyan.

\section{Model validation}

It is desirable that the results of the ATLAS model agree well with observations to increase the confidence in the model results for minor species and reaction rates which cannot be confirmed by observations. It is out of the scope of this study to give a comprehensive model validation against observations, but we include an extensive set of comparisons to observations of the MLS satellite instrument (e.g., Santee et al., 2008) and the ACE-FTS (Atmospheric Chemistry Experiment - Fourier Transform Spectrometer) satellite instrument (e.g., Bernath, 2017) in the Supplement to provide additional information for the interested reader. In addition, the reader is referred to Wohltmann et al. $(2010,2013)$ for a detailed validation.

Since there is reasonable agreement between measurements and the ATLAS model for many species, we will re- strict discussion to the notable differences between ATLAS and observations and show only some selected results in the main text. The focus is on a prominent disagreement between modeled mixing ratios of $\mathrm{HCl}$ and observations.

\subsection{HCl discrepancy between model and measurements}

Figures 21 and 22 show a comparison of the vortex-averaged mixing ratios of some important species $\left(\mathrm{O}_{3}, \mathrm{H}_{2} \mathrm{O}, \mathrm{HNO}_{3}\right.$, $\mathrm{HCl}$ and $\mathrm{N}_{2} \mathrm{O}$; blue and black lines) with corresponding vortex averages measured by the MLS satellite instrument (e.g., Santee et al., 2008) (red circles with bars for the accuracy, version 3 data; Livesey et al., 2011). Note that the vortex averages do not take into account the vortex tracer criterion (as in the preceding sections) to facilitate comparison with MLS (the Supplement contains comparisons with MLS at individual locations for more detailed information). The blue lines 

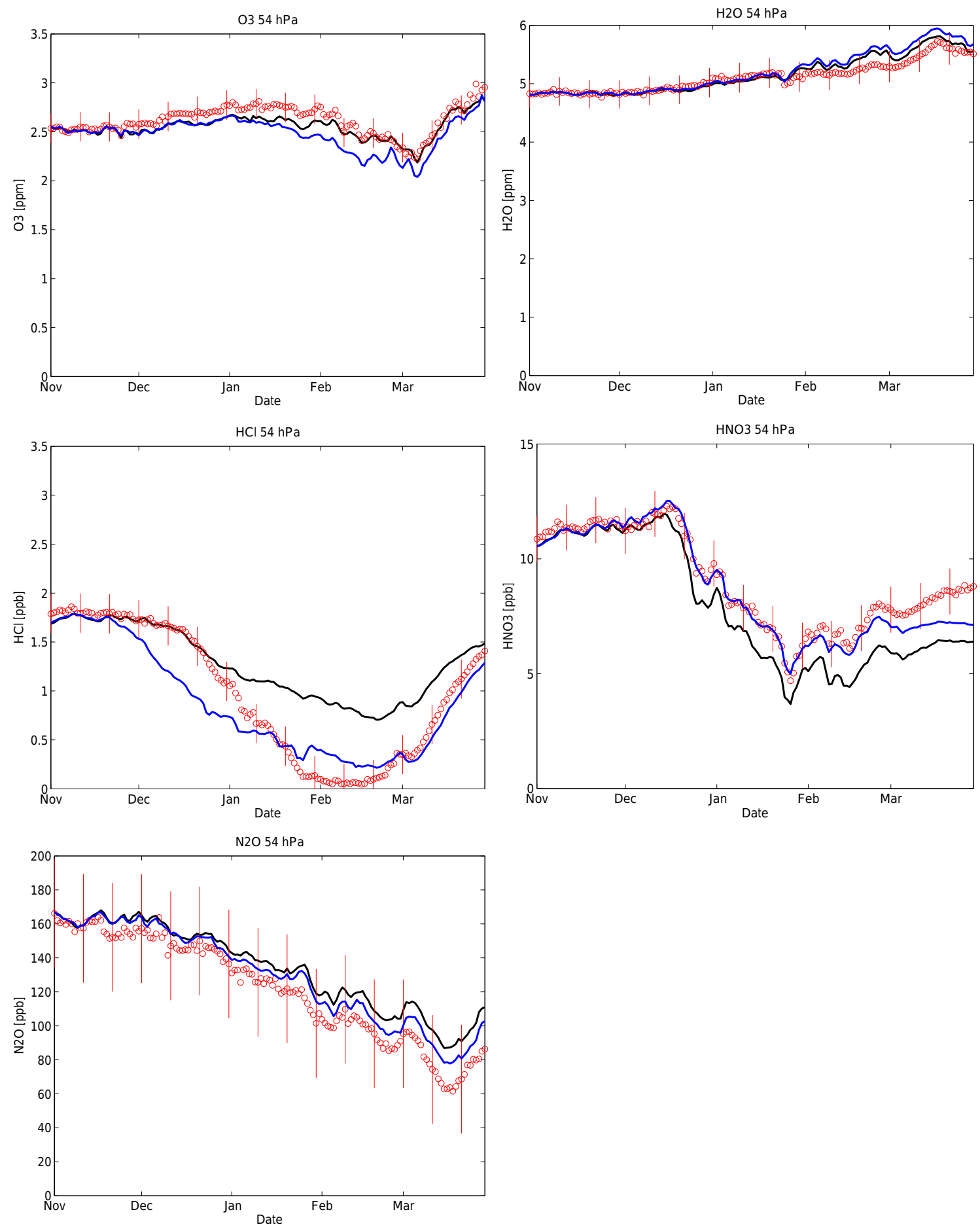

Figure 21. Vortex-averaged mixing ratios of $\mathrm{O}_{3}, \mathrm{H}_{2} \mathrm{O}, \mathrm{HCl}, \mathrm{HNO}_{3}$ and $\mathrm{N}_{2} \mathrm{O}$ for the Arctic winter 2004-2005 at $54 \mathrm{hPa}$. The red dots show MLS satellite measurements (version 3, with bars showing the accuracy), the blue lines show the ATLAS runs used in this paper and the black line shows the original runs which are not empirically corrected for the $\mathrm{HCl}$ discrepancy.

denote the runs actually used in this paper (with a $5 \mathrm{~K}$ offset to $\mathrm{HCl}$ solubility), and the black lines denote the uncorrected model runs (without any change to $\mathrm{HCl}$ solubility).
It is obvious that the runs without a change to the $\mathrm{HCl}$ solubility significantly overestimate $\mathrm{HCl}$, a behavior also observed in other models like SD-WACCM (Brakebusch et al., 2013; Wegner, 2013; Solomon et al., 2015) or MIMOSA- 

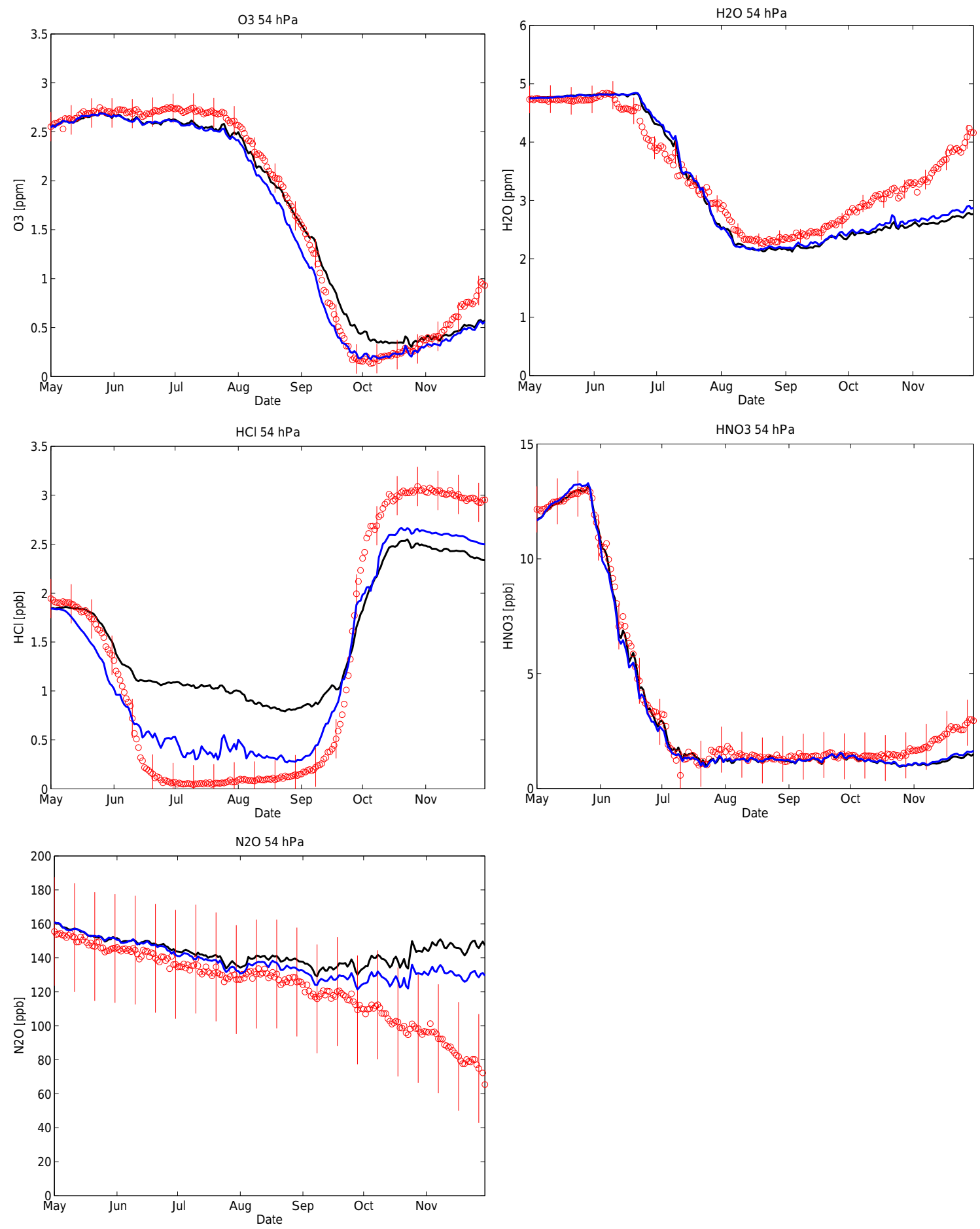

Figure 22. Comparison of vortex-averaged mixing ratios for the Antarctic winter 2006.

CHIM (Kuttippurath et al., 2015). Interestingly, the SLIMCAT CTM shows a discrepancy of the same order of magnitude, but with the opposite sign in a recent publication (Santee et al., 2008), while in an older version, species mixing ratios depend on the model resolution (Chipperfield et al., 1997).
Apart from the discrepancy in $\mathrm{HCl}$, the agreement of model and observations for other species like ozone, water vapor or $\mathrm{HNO}_{3}$ is quite satisfactory. The reason for the $\mathrm{HCl}$ discrepancy is unknown, but several solutions are possible: 
- The initial amount of $\mathrm{ClONO}_{2}$ in the model is underestimated, which hinders the $\mathrm{HCl}+\mathrm{ClONO}_{2}$ reaction (discussed in Santee et al., 2008; Brakebusch et al., 2013; Wegner, 2013). $\mathrm{ClONO}_{2}$ only represents about $30 \%$ of inorganic chlorine at the start of the winter and is clearly the limiting species of the reaction. An underestimation in ATLAS is however unlikely, since it is not supported by measurements of $\mathrm{ClONO}_{2}$ by ACE-FTS (Figs. S165, S167, .., S171 of the Supplement) and would require increasing the $\mathrm{ClONO}_{2}$ mixing ratios by more than $100 \%$.

- Less $\mathrm{NO}_{\mathrm{x}}$ is transported across the vortex edge in the model compared to the real atmosphere, which impedes the reformation of $\mathrm{ClONO}_{2}$ and $\mathrm{HCl}$ depletion via the $\mathrm{HCl}+\mathrm{ClONO}_{2}$ reaction (discussed in Solomon et al., 2015). This is likely very dependent on the transport and mixing scheme used in the model, and Eulerian (gridbased) models will show differences to Lagrangian (trajectory-based) models here due to the lower numerical diffusion in the latter. The underestimation of $\mathrm{HCl}$ in SLIMCAT (Santee et al., 2008) and the dependency of the species abundances on model resolution in the same model (Chipperfield et al., 1997) may point in this direction.

While it cannot be excluded that less $\mathrm{NO}_{\mathrm{x}}$ is transported across the vortex edge in ATLAS compared to the real atmosphere, the good agreement of most other species in ATLAS with measurements, including the tracer $\mathrm{N}_{2} \mathrm{O}$ (Figs. 21 and 22), suggests that this option is unlikely. As long as errors in subsidence do not compensate for errors in mixing, this also means that the $\mathrm{HCl}$ discrepancy cannot be caused by differences in subsidence between the model and real atmosphere.

Note that there is a marked discrepancy in $\mathrm{N}_{2} \mathrm{O}$ between MLS and the model in the Southern Hemisphere in October and November, which is however after the period of interest here. The reason for this discrepancy is unknown, but a possible reason could be overestimation of mixing across the vortex edge in ERA-Interim in this time period.

- $\mathrm{HCl}$ is taken up in PSCs and sediments out of the observed layer (discussed in Wegner, 2013). This is not supported by either the temporal or the spatial evolution of $\mathrm{HCl}$.

- An unknown heterogeneous reaction is depleting $\mathrm{HCl}$. This cannot be excluded, but some boundary conditions need to be fulfilled, e.g., the reaction needs to involve $\mathrm{HCl}$ and it must not change the mixing ratios of other observed species too much.

- There is a temperature bias in the ERA-Interim data compared to the real atmosphere or a water vapor bias in the model (discussed in Brakebusch et al., 2013; Wegner, 2013; Solomon et al., 2015). The solubility of $\mathrm{HCl}$ in STS droplets is a strong function of both temperature and water vapor. The discussion in Simmons et al. (2014) and our own comparisons at the station $\mathrm{Ny}$ Ålesund suggest that the bias between ERA-Interim and radiosonde data is less than $0.3 \mathrm{~K}$ in the considered altitude range and cannot explain the differences between MLS and ATLAS. The water vapor data are in good agreement between MLS and ATLAS (Figs. 21 and 22) and are also not likely to cause the differences in $\mathrm{HCl}$.

- The parameterized solubility of $\mathrm{HCl}$ in STS droplets is underestimated (discussed in Brakebusch et al., 2013; Wegner, 2013). This is a promising possibility (since it does not affect most other species, consistent with the reasonable agreement of the other species to measurements), but it requires changes to the solubility that are larger than the stated uncertainties of the solubility parameterization by Luo et al. (1995) that is used in the model.

Since there is not enough evidence to narrow down this list to a likely candidate, we decided on an empirical approach: we introduced a temperature offset for the calculation of the Henry constant of $\mathrm{HCl}$ and changed the offset until we obtained good agreement between measured and modeled $\mathrm{HCl}$, which was the case for an offset of $-5 \mathrm{~K}$. The effect of the changed Henry constant is twofold: first, it increases the amount of $\mathrm{HCl}$ dissolved in STS droplets. Second, it increases the rates of the heterogeneous reactions (even if only small amounts of $\mathrm{HCl}$ are dissolved) by changing the $\gamma$ values. Brakebusch et al. (2013) and Solomon et al. (2015) did take the approach to introduce a $-1.5 \mathrm{~K}$ temperature bias in the entire heterogeneous chemistry module, but we opted here for a different solution, since this would have an additional direct temperature effect on reaction rates in the model.

The $\mathrm{HCl}$ mixing ratios of the model runs with the changed Henry constant agree considerably better than those from the original runs with the satellite measurements in both hemispheres. However, there is a large underestimation of $\mathrm{HCl}$ in ATLAS now in December 2004 in the Northern Hemisphere. This causes chlorine activation to set in too early in December (similar to Santee et al., 2008), and there is an overestimation of peak $\mathrm{ClO}$ values of up to $0.5 \mathrm{ppb}$ on 15 December (Fig. S145 in the Supplement). In the Southern Hemisphere, an overestimation of $\mathrm{HCl}$ by ATLAS by about 0.2 $0.4 \mathrm{ppb}$ remains, which is roughly consistent with an underestimation of $\mathrm{ClO}$ in ATLAS of the same order of magnitude (Figs. S153, S155, .., S163 in the Supplement).

In addition to the results for the corrected runs, the Supplement shows the same figures for the uncorrected runs to assess the impact of the changes in $\mathrm{HCl}$ solubility. The main difference is considerably less chlorine activation in both hemispheres (e.g., the peak value of $\mathrm{ClO}_{\mathrm{x}}$ for the northern winter 2004-2005 at $54 \mathrm{hPa}$ changes from 2.5 to $1.5 \mathrm{ppb}$ ). 
This corresponds to higher mixing ratios of the reservoir gases and lower reaction rates of $\mathrm{HCl}$ and $\mathrm{ClONO}_{2}$. In the Northern Hemisphere, the reduced chlorine activation leads to reduced ozone loss (e.g., the mixing ratio of ozone at $70 \mathrm{hPa}$ at the end of March 2005 increases from 1 to $1.5 \mathrm{ppm})$. However, in the Southern Hemisphere, chlorine activation is still sufficient to deplete ozone to near-zero values. Most other findings remain largely unaffected, including the relative importance of reactions, the relative partitioning and the results for the $\mathrm{NO}_{\mathrm{x}}$ and $\mathrm{HO}_{\mathrm{x}}$ chemistry.

\subsection{Other notable differences}

The Supplement shows maps of comparisons to MLS satellite observations at $46 \mathrm{hPa}$ for the northern winter 20042005 and the southern winter 2006. The maps show all measurements on the 15 th of every month for the species $\mathrm{ClO}$, $\mathrm{HCl}, \mathrm{H}_{2} \mathrm{O}, \mathrm{HNO}_{3}, \mathrm{~N}_{2} \mathrm{O}$ and $\mathrm{O}_{3}$. Additionally, comparisons to ACE-FTS measurements are shown for the southern winter 2006 as a function of equivalent latitude and altitude. Species are $\mathrm{H}_{2} \mathrm{O}, \mathrm{O}_{3}, \mathrm{CH}_{4}, \mathrm{HCl}, \mathrm{ClONO}_{2}, \mathrm{~N}_{2} \mathrm{O}, \mathrm{NO}, \mathrm{NO}_{2}$, $\mathrm{N}_{2} \mathrm{O}_{5}$ and $\mathrm{HNO}_{3}$. In general, agreement is reasonable both for the spatial patterns and the absolute values, with the following exceptions:

- There is an underestimation of $\mathrm{HNO}_{3}$ in both hemispheres outside of the vortex by the model compared to both MLS and ACE-FTS, which is however outside of the region of interest here and may be related to the initialization.

- There is an overestimation of $\mathrm{O}_{3}$ outside of the vortex by the model, which may be related to the underestimation of $\mathrm{HNO}_{3}$ (less ozone depletion by $\mathrm{NO}_{\mathrm{x}}$ ).

- There is a significant overestimation of $\mathrm{ClONO}_{2}$ around $600 \mathrm{~K}$ by the model compared to ACE-FTS in the Southern Hemisphere, which may be caused in part by the initialization (there is only a limited amount of measurements of $\mathrm{ClONO}_{2}$ and initialization is based on a tracer relationship).

- $\mathrm{NO}_{\mathrm{x}}$ is significantly overestimated by the model above $600 \mathrm{~K}$ in the Southern Hemisphere compared to ACEFTS. This is, however, very difficult to interpret, since ACE-FTS measures only under high solar zenith angles, where the temporal change of the species is fast, which may lead to large errors in combination with the large satellite footprint.

\section{Conclusions}

We have given a quantitative analysis of the reactions involved in polar ozone depletion in the stratosphere. For clarity, this study focuses on vortex averages in a layer around
$54 \mathrm{hPa}$ for one specific winter in each hemisphere, with additional winters and pressure levels shown in the Supplement. The chemistry of polar ozone depletion is well known, but quantitative estimates of the partitioning of the chemical families or the importance of single reactions and reaction cycles are rare. To our knowledge, this is the first comprehensive study providing quantitative results averaged over the core of the polar vortex under conditions perturbed by heterogeneous chemistry. The main aim of this study is to quantify the partitioning of $\mathrm{HO}_{\mathrm{x}}, \mathrm{NO}_{\mathrm{x}}$ and $\mathrm{ClO}_{\mathrm{x}}$, the relative importance of production and loss reactions and the timing of the reactions. Some selected findings include the following:

- Our results suggest that the relative partitioning within chemical families and the relative importance of reactions in the northern winter 2004-2005 and the southern winter 2006 can be generalized to other winters. The absolute values of ozone depletion, the absolute values of the reaction rates and the timing of changes will differ, particularly in the Northern Hemisphere.

- The ClO dimer cycle contributes about $50 \%$ to the vortex-averaged ozone loss at $54 \mathrm{hPa}$ in both hemispheres, while the $\mathrm{ClO}-\mathrm{BrO}$ cycle contributes about $40 \%$, in good agreement with earlier studies (e.g., Frieler et al., 2006; Kuttippurath et al., 2010). The ClO$\mathrm{O}$ cycle contributes about $10 \%$ at $54 \mathrm{hPa}$ and increases in importance with altitude at the expense of the $\mathrm{ClO}$ dimer and $\mathrm{ClO}-\mathrm{BrO}$ cycles.

- In the Southern Hemisphere, there is a clear shift from chlorine activation by the $\mathrm{ClONO}_{2}+\mathrm{HCl}$ reaction in early winter to activation by the $\mathrm{HOCl}+\mathrm{HCl}$ reaction later in winter. $\mathrm{HOCl}+\mathrm{HCl}$ accounts for about $70 \%$ of the activation of $\mathrm{HCl}$ in the Southern Hemisphere at $54 \mathrm{hPa}$ in 2006 (integrated over time), while it accounts for only $30 \%$ of the activation in the Northern Hemisphere in 2005. The reason for this is the deactivation of chlorine by the reaction $\mathrm{Cl}+\mathrm{CH}_{4}$ in the Southern Hemisphere (caused in turn by the low ozone values), which provides $\mathrm{HCl}$ and produces $\mathrm{HO}_{\mathrm{x}}$ (see, e.g., Crutzen et al., 1992; Portmann et al., 1996). This can clearly be seen in rising $\mathrm{HCl}$ levels in September in the Southern Hemisphere and in increased $\mathrm{HO}_{\mathrm{x}}$ levels.

- $\mathrm{ClO}_{\mathrm{x}}$ peaks at $2.0 \mathrm{ppb}$ at $70 \mathrm{hPa}$ and at $2.5 \mathrm{ppb}$ from 54 to $32 \mathrm{hPa}$ in the Northern Hemisphere in both 2005 and 2010 in the model. The peak values in the Southern Hemisphere in 2006 and 2011 are lower $(2.0 \mathrm{ppb}$ at 54 and $42 \mathrm{hPa}$ ). There is, however, an underestimation of $\mathrm{ClO}$ of about $0.2-0.4 \mathrm{ppb}$ compared to MLS in the Southern Hemisphere in ATLAS, consistent with an overestimation of $\mathrm{HCl}$ and an underestimation of chlorine activation, which is related to a difficulty to model $\mathrm{HCl}$ correctly in state-of-the-art CTMs (see below). Taking this into account, similar $\mathrm{ClO}_{\mathrm{x}}$ levels are 
expected in the real atmosphere in both hemispheres. Under this assumption, our model results suggest that more transport of $\mathrm{Cl}_{\mathrm{y}}$ from above in the Northern Hemisphere is countered by a more efficient activation of chlorine in the Southern Hemisphere. The higher ozone depletion in the Southern Hemisphere is mainly caused by the much longer time period in which $\mathrm{ClO}_{\mathrm{x}}$ is activated in our model. About $70 \%$ of $\mathrm{ClO}_{\mathrm{x}}$ is present as $\mathrm{ClO}$ during daytime at $54 \mathrm{hPa}$, in good agreement with, e.g., Stimpfle et al. (2004).

- $\mathrm{HO}_{\mathrm{x}}$ levels peak at 4 ppt. $\mathrm{HO}_{\mathrm{x}}$ is mainly produced from $\mathrm{CH}_{4}$ oxidation in the Southern Hemisphere, while in the Northern Hemisphere production by $\mathrm{HNO}_{3}, \mathrm{CH}_{4}$ and $\mathrm{H}_{2} \mathrm{O}$ plays comparable roles. The partitioning between $\mathrm{OH}$ and $\mathrm{HO}_{2}$ results in $20-40 \% \mathrm{OH}$ in the Southern Hemisphere and in 10-20\% OH in the Northern Hemisphere.

- $\mathrm{NO}_{\mathrm{x}}$ levels are smaller than $2 \mathrm{ppb}$ in the Northern Hemisphere and smaller than $0.75 \mathrm{ppb}$ in the Southern Hemisphere due to the denitrified conditions there. The partitioning between $\mathrm{NO}$ and $\mathrm{NO}_{2}$ during daytime results in 80-90\% NO in the Southern Hemisphere and 20-40\% NO in the Northern Hemisphere. The higher NO levels are caused by the much lower ozone levels in the Southern Hemisphere (e.g., Douglass et al., 1995).

- A total of 60-80\% of the production of $\mathrm{NO}_{\mathrm{x}}$ in spring is caused by the $\mathrm{HNO}_{3}+\mathrm{OH}$ reaction at $54 \mathrm{hPa}$ in the Northern Hemisphere, the remainder is caused by the $\mathrm{HNO}_{3}+h v$ reaction (compare Portmann et al., 1996). Deactivation of $\mathrm{ClO}_{\mathrm{x}}$ by the formation of $\mathrm{ClONO}_{2}$ in the Northern Hemisphere is caused by a shift in the fast equilibrium between $\mathrm{ClO}, \mathrm{NO}_{2}$ and $\mathrm{ClONO}_{2}$, which in turn is caused by the production of $\mathrm{NO}_{\mathrm{x}}$ (e.g., Portmann et al., 1996).

There was a significant discrepancy between the modeled and measured $\mathrm{HCl}$ mixing ratios in our original model runs, which has also been observed in other state-of-the-art models like SD-WACCM (Brakebusch et al., 2013; Wegner, 2013; Solomon et al., 2015), MIMOSA-CHIM (Kuttippurath et al., 2015) or SLIMCAT (Santee et al., 2008). The cause of these discrepancies in the different models is currently unknown. In the runs actually used in this paper, we apply an empirical correction based on changing the $\mathrm{HCl}$ solubility to bring the $\mathrm{HCl}$ mixing ratios in closer agreement to observations. However, a detailed discussion of this important issue comparing the different models would deserve its own dedicated study.

Results of this study are extensively used in a companion paper (Wohltmann et al., 2017) to develop a fast model for polar ozone chemistry.
Data availability. Data of the ATLAS model runs are available from the authors upon request. MLS data are available from https: //mls.jpl.nasa.gov, ACE-FTS data from http://www.ace.uwaterloo. $\mathrm{ca} /$ and JPL reaction coefficients from https://jpldataeval.jpl.nasa. gov/download.html.

\section{The Supplement related to this article is available online at https://doi.org/10.5194/acp-17-10535-2017- supplement.}

Competing interests. The authors declare that they have no conflict of interest.

Acknowledgements. This work was supported by the BMBF under the FAST-O3 project in the MiKliP framework program (FKZ 01LP1137A) and in the MiKliP II program (FKZ 01LP1517E). This research has received funding from the European Community's Seventh Framework Programme (FP7/2007-2013) under grant agreement no. 603557 (StratoClim). We thank Peter von der Gathen for providing the Ny-Ålesund temperature analysis. We thank ECMWF for providing the reanalysis data.

The article processing charges for this open-access

publication were covered by a Research

Centre of the Helmholtz Association.

Edited by: Martin Dameris

Reviewed by: three anonymous referees

\section{References}

Bernath, P. F.: The Atmospheric Chemistry Experiment (ACE), J. Quant. Spectrosc. Ra., 186, 3-16, 2017.

Brakebusch, M., Randall, C. E., Kinnison, D. E., Tilmes, S., Santee, M. L., and Manney, G. L.: Evaluation of Whole Atmosphere Community Climate Model simulations of ozone during Arctic winter 2004-2005, J. Geophys. Res., 118, 2673-2688, https://doi.org/10.1002/jgrd.50226, 2013.

Brasseur, G. and Solomon, S.: Aeronomy of the Middle Atmosphere, D. Reidel Publishing Company, Dordrecht, 2005.

Brasseur, G., Orlando, J. J., and Tyndall, G. S. (Eds.): Atmospheric Chemistry and Global Change, Oxford University Press, New York, Oxford, 1999.

Burkholder, J. B., Orlando, J. J., and Howard, C. J.: Ultraviolet absorption cross sections of chlorine oxide $\left(\mathrm{Cl}_{2} \mathrm{O}_{2}\right)$ between 210 and $410 \mathrm{~nm}$, J. Phys. Chem., 94, 687-695, 1990.

Canty, T. P., Salawitch, R. J., and Wilmouth, D. M.: The kinetics of the ClOOCl catalytic cycle, J. Geophys. Res., 121, 13768-13783, https://doi.org/10.1002/2016JD025710, 2016.

Chapman, S.: A theory of upper-atmospheric ozone, Mem. Roy. Soc., 3, 103-125, 1930.

Chipperfield, M. P., Lutman, E. R., Kettleborough, J. A., Pyle, J. A., and Roche, A. E.: Model studies of chlorine deactivation and formation of $\mathrm{ClONO}_{2}$ collar in the Arctic polar vortex, J. Geophys. Res., 102, 1467-1478, 1997. 
Cohen, R. C., Wennberg, P. O., Stimpfle, M., Koplow, J., Anderson, J. G., Fahey, D. W., Woodbridge, E. L., Keim, E. R., Gao, R., Proffitt, M. H., Loewenstein, M., and Chan, K. R.: Are models of catalytic removal of $\mathrm{O}_{3}$ by $\mathrm{HO}_{\mathrm{x}}$ accurate? Constraints from in situ measurements of the $\mathrm{OH}$ to $\mathrm{HO}_{2}$ ratio, Geophys. Res. Lett., 21, 2539-2542, 1994.

Crutzen, P. J., Müller, R., Brühl, C., and Peter, T.: On the potential importance of the gas phase reaction $\mathrm{CH}_{3} \mathrm{O}_{2}+\mathrm{ClO} \rightarrow \mathrm{ClOO}+$ $\mathrm{CH}_{3} \mathrm{O}$ and the heterogeneous reaction $\mathrm{HOCl}+\mathrm{HCl} \rightarrow \mathrm{H}_{2} \mathrm{O}+\mathrm{Cl}_{2}$ in "ozone hole" chemistry, Geophys. Res. Lett., 19, 1113-1116, 1992.

Dee, D. P., Uppala, S. M., Simmons, A. J., Berrisford, P., Poli, P., Kobayashi, S., Andrae, U., Balmaseda, M. A., Balsamo, G., Bauer, P., Bechtold, P., Beljaars, A. C. M., van de Berg, L., Bidlot, J., Bormann, N., Delsol, C., Dragani, R., Fuentes, M., Geer, A. J., Haimberger, L., Healy, S. B., Hersbach, H., Hólm, E. V., Isaksen, L., Kållberg, P., Köhler, M., Matricardi, M., McNally, A. P., Monge-Sanz, B. M., Morcrette, J.-J., Park, B.-K., Peubey, C., de Rosnay, P., Tavolato, C., Thépaut, J.-N., and Vitart, F.: The ERA-Interim reanalysis: configuration and performance of the data assimilation system, Q. J. Roy. Meteor. Soc., 137, 553-597, 2011.

Douglass, A. R., Schoeberl, M. R., Stolarski, R. S., Waters, J. W., III, J. M. R., Roche, A. E., and Massie, S. T.: Interhemispheric differences in springtime production of $\mathrm{HCl}$ and $\mathrm{ClONO}_{2}$ in the polar vortices, J. Geophys. Res., 100, 13967-13978, 1995.

Fahey, D. W., Kelly, K. K., Kawa, S. R., Tuck, A. F., Loewenstein, M., Chan, K. R., and Heidt, L. E.: Observations of denitrification and dehydration in the winter polar stratospheres, Nature, 344, 321-324, 1990.

Farman, J. C., Gardiner, B. G., and Shanklin, J. D.: Large losses of total ozone in Antarctica reveal seasonal $\mathrm{ClOx} / \mathrm{NOx}$ interaction, Nature, 315, 207-210, 1985.

Frieler, K., Rex, M., Salawitch, R. J., Canty, T., Streibel, M., Stimpfle, R. M., Pfeilsticker, K., Dorf, M., Weisenstein, D. K., and Godin-Beekmann, S.: Toward a better quantitative understanding of polar stratospheric ozone loss, Geophys. Res. Lett., 33, L10812, https://doi.org/10.1029/2005GL025466, 2006.

Grenfell, J. L., Lehmann, R., Mieth, P., Langematz, U., and Steil, B.: Chemical reaction pathways affecting stratospheric and mesospheric ozone, J. Geophys. Res., 111, D17311, https://doi.org/10.1029/2004JD005713, 2006.

Grooß, J.-U. and Russell III, J. M.: Technical note: A stratospheric climatology for $\mathrm{O}_{3}, \mathrm{H}_{2} \mathrm{O}, \mathrm{CH}_{4}, \mathrm{NO}_{x}, \mathrm{HCl}$ and $\mathrm{HF}$ derived from HALOE measurements, Atmos. Chem. Phys., 5, 2797-2807, https://doi.org/10.5194/acp-5-2797-2005, 2005.

Grooß, J.-U., Günther, G., Konopka, P., Müller, R., McKenna, D. S., Stroh, F., Vogel, B., Engel, A., Müller, M., Hoppel, K., Bevilacqua, R., Richard, E., Webster, C. R., Elkins, J. W., Hurst, D. F., Romashkin, P. A., and Baumgardner, D. G.: Simulation of ozone depletion in spring 2000 with the Chemical Lagrangian Model of the Stratosphere (CLaMS), J. Geophys. Res., 107, 8295, https://doi.org/10.1029/2001JD000456, 2002.

Hanisco, T. F.: Stratospheric chemistry and composition/ $/ \mathrm{HO}_{\mathrm{x}}$, in: Encyclopedia of Atmospheric Sciences, edited by: Holton, J. R., Curry, J. A., and Pyle, J. A., Academic Press, Elsevier, 5, 2174 $2180,2003$.
Kawa, S. R., Stolarski, R. S., Newman, P. A., Douglass, A. R., Rex, M., Hofmann, D. J., Santee, M. L., and Frieler, K.: Sensitivity of polar stratospheric ozone loss to uncertainties in chemical reaction kinetics, Atmos. Chem. Phys., 9, 8651-8660, https://doi.org/10.5194/acp-9-8651-2009, 2009.

Kremser, S., Schofield, R., Bodeker, G. E., Connor, B. J., Rex, M., Barret, J., Mooney, T., Salawitch, R. J., Canty, T., Frieler, K., Chipperfield, M. P., Langematz, U., and Feng, W.: Retrievals of chlorine chemistry kinetic parameters from Antarctic $\mathrm{ClO}$ microwave radiometer measurements, Atmos. Chem. Phys., 11, 5183-5193, https://doi.org/10.5194/acp-11-5183-2011, 2011.

Kuttippurath, J., Godin-Beekmann, S., Lefèvre, F., and Goutail, F.: Spatial, temporal, and vertical variability of polar stratospheric ozone loss in the Arctic winters 2004/2005-2009/2010, Atmos. Chem. Phys., 10, 9915-9930, https://doi.org/10.5194/acp10-9915-2010, 2010.

Kuttippurath, J., Godin-Beekmann, S., Lefèvre, F., Santee, M. L., Froidevaux, L., and Hauchecorne, A.: Variability in Antarctic ozone loss in the last decade (2004-2013): high-resolution simulations compared to Aura MLS observations, Atmos. Chem. Phys., 15, 10385-10397, https://doi.org/10.5194/acp-15-103852015, 2015.

Lait, L. R.: An alternative form for potential vorticity, J. Atmos. Sci., 51, 1754-1759, 1994.

Lary, D. J.: Gas phase atmospheric bromine photochemistry, J. Geophys. Res., 101, 1505-1516, 1996.

Lary, D. J., Chipperfield, M. P., Toumi, R., and Lenton, T.: Heterogeneous atmospheric bromine chemistry, J. Geophys. Res., 101, 1489-1504, 1996.

Lehmann, R.: Determination of dominant pathways in chemical reaction systems: An algorithm and its Application to Stratospheric Chemistry, J. Atmos. Chem., 41, 297-314, 2002.

Livesey, N. J., Read, W. G., Froidevaux, L., Lambert, A., Manney, G. L., Pumphrey, H. C., Santee, M. L., Schwartz, M. J., Wang, S., Cofeld, R. E., Cuddy, D. T., , Fuller, R. A., Jarnot, R. F., Jiang, J. H., Knosp, B. W., Stek, P. C., Wagner, P. A., and Wu, D. L.: Version 3.3 Level 2 data quality and description document, JPL D-33509, available at: http://mls.jpl.nasa.gov (last access: $22 \mathrm{Au}-$ gust 2017), 2011.

Lowe, D. and MacKenzie, A. R.: Polar stratospheric cloud microphysics and chemistry, J. Atmos. Sol.-Terr. Phys., 70, 13-40, 2008.

Luo, B., Carslaw, K. S., Peter, T., and Clegg, S. L.: Vapour pressures of $\mathrm{H}_{2} \mathrm{SO}_{4} / \mathrm{HNO}_{3} / \mathrm{HCl} / \mathrm{HBr} / \mathrm{H}_{2} \mathrm{O}$ solutions to low stratospheric temperatures, Geophys. Res. Lett., 22, 247-250, 1995.

McElroy, M. B., Salawitch, R. J., Wofsy, S. C., and Logan, J. E.: Reductions of Antarctic ozone due to synergistic interactions of chlorine and bromine, Nature, 321, 759-762, 1986.

Molina, L. T. and Molina, M. J.: Production of $\mathrm{Cl}_{2} \mathrm{O}_{2}$ from the selfreaction of the ClO radical, J. Phys. Chem., 91, 433-436, 1987.

Montzka, S. A.: Source gases that affect stratospheric ozone, in: Stratospheric Ozone Depletion and Climate Change, edited by: Müller, R., chap. 2, 33-77, RSC Publishing, Cambridge, 2012.

Müller, R. (Ed.): Stratospheric Ozone Depletion and Climate Change, RSC Publishing, Cambridge, 2012.

Nakajima, H., Wohltmann, I., Wegner, T., Takeda, M., Pitts, M. C., Poole, L. R., Lehmann, R., Santee, M. L., and Rex, M.: Polar stratospheric cloud evolution and chlorine activation measured by CALIPSO and MLS, and modeled by ATLAS, At- 
mos. Chem. Phys., 16, 3311-3325, https://doi.org/10.5194/acp16-3311-2016, 2016.

Peter, T. and Grooß, J.-U.: Polar Stratospheric Clouds and Sulfate Aerosol Particles: Microphysics, Denitrification and Heterogeneous Chemistry, in: Stratospheric Ozone Depletion and Climate Change, edited by: Müller, R., chap. 4, pp. 108-144, RSC Publishing, Cambridge, 2012.

Pitts, M. C., Poole, L. R., Dörnbrack, A., and Thomason, L. W.: The 2009-2010 Arctic polar stratospheric cloud season: a CALIPSO perspective, Atmos. Chem. Phys., 11, 2161-2177, https://doi.org/10.5194/acp-11-2161-2011, 2011.

Portmann, R. W., Solomon, S., Garcia, R. R., Thomason, L. W., Poole, L. R., and McCormick, M. P.: Role of aerosol variations in anthropogenic ozone depletion in the polar regions, J. Geophys. Res., 101, 22991-23006, 1996.

Sander, S. P., Abbatt, J., Barker, J. R., Burkholder, J. B., Friedl, R. R., Golden, D. M., Huie, R. E., Kolb, C. E., Kurylo, M. J., Moortgat, G. K., Orkin, V. L., and Wine, P. H.: Chemical kinetics and photochemical data for use in atmospheric studies, Evaluation Number 17, JPL Publication 10-06, Jet Propulsion Laboratory, California Institute of Technology, Pasadena, available at: http://jpldataeval.jpl.nasa.gov (last access: 22 August 2017), 2011.

Santee, M. L., MacKenzie, I. A., Manney, G. L., Chipperfield, M. P., Bernath, P. F., Walker, K. A., Boone, C. D., Froidevaux, L., Livesey, N. J., and Waters, J. W.: A study of stratospheric chlorine partitioning based on new satellite measurements and modeling, J. Geophys. Res., 113, D12307, https://doi.org/10.1029/2007JD009057, 2008.

Schofield, R., Frieler, K., Wohltmann, I., Rex, M., von Hobe, M., Stroh, F., Koch, G., Peter, T., Canty, T., Salawitch, R., and Volk, C. M.: Polar stratospheric chlorine kinetics from a selfmatch flight during SOLVE-II/EUPLEX, Geophys. Res. Lett., 35, L01807, https://doi.org/10.1029/2007GL031740, 2008.

Simmons, A. J., Poli, P., Dee, D. P., Berrisford, P., Hersbach, H., Kobayashi, S., and Peubey, C.: Estimating low-frequency variability and trends in atmospheric temperature using ERAInterim, Q. J. Roy. Meteor. Soc., 140, 329-353, 2014.

Solomon, S.: Stratospheric ozone depletion: A review of concepts and history, Rev. Geophys., 37, 275-316, 1999.

Solomon, S., Garcia, R. R., Rowland, F. S., and Wuebbles, D. J.: On the depletion of Antarctic ozone, Nature, 321, 755-758, 1986.

Solomon, S., Kinnison, D., Bandoro, J., and Garcia, R.: Simulation of polar ozone depletion: An update, J. Geophys. Res., 120, 7958-7974, https://doi.org/10.1002/2015JD023365, 2015.

Stimpfle, R. M., Wilmouth, D. M., Salawitch, R. J., and Anderson, J. G.: First measurements of $\mathrm{ClOOCl}$ in the stratosphere: The coupling of $\mathrm{ClOOCl}$ and $\mathrm{ClO}$ in the Arctic polar vortex, J. Geophys. Res., 109, D03301, https://doi.org/10.1029/2003JD003811, 2004.

Toon, O. B., Hamill, P., Turco, R. P., and Pinto, J.: Condensation of $\mathrm{HNO}_{3}$ and $\mathrm{HCl}$ in the winter polar stratosphere, Geophys. Res. Lett., 13, 1284-1287, 1986.

von Hobe, M. and Stroh, F.: Stratospheric halogen chemistry, in: Stratospheric Ozone Depletion and Climate Change, edited by: Müller, R., chap. 2, RSC Publishing, Cambridge, 78-107, 2012. von Hobe, M., Bekki, S., Borrmann, S., Cairo, F., D’Amato, F., Di Donfrancesco, G., Dörnbrack, A., Ebersoldt, A., Ebert, M., Emde, C., Engel, I., Ern, M., Frey, W., Genco, S., Griessbach,
S., Grooß, J.-U., Gulde, T., Günther, G., Hösen, E., Hoffmann, L., Homonnai, V., Hoyle, C. R., Isaksen, I. S. A., Jackson, D. R., Jánosi, I. M., Jones, R. L., Kandler, K., Kalicinsky, C., Keil, A., Khaykin, S. M., Khosrawi, F., Kivi, R., Kuttippurath, J., Laube, J. C., Lefèvre, F., Lehmann, R., Ludmann, S., Luo, B. P., Marchand, M., Meyer, J., Mitev, V., Molleker, S., Müller, R., Oelhaf, H., Olschewski, F., Orsolini, Y., Peter, T., Pfeilsticker, K., Piesch, C., Pitts, M. C., Poole, L. R., Pope, F. D., Ravegnani, F., Rex, M., Riese, M., Röckmann, T., Rognerud, B., Roiger, A., Rolf, C., Santee, M. L., Scheibe, M., Schiller, C., Schlager, H., Siciliani de Cumis, M., Sitnikov, N., Søvde, O. A., Spang, R., Spelten, N., Stordal, F., Suminska-Ebersoldt, O., Ulanovski, A., Ungermann, J., Viciani, S., Volk, C. M., vom Scheidt, M., von der Gathen, P., Walker, K., Wegner, T., Weigel, R., Weinbruch, S., Wetzel, G., Wienhold, F. G., Wohltmann, I., Woiwode, W., Young, I. A. K., Yushkov, V., Zobrist, B., and Stroh, F.: Reconciliation of essential process parameters for an enhanced predictability of Arctic stratospheric ozone loss and its climate interactions (RECONCILE): activities and results, Atmos. Chem. Phys., 13, 92339268, https://doi.org/10.5194/acp-13-9233-2013, 2013.

Waters, J. W., Froidevaux, L., Harwood, R. S., Jarnot, R. F., Pickett, H. M., Read, W. G., Siegel, P. H., Coeld, R. E., Filipiak, M. J., Flower, D. A., Holden, J. R., Lau, G. K., Livesey, N. J., Manney, G. L., Pumphrey, H. C., Santee, M. L., Wu, D. L., Cuddy, D. T., Lay, R. R., Loo, M. S., Perun, V. S., Schwartz, M. J., Stek, P. C., Thurstans, R. P., Chandra, K. M., Chavez, M. C., Chen, G.-S., Boyles, M. A., Chudasama, B. V., Dodge, R., Fuller, R. A., Girard, M. A., Jiang, J. H., Jiang, Y., Knosp, B. W., LaBelle, R. C., Lam, J. C., Lee, K. A., Miller, D., Oswald, J. E., Patel, N. C., Pukala, D. M., Quintero, O., Scaff, D. M., Snyder, W. V., Tope, M. C., Wagner, P. A., and Walch, M. J.: The Earth Observing System Microwave Limb Sounder (EOS MLS) on the Aura satellite, IEEE T. Geosci. Remote Sens., 44, 1075-1092, 2006.

Wayne, R. P., Poulet, G., Biggs, P., Burrows, J. P., Cox, R. A., Crutzen, P. J., Hayman, G. D., Jenkin, M. E., Bras, G. L., Moortgat, G. K., Platt, U., and Schindler, R. N.: Halogen oxides: Radicals, sources and reservoirs in the laboratory and in the atmosphere, Atmos. Environ., 29, 2677-2881, 1995.

Wegner, T.: Chlorine activation and heterogenous chemistry in the polar stratosphere: Model simulations, in-situ- and satellite observations, $\mathrm{PhD}$ thesis, University Wuppertal, available at: http://elpub.bib.uni-wuppertal.de/servlets/DocumentServlet? id=3573 (last access: 22 August 2017), 2013.

WMO: World Meteorological Organization (WMO)/United Nations Environment Programme (UNEP), Scientific assessment of ozone depletion: 2010, Global Ozone Research and Monitoring Project - Report No. 52, 2011.

Wohltmann, I. and Rex, M.: The Lagrangian chemistry and transport model ATLAS: validation of advective transport and mixing, Geosci. Model Dev., 2, 153-173, https://doi.org/10.5194/gmd-2153-2009, 2009.

Wohltmann, I., Lehmann, R., and Rex, M.: The Lagrangian chemistry and transport model ATLAS: simulation and validation of stratospheric chemistry and ozone loss in the winter 1999/2000, Geosci. Model Dev., 3, 585-601, https://doi.org/10.5194/gmd-3585-2010, 2010.

Wohltmann, I., Wegner, T., Müller, R., Lehmann, R., Rex, M., Manney, G. L., Santee, M. L., Bernath, P., Suminska-Ebersoldt, O., Stroh, F., von Hobe, M., Volk, C. M., Hösen, E., Raveg- 
nani, F., Ulanovsky, A., and Yushkov, V.: Uncertainties in modelling heterogeneous chemistry and Arctic ozone depletion in the winter 2009/2010, Atmos. Chem. Phys., 13, 3909-3929, https://doi.org/10.5194/acp-13-3909-2013, 2013.
Wohltmann, I., Lehmann, R., and Rex, M.: Update of the Polar SWIFT model for polar stratospheric ozone loss (Polar SWIFT version 2), Geosci. Model Dev., 10, 2671-2689, https://doi.org/10.5194/gmd-10-2671-2017, 2017. 